University of Louisville

ThinkIR: The University of Louisville's Institutional Repository

Electronic Theses and Dissertations

$12-2011$

\title{
Theory of mind, social functioning, and awareness of ability in older adults.
}

Sarah Vedrody Rowe

University of Louisville

Follow this and additional works at: https://ir.library.louisville.edu/etd

\section{Recommended Citation}

Rowe, Sarah Vedrody, "Theory of mind, social functioning, and awareness of ability in older adults." (2011). Electronic Theses and Dissertations. Paper 1239.

https://doi.org/10.18297/etd/1239

This Doctoral Dissertation is brought to you for free and open access by ThinkIR: The University of Louisville's Institutional Repository. It has been accepted for inclusion in Electronic Theses and Dissertations by an authorized administrator of ThinkIR: The University of Louisville's Institutional Repository. This title appears here courtesy of the author, who has retained all other copyrights. For more information, please contact thinkir@louisville.edu. 


\title{
THEORY OF MIND, SOCIAL FUNCTIONING, AND AWARENESS OF ABILITY IN OLDER ADULTS
}

\section{By}

Sarah Vedrody Rowe

B.A. University of Georgia, 1996

B.A. Queens College, City University of New York, 2005

M.A. University of Louisville, 2007

\author{
A Dissertation \\ Submitted to the Faculty of the \\ College of Arts and Sciences of the University of Louisville \\ in Partial Fulfillment of the Requirements \\ for the Degree of
}

Doctor of Philosophy

Department of Psychological and Brain Sciences

University of Louisville

Louisville, KY

December 2011 
Copyright 2011 by Sarah Vedrody Rowe

All rights reserved 
THEORY OF MIND, SOCIAL FUNCTIONING, AND AWARENESS OF ABILITY IN OLDER ADULTS

By

Sarah Vedrody Rowe

B.A. University of Georgia, 1996

B.A. Queens College, City University of New York, 2005

M.A. University of Louisville, 2007

A Dissertation Approved on

August 10, 2011

By the Following Dissertation Committee:

Benjamin T. Mast, Dissertation Director

Cara H. Cashon 


\section{DEDICATION}

This dissertation is dedicated to:

My grandmother, Velma Jeffers Hutchens,

and my friend, Carl Jack Forman II. 


\section{ACKNOWLEDGEMENTS}

First, I would like to thank my mentor, Benjamin T. Mast, Ph.D., for his guidance and unwavering support throughout graduate school and particularly on this study. I also greatly appreciate my committee members for their enthusiasm as well as for their suggestions regarding the methodology. I would also like to thank Jamie Shouse, B.A., who served in every possible role as a research assistant on the study and did a wonderful job coordinating the study when I left to go on internship. Additionally, I would like to thank the undergraduate and graduate students who helped collect data on the study and provided assistance with organizational aspects. Their names include: Jennifer Zimmerman, M.A., Adam Gerstenecker, M.A. Jeremy Carmasin, B.A., Katie Higson, B.A., Tricia Cooper, B.A., Lora Rose, B.A., Ashley Vaden, B.A., Anna Roeder, Crystal Goodwin, Adrian Boyer, Samantha Yung, Jordan Williams, Kayla Thornberry, and Seth Kline. I would also like to thank the individuals who participated in the research. I am also very grateful to my husband, Patrick Rowe, for his consistent love and support throughout graduate school. I also appreciate the ongoing support of my family members and friends. Last, but certainly not least, I would like to thank God and the congregation of St. Paul's Episcopal Church. 


\begin{abstract}
THEORY OF MIND, SOCIAL FUNCTIONING, AND AWARENESS OF ABILITY IN OLDER ADULTS

Sarah Vedrody Rowe

December 16, 2011

Declines in social resources and in the quality of interpersonal interactions have
\end{abstract} been observed in some older adults. Unawareness of ability is a clinical problem that has been found in some older adults with dementia, but has also been found in nondemented older adults, and the clinical correlates have not been reliably established. Theory of mind (ToM) is a social-cognitive construct that refers to the ability to infer the mental states of others and the self. ToM has been linked with social functioning and selfawareness, but few studies have examined these variables in older adults. The current study tested the hypotheses that lower levels of ToM ability would predict lower levels of social functioning and higher levels of unawareness of ability.

Seventy-eight community dwelling older adults and their informants participated. Participants completed multiple measures of ToM, memory, executive functioning, social resources, social behaviors, and awareness of ability on different tasks. Correlations, $t$ tests, chi-square and path analysis were used to test the hypotheses. Study results indicated the presence of impaired performance on ToM measures in the communitydwelling sample, but relatively accurate awareness and strong social functioning across measures. Despite the presence of impaired performance on ToM, ToM did not predict 
any of the social relations variables. The results of the ToM and awareness analyses were mixed, with one association that approached significance in the predicted direction and other significant associations that were in the opposite direction.

The results suggest that ToM may not be a valid construct for predicting social functioning in community-dwelling older adults. ToM may have been confounded with general cognitive processes, indicating that the demonstrated impairment was not ToMspecific. An underlying neurological process also may have been detected by the ToM tests that has not yet impacted social relations or awareness. Improvement in the measurement of the three constructs, continued research into the correlates of awareness and social relations, and longitudinal study in community-dwelling older adults, will help clarify the relationship, if any, between the three constructs. 


\section{TABLE OF CONTENTS}

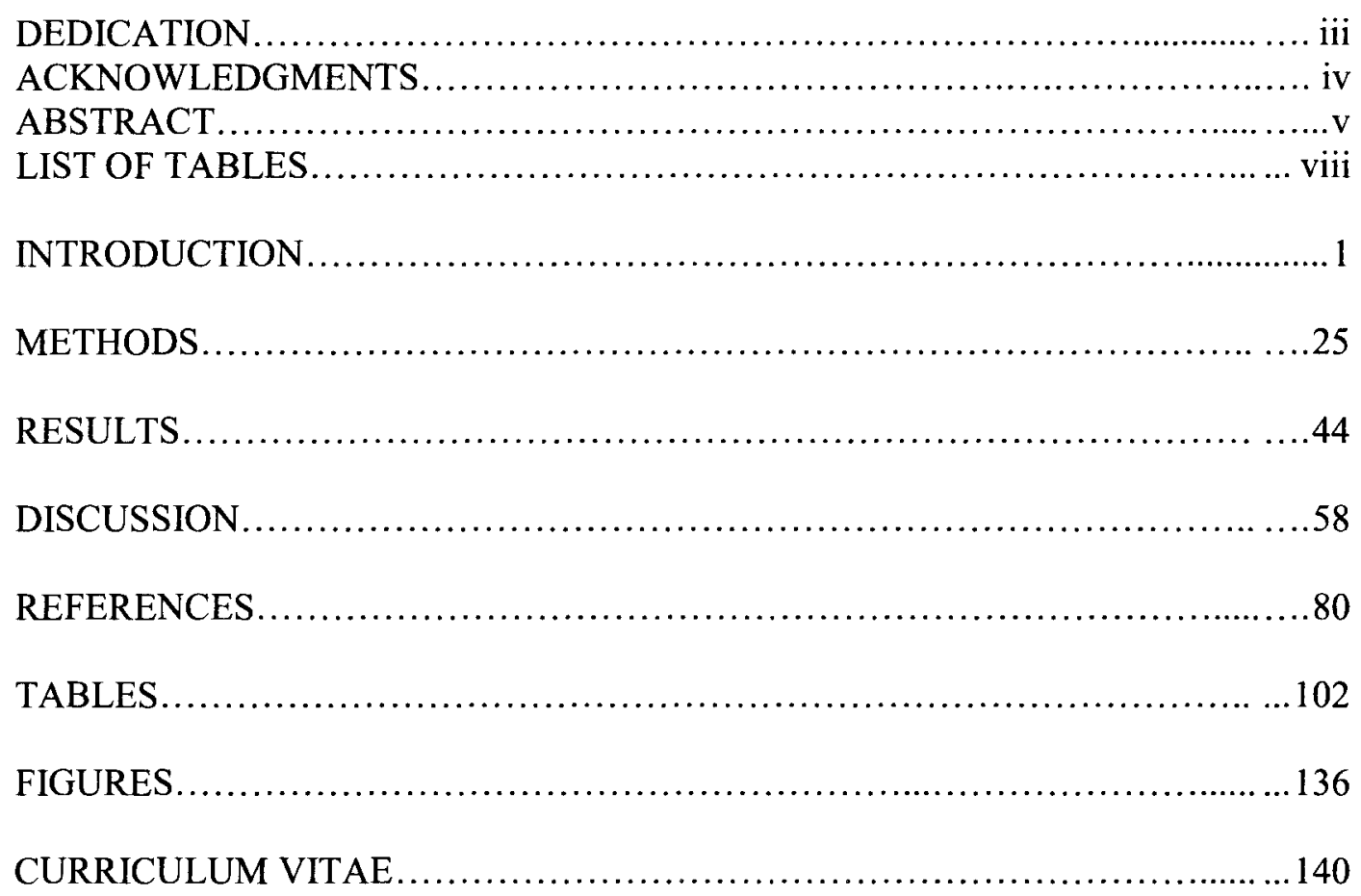




\section{LIST OF TABLES}

$\begin{array}{lll}\text { TABLE PAGE } & \text { PAT }\end{array}$

1. Studies comparing ToM in younger and older adults.......................... 102

2. Effect sizes regarding ToM and different social variables....................... 111

3. Abbreviations and study variables, including transformations of key variables and their subsequent meaning.................................. 112

4. Characteristics of Primary Participants and Informants ....................... 115

5. Cognitive variables - Means and $95 \%$ confidence intervals

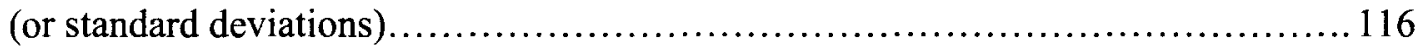

6. Characteristics Regarding the Relationships of Primary Participants and Informants

7. EYES Test - Mean EYES Test scores in Recent Studies with older adults.

8. Faux Pas Test Composite, FP HITS, and FP REJECTIONS scores in recent studies with older adults without clinical diagnosis.

9. Social Relations variables - Means and $95 \%$ confidence intervals.

10. Correlations between Social Relations, Health, Demographics, and Depression.

11. Measures of awareness - Means and Standard Deviations (or $95 \%$ confidence intervals)

12. Correlations between Awareness, Health, Demographics, and depression.

13. Correlations between Performance-Based Measures of Awareness and Associated Cognitive Variables.

14. Significant Mean Differences between Men and Women on the HVLT-R performance-based Awareness Measures. 
15. Significant Differences between the African-American group

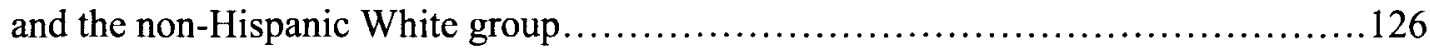

16. Correlations between ToM and Health Variables, Demographic

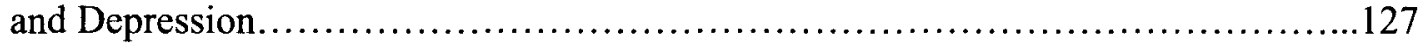

17. Correlations between ToM and Cognition.................................... 128

18. Correlations between Social Relations and Cognition....................... 129

19. Correlations between Awareness and Cognition........................... 130

20. Significant Mean Differences on Cognition between Impaired and Non-Impaired Groups, as measured by ToM tests.......................... 131

21. Correlations between ToM and Social Relations Variables...................... 132

22. Correlations between ToM and Awareness Variables............................ 133

23. Significant Mean Differences on Awareness Measures between

Impaired and Non-Impaired Groups, as measured by ToM tests....................134

24. Reference Table for significant relationships between ToM variables and selected study variables across analyses methods............................ 135 


\section{INTRODUCTION}

The purpose of the present study was to explore the relationships between theory of mind (ToM), social relations in older adults, and the clinical problem of lack of awareness of performance deficits in dementia and mild cognitive impairment. Specifically, it was hypothesized that theory of mind measures may be useful in predicting problematic social relations in older adults as well as a lack of awareness of cognitive and behavioral deficits associated with dementing disorders. In order to establish the basis for positing links between these three constructs, relevant background information on each construct and its importance to successful aging will be discussed in the following sections. The last section of the introduction will introduce hypotheses generated from the literature review.

\section{Social Relations}

Social resources are instrumental to successful aging, and support from others through social interactions is theorized to provide a buffer for the stresses of daily life (see reviews, Bath \& Deeg, 2005; Cohen et al., 2001; Antonucci, 2001). Social networks and social support are two types of social resources (Antonucci, 2001; Barnes et al., 2004b). Larger social networks have been associated with better health (Berkman \& Syme, 1979) and may provide increased opportunities for social support and participation in social activities (Berkman \& Syme, 1979; Berkman et al., 2000; Bath \& Deeg, 2005; Gurung et al., 2003). Greater levels of social support have been associated with better 
physical and mental health, lower levels of cognitive decline over time, lower levels of frailty, lower levels of depression and suicidal ideation and decreased risk for mortality in studies of older adults (DuPertuis et al., 2001; Beland et al., 2005; Barnes et al., 2004a; Woo et al., 2005; Vanderhorst \& McLaren, 2005; Hsu, 2007). Additionally, in older adults with dementia, those with greater social support demonstrated reduced levels of mortality (Orrell et al., 2000).

Older adults tend to limit their contact to close friends and family members (Field $\&$ Minkler, 1988), and their social networks may diminish as they allocate their resources to these smaller networks of more intimate relationships (Field \& Minkler, 1988; Lang \& Carstensen, 1994; Carstensen et al., 1999). As a group, older adults also decrease the frequency of their contact with their network members (Carstensen, 1992). Socioemotional selectivity theory (SST) predicts that as individuals grow older, their motivations for socialization with others may shift from information-seeking or achievement-oriented goals to emotionally-rewarding goals (Lang \& Carstensen, 1994). SST proposes that the shift in motivation for socialization occurs as individuals become increasingly aware of their limited time left to live (Lang \& Carstensen, 1994). As a result of this shift toward more emotionally-rewarding relationships, older adults consciously and proactively select out of relationships that are less emotionally satisfying. Similarly, the Social Convoy Model posits that individuals may change the structure of and members in their networks, but they seek to maintain consistent levels of social support across their lifetimes (Kahn \& Antonucci, 1980). The Social Convoy Model suggests that as individuals age they become more adept at identifying and maximizing relationships with supportive network members and more likely to discard 
unsupportive network members, which results in smaller networks (Kahn \& Antonucci, 1980).

While larger network sizes may increase opportunities to receive social support, the subjective well-being of older adults has demonstrated greater association with the quality of their relationships as opposed to the quantity of their relationships (Pinquart \& Sorensen, 2000). Social support is often divided between instrumental and perceived social support. Instrumental social support reflects receipt of help from others in carrying out daily activities or providing material resources, while perceived social support measures individuals' subjective appraisals of how well they are supported by those around them (Sarason et al., 1987). The quality of relationships is typically determined by assessments of how well older adults perceive that they are supported (Sarason et al., 1987). While both instrumental and perceived social support are important, perceived social support has demonstrated the greatest ability to predict overall well-being, which has in turn, been associated with better health outcomes (Cohen et al., 1985; Cohen et al., 2001).

The subjective nature of perceived social support highlights the importance of the quality of the interaction between individuals and members of their networks. In other words, whether individuals perceive themselves as being supported by their network members may depend on the types of interpersonal interactions that they have with them. Reis, Clark and Holmes (2004) have linked perceived support with the responsiveness of the individual providing support to the needs of the recipient. Studies examining the frequency of positive and negative social exchanges have also emphasized the contribution of interpersonal interactions to well-being. In a longitudinal study utilizing daily diaries that captured the number of positive and negative social interactions that 
older adults experienced, higher levels of negative social interactions were associated with a lack of well-being and depression (Rook, 2001). In this study, negative social interactions also appeared to mitigate the impact of positive interactions on mood. Another study found that negative social exchanges seem to have longer-lasting effects on both positive and negative affect (Newsom et al., 2003). In yet another study, older men who reported that the people close to them were too demanding and older women who reported that individuals close to them were irritating, reported lower levels of happiness (Antonucci et al., 1998). Perceived poorer quality support has also been associated with the decision to hasten death in terminally ill older adults (Schroepfer, 2008). Collectively, these findings emphasize the importance of the quality of the interpersonal interaction between older adults and network members.

Individual characteristics such as depression and cognitive impairment may make some older adults more likely to experience negative social exchanges. A large longitudinal study found that older adults who were depressed or cognitively-impaired at baseline reported more negative interpersonal interactions with members of their network approximately two years later (Gurung et al., 2003). Older adults' exposure to negative social exchanges has also been associated with less supportive networks and greater life stress, and decreases in exposure to negative social exchanges over time have been associated with satisfaction with friend relationships (Rook, 2003). Notably, increases in the exposure to negative exchanges has been associated with increases in total support (including instrumental support) provided by the network (Rook, 2003). The positive correlation between negative social exchanges and total support may be explained by individuals needing increased emotional and instrumental support due to declines in cognition or daily functioning, such as declines in basic activities of daily living (ADLs) 
or instrumental activities of daily living (IADLs). In essence, changes in function may alter the number or content of social exchanges with network members. In such cases, the support provided to individuals may be inadequate or may not match their support needs. Negative social exchanges may result from this mismatch, as individuals needing support become frustrated with their support networks and network members adapt, with varying levels of success, their behavior to meet the needs of their loved ones. Thus, changes in function may increase older adults' exposure to negative social exchanges.

Increases in negative social exchanges may also be explained by increases in inappropriate social behaviors displayed by some older adults. Inappropriate social behaviors that have demonstrated greater frequencies in older adults compared to younger adults include higher levels of off-target verbosity, discussion of private events in public settings, and prejudicial and stereotyping behavior (Henry et al., 2009; Pushkar et al., 2000; von Hippel et al., 2000; von Hippel \& Dunlop, 2005). Henry et al. (2009) have found that the relationship between age and social inappropriateness is mediated by executive functioning, though this model only partially explains the variance in social appropriateness. This finding is particularly important because executive functioning has been linked with frontal lobe integrity, which may be linked with social functioning (Stuss \& Levine, 2002).

Additional evidence for the importance of the frontal lobes to social functioning comes from illnesses that damage frontal lobe structures. The frontal variant frontotemporal dementia (fvFTD), which initially affects the orbitofrontal and ventromedial areas of the prefrontal cortex, provides an extreme example of how dysfunction in the prefrontal cortex can affect social behavior. Patients with fvFTD initially present with severe deficits in social functioning that include "breaches of 
interpersonal etiquette, tactlessness, and disinhibition," (Snowden et al., 2002 p. 140; see also Neary et al., 1998; Gregory et al., 1999; Lough \& Hodges, 2002; Bozeat et al., 2000).

In normal aging, cognitive functions associated with the prefrontal cortex decline first (West, 1996; Raz \& Rodrigue, 2006) and may explain changes associated with social behavior. The end of the lifespan is widely recognized as a time of loss in multiple domains, but it is also characterized by variability in these losses across individuals. Aging demonstrates differential effects across the brains of individuals due to diseases of age, cardiovascular diseases, metabolic disorders, etc. (Raz \& Rodrigue, 2006). While normal aging may not involve the pervasive deterioration in frontal lobe integrity seen in fvFTD, many normally aging individuals may experience relative loss of various frontal functions which may, in turn, affect their social behavior (Henry et al., 2009).

\section{Theory of Mind}

Social-cognitive constructs, such as empathy and morality, are hypothesized to be recruited by the cognitive system for the processing of social stimuli; they enable humans to make sense of the social world and interact productively with others (Washburn et al., 2003). Theory of mind (ToM) is a social-cognitive construct that may account for variability in social functioning in older adults, particularly those in the early stages of dementia. ToM concerns the ability to attribute mental states to the self and others in order to explain and predict behavior (Premack \& Woodruff, 1978; Frith \& Frith, 1999). ToM involves an awareness that others may have thoughts, beliefs, emotions, or intentions that are different from one's own (Frith \& Frith, 1999). Knowledge of others' mental states can be used to effectively adapt one's own behavior to achieve desired outcomes. ToM, or the ability to "mentalize" or "mind-read," has been associated with 
evolutionary advantages, as mind-reading abilities would allow human beings to better adapt to social complexities (Brune \& Brune-Cohrs, 2006). ToM reliably emerges in healthy children across different cultures around the age of four and develops throughout childhood, and ToM may represent an important resource for social relations (Perner \& Wimmer, 1985; Wimmer \& Perner, 1983; Liu et al., 2008).

A premise of social cognitive measures is that such measures should be able to explain social functioning better than nonsocial cognitive measures, such as those used in typical assessment batteries. ToM has been implicated in social functioning through studies with clinical populations that have marked social deficits. Individuals with autism, Asperger's syndrome, schizophrenia, traumatic brain injury, and dementia have all demonstrated deficits on tests of ToM (Baron-Cohen et al., 2001; Baron-Cohen et al., 1985; Brune, 2005; Langdon et al., 2002; Torralva et al., 2007; Gregory et al., 2002; Happe et al., 1998; Happe, 1994; Milders et al., 2006). ToM abilities also predict social functioning in childhood, as children with ToM are more likely to initiate play and assign roles for pretend play than children without ToM (Astington \& Jenkins, 1995). There have only been two studies that examined the direct relationship between ToM and social relations in older adults. While one study found that nurses ratings' of nursing home residents' social functioning were predicted by their performance on a ToM task (Washburn, 2003), the other study found no relationship between ToM and prosocial behaviors in healthy older adults living in the community (Washburn et al., 2003; Bailey et al., 2008).

Measures of ToM have demonstrated utility over traditional neuropsychological tests in differentiating individuals in the early stages of fvFTD from healthy older adults and from patients with Alzheimer's disease (AD; Gregory et al., 2002; Torralva et al., 
2009). Patients with fvFTD may not initially demonstrate deficits on traditional neuropsychological tests, and imaging procedures may provide little assistance in diagnosing fvFTD in the initial stages (Gregory et al., 2002; Neary et al., 1998; Lough \& Hodges, 2002; Bozeat et al., 2000; Gregory et al., 1999). Thus, the development and utilization of ToM measures could have considerable value in dementia assessment, and possibly in pre-dementia states.

Lesion and functional magnetic resonance imaging ( $\mathrm{MRR}$ ) studies have primarily associated ToM with the prefrontal cortex, particularly the orbitofrontal and ventromedial areas, though other areas of prefrontal cortex, the limbic system, and the temporo-parietal junction appear to be important in carrying out ToM tasks as well (Gregory, 2002;

Gallagher et al., 2000; Rowe et al., 2001; Baird et al., 2006; Saxe \& Powell, 2006; Stone et al., 2003; Stuss et al., 2001). Individuals with damage to these areas often demonstrate impairments on ToM tasks compared to healthy controls and display deficits in social functioning that include disruptive behaviors. For example, patients with orbitofrontal lobe lesions and patients with fVFTD have demonstrated significantly poorer performance compared to healthy controls in detecting social faux pas (Gregory et al., 2002; Stone et al., 1998). Additionally, ToM performance was significantly related to the amount of atrophy in the ventromedial prefrontal cortex in patients with fvFTD, with individuals who had greater atrophy displaying poorer performance on ToM tasks (Gregory et al., 2002).

\section{ToM Measures}

Based on empirical evidence from clinical populations with developmental disabilities, Tager-Flusberg \& Sullivan (2000) have suggested that ToM has two components: a social-cognitive component and a social-perceptual component. The 
social-perceptual component is hypothesized to be linked to the affective system and involves the processing of the social expressions of others, including their gestures, facial expressions, and vocal tone. The social-perceptual component of ToM is important for making rapid online judgments about others' mental states. The social-cognitive component involves the representational aspect of ToM and likely relies on both social and nonsocial cognitive processes; relevant nonsocial cognitive processes include language ability and working memory. While some ToM tests may emphasize the socialperceptual component more than the social-cognitive component, the social-cognitive component is still necessary to perform well on social-perceptual ToM tasks due to the language or working memory demands on those tasks. Likewise, the social-cognitive component may be influenced by information gathered by the social-perceptual component. Developmentally, both components are theorized to continue developing throughout childhood (Tager-Flusberg \& Sullivan, 2000).

In children, tasks that measure the ability to comprehend false beliefs are the gold standard for assessing the social-cognitive component of ToM (Tager-Flusberg \& Sullivan, 2000). Such ToM tasks are often embedded within a series of questions about a vignette. Vignettes, as well as non-verbal stimuli such as cartoons, are frequently used to test false beliefs, as well as the ability to infer the emotions, motivations, or intentions of the characters depicted in them. There are essentially two main kinds of false belief tasks: first-order false belief tasks and second-order false belief tasks. A first-order false belief task measures the ability to detect when someone has a belief that is different from one's own (Wimmer \& Perner, 1983). An example of a first-order task involves presenting participants with a scenario such as, "Mary put a glass of water on the kitchen table and then she left the kitchen; after she left, John moved the glass of water to the 
sink" (Wimmer \& Perner, 1983). The ToM question in this example would be "Where does Mary think the water is?" At approximately the age of four, children pass first-order false belief tasks by correctly stating a character's false belief. However, normally developing children below the age of four usually respond that the glass is where they (the children being tested) believe it to be in reality (Wimmer \& Perner, 1983). Participants are also asked questions to ascertain their factual understanding of the story, such as, "Where is the glass of water?" They are also asked questions testing their memory of the story content. The aim of these questions is to control for possible confounds and increase the specificity of the task for identifying ToM abilities.

Second-order false belief tasks involve the ability to metarepresent the mental states of two people (Perner \& Wimmer, 1985). Second-order false belief tasks present participants with a scenario similar to the first-order false belief task, but the scenario is modified. For example, the same scenario from the first-order false belief task could be used with the following addition: "Mary peeks back into the kitchen to see John move the glass without John noticing that Mary is spying on him" (Perner \& Wimmer, 1985). The second-order ToM question for this scenario would be, "Where does John think that Mary thinks the glass is?" Children would not typically give the correct answer that John thinks that Mary thinks the glass is on the table until at least the age of seven (Perner \& Wimmer, 1985).

The usefulness of false belief tasks (as described above) as a measure of ToM ability in older adults may be limited. First-order false belief tasks are often too easy for older adults, even those with Alzheimer's disease; the results of studies that have used first-order false belief tasks with older adults tend to demonstrate ceiling effects (Zaitchik et al., 2004; Zaitchik et al., 2006). Second-order false belief tasks rely heavily on 
working memory, which often declines with age (McKinnon \& Moscovitch, 2007).

Finally, some high-functioning patients in clinical populations who display social deficits have been able to pass traditional false belief tasks, indicating that false belief tasks may not be as sensitive to subtle deficits in social functioning (Baron-Cohen et al., 1997; Baron-Cohen et al., 1999; Happe, 1994).

Advanced tests of ToM have been developed for adults and patients in clinical populations who can pass the false belief tasks described above but who still demonstrate social deficits compared to healthy controls (Gregory et al., 2002; Baron-Cohen et al., 1999). Advanced ToM tests attempt to replicate the complexity of naturally occurring social situations in which ToM abilities must be employed. Two such tests are the Faux Pas Test and the Reading the Eyes in the Mind test (EYES; Baron-Cohen et al., 1999; Baron-Cohen et al., 2001; Stone et al., 1998; Gregory et al., 2002). For the Faux Pas Test, individuals are presented with vignettes in which a faux pas may or may not have occurred. The test requires individuals to correctly detect when a faux pas has occurred, and it also assesses faux pas understanding. To succeed, older adults must metarepresent two mental states: the mental state of the character committing the faux pas and the mental state of the person who may be disturbed by the faux pas (Stone et al., 1998). While the Faux Pas Test requires cultural knowledge, it also requires both affective and cognitive elements of ToM (Stone et al., 1998). Although older adults are read the vignette by an examiner, working memory demands are reduced because older adults are allowed to refer to a written copy of the vignette as they answer questions (Gregory et al., 2002). With regard to clinical populations, the Faux Pas Test demonstrated the greatest sensitivity in detecting patients with fvFTD compared to other tests of ToM, and it has also demonstrated greater sensitivity than false belief tasks in detecting Asperger's 
syndrome (Gregory et al., 2002; Baron-Cohen et al., 1999). Thus, the Faux Pas Test appears to be an advanced ToM measure that is extremely sensitive to deficits in social functioning in adults.

EYES is a measure of higher-order ToM ability that was designed to tap the social-perceptual component of ToM (Baron-Cohen et al., 1997; Baron-Cohen et al., 2001; Tager-Flusberg \& Sullivan, 2000). It requires individuals to discern complex mental states just by viewing a picture of a pair of human eyes (Tager-Flusberg \& Sullivan, 2000; Baron-Cohen et al., 1997; Baron-Cohen et al., 2001; Stone et al., 1998). Participants are shown a picture of the eyes surrounded by four mental state words (i.e. grateful, bored, aghast, etc.) and instructed to choose "the word that best describes what the person in the picture is thinking or feeling" (Baron-Cohen et al., 2001). Like the Faux Pas Test, EYES demonstrates age differentiation in children and has successfully differentiated patients with Asperger's syndrome and fvFTD from healthy controls (Baron-Cohen et al., 2001; Gregory et al., 2002). Scores on EYES are also normally distributed among healthy controls, making it an excellent measure of ToM ability in older adults.

While both EYES and the Faux Pas test are considered advanced ToM tests, they do not always correlate with one another. In patients with fvFTD, performance on EYES and the Faux Pas Test were significantly correlated in one study (Torralva et al., 2007). In another study comparing patients with $\mathrm{AD}$, fvFTD, and healthy controls, significant correlations were found between first-order false belief tasks, second-order false belief tasks, and the Faux Pas Test, although none of these measures correlated with EYES (Gregory et al., 2002). Explanations for the lack of correlation between different ToM measures in some samples have included hypotheses that the tests were measuring 
different aspects of ToM (i.e. social-cognitive vs. social-perceptual; visual vs. verbal; affective vs. cognitive) or findings that variance in some ToM tasks may be better explained by other cognitive processes (Gregory et al., 2002; Saltzman et al., 2000; Tager-Flusberg \& Sullivan, 2000; Shamay-Tsoory \& Haron-Peretz, 2007).

Variability in performance accounted for by other cognitive processes is at the root of a debate regarding the existence of a dedicated ToM module because ToM abilities have been associated with language, attention, memory, and executive functioning; these cognitive abilities are believed to contribute to performance on ToM tasks, but may not fully explain ToM abilities (Milligan et al., 2007). Evidence for the modularity of ToM has been found in studies demonstrating dissociations from other cognitive processes as well as studies in which ToM performance significantly distinguishes groups even after controlling for associated cognitive processes (Rowe et al., 2001; Lough et al., 2006). Because aging is characterized by average declines in a range of cognitive processes; including perceptual speed, spatial orientation, and verbal memory; deficits in cognitive processes could explain any deficits that older adults exhibit on ToM measures (Schaie, 1994). As the declines in cognitive functioning seen in patients with dementia are even more profound, studies of ToM in patients with dementia must control for associated cognitive processes in order to determine whether an individual has a specific impairment regarding inferring the mental states of others. For example, an individual in the mild stages of dementia may have great difficulty recalling a vignette and answering questions about it not because of a ToM deficit, but because of a working memory deficit. Control conditions and controlling for confounding variables within analyses are ways that researchers have attempted to isolate ToM performance in older adult samples. The loss of supportive general cognitive 
processes with age may make some tests of ToM less specific for ToM deficits in older adults if damaged general cognitive processes are recruited during task performance. Additionally, the loss of general cognitive processes also may contribute to deficits in social functioning (Henry et al., 2009). For example, if an individual with dementia has deficits in working memory, the individual may have difficulty following the flow of a conversation. With these issues in mind, studies examining whether ToM abilities decline in healthy older adults will be reviewed.

\section{ToM and Healthy Aging}

The first study of ToM in older adults was in 1998 (Happe et al., 1998). Since that time, there have been 16 studies that have examined the performance of older adults on ToM tests in comparison to younger adults. These studies, their findings, and their limitations are outlined in Table 1. The first study, by Happe et al. (1998), indicated that older adults have superior ToM abilities in comparison to younger adults, which was a very exciting finding when compared to the other cognitive losses that characterize the aging process (Schaie, 1994). However, the sample of older adults had a higher mean education level than the mean of the population within their age group, leading the authors to speculate that their superior performance on ToM may have been related to higher intelligence rather than age. Unfortunately, no measures of potentially confounding cognitive variables; such as intelligence, executive functioning, or memory; were collected.

Results of the 15 studies since then have been mixed, but they have failed to replicate Happe et al.'s results (1998). Subsequent studies have indicated that ToM abilities are either preserved or decline in older adults. Twelve of these studies have demonstrated a main effect of age on overall task performance on at least one ToM 
measure, although the use of control conditions and covariates have enabled researchers to attribute some age effects to declines in other cognitive processes rather than a decline specifically related to ToM (Saltzman et al., 2000; Maylor et al., 2002; Phillips et al., 2002; Sullivan \& Ruffman, 2004; German \& Hehman, 2006; Wang \& Su, 2006; Uekermann et al., 2006; McKinnon \& Moscovitch, 2007; Bailey \& Henry, 2008; Bailey et al., 2008; Pardini \& Nichelli, 2009). Some studies have found that lower ToM ability in older adults compared to younger adults can be accounted for by declines in general cognitive processes such as working memory or executive functioning, rather than ToMspecific declines (Sullivan \& Ruffman, 2004; Saltzman et al., 2000; German \& Hehman, 2006; McKinnon \& Moscovitch, 2007). Other studies have not been able to account for ToM-specific differences with general cognitive processes; they have found evidence of ToM-specific impairment with age on some tasks (Phillips et al., 2002; Wang \& Su, 2006; Uekermann et al., 2006; Slessor et al., 2007; Bailey \& Henry, 2008; Bailey et al., 2008). Including 3 studies that have had mixed results across different ToM measures, 9 studies have found evidence suggesting that ToM-specific ability is relatively preserved with age (Saltzman et al., 2000; Sullivan \& Ruffman, 2004; MacPherson et al., 2002; German \& Hehman, 2006; Wang \& Su, 2006; Keightley et al., 2006; McKinnon \& Moscovitch, 2007; Slessor et al., 2007; Verdon et al., 2007), while 9 studies have found evidence suggesting that ToM may decline with age (Saltzman et al., 2000; Maylor et al., 2002; Sullivan \& Ruffman, 2004; Phillips et al., 2002; Wang \& Su, 2006; Uekermann et al., 2006; Bailey \& Henry, 2008; Bailey et al., 2008; Pardini \& Nichelli, 2009). These mixed findings may be explained by differences in the ToM and general cognitive tasks employed across studies, as well as varying levels of ToM ability within samples. Only one study (Bailey, 2008) has explored the relevance of lower ToM abilities in 
community-dwelling older adults with regard to their daily lives (Bailey et al., 2008). While that study found that older adults performed worse than younger adults on EYES and had lower levels of social participation compared to younger adults, performance on EYES was not a significant mediator between age and participation in social activities (Bailey et al., 2008). However, cognitive empathy, as measured by a self-report inventory, was found to mediate the relationship between age and participation in social activities, providing some evidence that the ability to take the perspective of another has some bearing on social behavior in older adults (Bailey et al., 2008).

\section{Impaired Awareness}

Impaired self-awareness has been defined as an inadequate assessment of one's abilities, a lack of understanding of the consequences of carrying out behaviors exceeding the limits of one's ability, failure to use information to change one's personal awareness of deficits, and problems making decisions that relate past selves to current or future selves (Stuss, 1991; Clare, 2004b). Notably, the terms impaired awareness, lack of insight, and anosognosia are used throughout the literature to refer to a lack of knowledge of one's cognitive and social deficits, and these terms will be used interchangeably in this paper. Impaired self-awareness places older adults at significant social and physical risk as they may not employ sufficient compensation to carry out tasks that they attempt, or they may choose to carry out tasks that they do not have the cognitive or physical resources to safely attempt even with the use of compensatory aids. Lack of awareness into behavioral and social deficits is such a common feature of frontotemporal dementia that it is part of the diagnostic criteria (Neary et al., 1998). Lack of awareness of cognitive deficits has also been noted in patients with $\mathrm{AD}$. In one study of patients diagnosed with probable $\mathrm{AD}$, approximately $54 \%$ of the sample was classified as 
unaware of their cognitive deficits (Auchus et al., 1994). Lack of awareness of deficits in independent living skills and memory ability have also been positively associated with caregiver burden, suggesting that lack of awareness may directly impact interpersonal relationships (Seltzer et al., 1997; DeBettignies et al., 1990). Additionally, individuals with dementia who lack awareness of their deficits have also demonstrated higher levels of neuropsychiatric disturbance, which has also been shown to increase caregiver burden (Mangone et al., 1991; Rymer et al., 2002). Clearly impaired awareness represents a clinical problem that is present in some, but not all, individuals with dementia.

Mild cognitive impairment (MCI) typically indicates impaired memory in the absence of other symptoms of dementia (Petersen et al., 2001). Patients who have been diagnosed with $\mathrm{MCl}$ appear to be at greater risk for conversion to dementia of the Alzheimer's type compared to older adults without MCI (Morris \& Cummings, 2005). One study found that $31.1 \%$ of patients diagnosed with Mild Cognitive Impairment (MCI) demonstrated a lack of awareness with regard to their ability to manage bank statements whereas only $5.6 \%$ of older adults without MCI demonstrated lack of awareness of their ability for that task (Okonkwo et al., 2008). The same study found that patients with $\mathrm{MCI}$ significantly overestimated their financial abilities in other areas as well. Impaired self-awareness, however, is not restricted to individuals diagnosed with cognitive impairment. For example, in a study of patients with $\mathrm{AD}$ and normally aging individuals, $31 \%$ of the normally aging individuals gave better assessments of their performance after completing cognitive tasks than their performances actually warranted (Graham et al., 2005). These results suggest that impaired awareness may be present in community-dwelling older adults without a formal diagnosis of dementia and that impaired awareness increases the vulnerability of older adults in vital domains. 
Studies have revealed contradictory findings regarding the clinical correlates of impaired awareness in dementia, making impaired awareness difficult to predict (see reviews, Aalten et al., 2005; Clare, 2004a). Neither demographics nor neuropsychological measures are particularly helpful in predicting awareness deficits (Aalten et al., 2005; Clare, 2004a). Furthermore, while some studies have found significant positive associations between dementia severity and impaired awareness (Mangone et al., 1991; McDaniel et al., 1995), other studies have not (Michon et al., 1994; Auchus et al., 1994). Between AD and fvFTD and even across individuals with the same dementia diagnosis, there appears to be variability in the presence, severity, and domain (social, behavioral, cognitive, IADLs, etc.) of impaired awareness (Smith et al., 2000; Aalten et al., 2005; Clare et al., 2005a; Clare, 2004a; Clare, 2004b; Evers et al., 2007). Additionally, there is intraindividual variability in awareness, in which an individual may be aware of some deficits, but not others.

One reason for this variability may reside in the different methods used to measure the construct of awareness. In general, there are five ways in which awareness has been assessed in dementia (see reviews Clare, 2004a; Clare et al., 2005b). Some studies have assessed awareness by using clinician ratings. Other studies have compared patients' ratings of their ability in different domains, such as memory and ADLs, with informants' ratings of patients' abilities in those domains. A third way that awareness has been assessed is by comparing patients' ratings of their performance on cognitive tasks with their actual performance on those tasks. Phenomenological methods have also been used to explore different aspects of awareness. Finally, some studies have employed a combination of the above methods (Clare et al., 2005a; Clare, 2004a). All of 
these methods have been found to be limited in their ability to assess awareness (Clare et al., 2005a; Clare, 2004a).

A second reason for the variability seen in awareness may be related to the conceptual complexities inherent in the construct of awareness. Specifically, impaired awareness is determined through social processes that involve a patient's self-report. Clare has presented a biopsychosocial model of awareness that highlights the difficulties in concluding that individuals are unaware of problems based on what they say or do (Clare, 2003; Clare, 2002). In this model, self-awareness is made possible by the neurological structure of the brain and the integrity of supportive cognitive processes. Defensive denial is a psychological process that can result in behaviors that appear to outside observers to indicate a lack of awareness of a problem. Defensive denial is not specific to dementia, however, and may be seen across all illnesses. Thus individuals may have difficulty accepting their problems and may deny that they have problems when asked about them, making them appear unaware of their deficits. In support of this, studies have found that patients with dementia who were more aware of their deficits also tended to be dysthymic or had subsyndromal depression, whereas patients categorized as unaware were less likely to have symptoms of depression (see review, Aalten et al., 2005). Thus, unawareness at the psychological level could protect the individual from depression. The social reasons that individuals may deny their deficits even if they are aware of them include the desire to present themselves well to practitioners as well as recognition of limitations that could be placed on their activities (such as driving) if they admit that there is a problem.

ToM appears to be closely related to self-awareness, and disruptions in ToM ability may explain impaired awareness in dementing disorders, particularly with regard 
to the biological and cognitive aspects of Clare's model. Evidence for the close relationship between ToM and self-awareness comes from the child development and brain imaging literatures. First, ToM ability includes the ability to attribute mental states to the self as well as to others, and self-awareness involves the ability to metarepresent the self. Second, the abilities to attribute mental states to the self and to others appear to emerge in children simultaneously, suggesting that ToM is required in order to make mental representations about the self that allow for consciousness of the self (Gopnik \& Meltzoff, 1994; Happe, 2003). Based on their work with patients who have brain lesions and functional neuroimaging, Stuss and Anderson (Stuss \& Anderson, 2004) have related both ToM and self-awareness to the right ventromedial prefrontal cortex. This overlap in the ventromedial areas of the prefrontal cortex may explain why individuals with fvFTD tend to demonstrate poor performance on ToM tasks and tend to exhibit impaired awareness into their behavioral and social deficits. However, although both selfawareness and ToM may share key neural circuitry, they appear to be dissociable constructs. Imaging studies utilizing fMRI that have compared self-awareness and ToM have found that the two constructs rely on overlapping yet distinct neural substrates (Saxe et al., 2006; Vogeley et al., 2001). Experimental research using transcranial magnetic stimulation (TMS) also found that stimulation of the right prefrontal cortex disrupted individuals' self-perspectives, but not their ability to infer others' mental states (Guise et al., 2007). While self-awareness and ToM may be dissociable, ToM deficits may predict impaired self-awareness, as deficits on ToM tasks may indicate an inability to adequately process social information about the self that is needed to update self-schemas.

Additionally, deficits on ToM tasks may reflect damage to neural circuitry that is also 
needed for self-awareness. Thus, ToM tests may have clinical value in identifying and predicting individuals who may have or who will have deficits in self-awareness.

To date, there have been two studies of ToM and awareness in relation to dementia (Cuerva et al., 2001; Caoile, 2002). Both studies compared patients diagnosed with $\mathrm{AD}$ to healthy controls. Both studies also defined awareness as the discrepancy between informant and participant responses on a single measure of insight. While one study found no relationship between ToM and awareness (Cuerva et al., 2001), the other study found a significant negative relationship $\left(r^{2}=0.42\right)$ between awareness of deficits and ToM performance across all participants but not within each group (Caoile, 2002). The study that found no relationship between ToM and awareness used a ToM task that has been shown to make significant demands on working memory, which was not controlled for in the study (Cuerva et al., 2001). The findings of the second study suggest that general cognitive ability may explain the relationship between ToM and awareness in that study, although the authors did not specifically investigate this. Other studies have also found no association between awareness deficits and cognitive ability in dementia (see review, Aalten et al., 2005). Importantly, in the studies that have explored ToM and awareness in dementia, the use of only one type of measure of awareness may not have adequately represented the construct of awareness and neither patient nor informant depression, which have been found to influence response style, were controlled for in the analyses. The proposed study attempted to address these limitations in order to clarify the relationship, if any, between impaired awareness and ToM.

The differential effects of aging on the brains of older adults, however, suggest that damage to brain areas important for both ToM and awareness may be present in older adults with and without dementia. As noted in the paragraphs above, supposedly 
healthy community-dwelling older adults may demonstrate impaired awareness while some individuals with dementia do not. This variability may be explained by individual differences in the integrity of underlying brain systems, but knowledge of the clinical correlates of unawareness is limited. Efforts to increase knowledge of the clinical correlates of unawareness may be helpful for identifying older adults in need of assistance. Individual differences in ToM ability may relate to the problem of unawareness of ability level found in community-dwelling older adults with and without dementia and may explain the variability that has been found in previous studies. There are other reasons for exploring the relationship between ToM and awareness in a community sample. First, community-dwelling older adults are likely at greater risk of harm when they do not have a good understanding of their abilities compared to older adults living in institutional settings. Second, while cognitively intact older adults may demonstrate impaired awareness of their ability, problems with insight into ability level may also indicate dementia onset. Prevalence estimates for undiagnosed dementia in community-dwelling older adults have been estimated to be more than $50 \%$ (Boustani et al., 2003). One reason for the high prevalence rate of undetected dementia in community-dwelling older adults could be related to a lack of awareness of a change in ability. In other words, individuals would be unlikely to contact their physician when they are not aware of any significant changes. If lower levels of ToM ability are related to problems with awareness, then ToM tests could be a useful tool for identifying older adults whose general safety may be at risk as well as older adults in the early stages of dementia. Thus, the proposed study explored the relationship between ToM and awareness in community-dwelling older adults, including individuals with dementia, 
because it was hypothesized that ToM represents an important clinical correlate of impaired awareness.

\section{Research Questions and Hypotheses}

The current study addressed the following research questions:

1. Does ToM ability predict social resources and social behavior of older adults living in the community? In order to answer this question, the correlates of ToM were explored in relation to social networks, perceived social support, and interpersonal behavior. Specifically, it was hypothesized that older adults with lower levels of ToM ability would have smaller social networks, report lower levels of perceived social support, and would exhibit greater disturbance in interpersonal exchanges. With respect to social networks, the hypothesis was based on some evidence that healthy older adults demonstrate worse performance on advanced ToM tests compared to younger adults and the parallel phenomena of decreasing network sizes with increasing age. The relationship of ToM and problems in interpersonal relations was based on findings from research with ToM and clinical populations, particularly patients with fvFTD, that demonstrate problematic interpersonal behavior. Although social support may be relatively steady throughout the lifespan (according to the Convoy Model), it was hypothesized that deficits in ToM ability would preclude older adults from successfully interacting with others in a manner that would get them the support they need. Finally, it was hypothesized that ToM would contribute to the variance in these social variables even after controlling for associated demographics, health, and cognitive variables. A model of the primary 
hypotheses related to the social variables and ToM is presented in Figure 1 in the appendix.

2. How does ToM ability relate to awareness of cognitive and social ability? It was hypothesized that individuals who demonstrate lower levels of performance on ToM tests would also demonstrate higher levels of awareness difficulties. Further it was hypothesized that ToM would independently predict awareness difficulties even after controlling for associated variables. A model depicting the primary hypotheses related to awareness is depicted in Figure 2 in the appendix. 


\section{METHODS}

\section{Sample}

Eighty one participants were recruited for approximately one year from a variety of sources in the community, including advertisements and contacts with senior centers, churches, and physicians. To be included in the study, individuals had to be at least 60 years of age, reside within the community, and have an informant who knew them well and who was willing to participate in the study'. Older adults in the severe stages of dementia, who demonstrated evidence of psychosis (as observed by the clinician or researcher), or who had significant hearing and vision deficits (as measured by Snellen Eye Chart) were excluded from the study. Of the 81 participants who consented to participate, three were excluded from data analyses for the following reasons: two individuals met criteria for impaired vision (WHO, 1993) and one individual dropped out before completing most study measures due to difficulties understanding the English language.

An informant for one primary participant also refused to consent to participation. The primary participant was allowed to continue participating as she had consented to participate and also listed alternative informants that would likely participate in the place

of the informant who had refused. However, the alternative informants did not choose to participate. Thus, this primary participant's data is included in analyses that do not 
require informant data. In sum, the final data set for statistical analyses included 78 primary participants and 77 informants.

Measures

Background Variables

Sociodemographic information for participants and informants were collected through self-report, and included age, gender, ethnicity/race, education, employment information, household income, marital status, the relationship of the participant to the informant, the length of time that the informant has known the participant, and how often the informant spent time with the participant.

$\underline{\text { Health }}$

Charlson Comorbidity Index (CMI)

The self-report version of the Charlson Comorbidity Index (CMI) is a checklist of chronic diseases, and each disease contributing to the index is weighted according to risk for mortality (Charlson et al., 1987). The CMI has significantly predicted one-year survival in medical patients (Charlson et al., 1987) and recovery in the ability to carry out activities of daily living (ADL) in patients engaging in medical rehabilitation (Moore \& Lichtenberg, 1996). CMI medical conditions include myocardial infarct, congestive heart failure, peripheral vascular disease, cerebrovascular disease, dementia, chronic pulmonary disease, connective tissue disease, ulcer disease, mild liver disease, diabetes, hemiplegia, moderate or severe renal disease, diabetes with end organ damage, any tumor, leukemia, lymphoma, moderate or severe liver disease, metastatic solid tumor, and AIDS.

Vascular Risk 
Items taken from the Probability of Stroke Risk Profile were used to calculate a composite score for vascular risk. Probability of Stroke Risk Profile items included: current cigarette smoking, history of cardiovascular disease, history of atrial fibrillation, left ventricular hypertrophy, history of high blood pressure or treatment for hypertension, and history of diabetes (Wolf et al., 1991). A weighted score may be calculated using specific medical data, such as actual systolic blood pressure. As the current study utilizes a self-report format, a composite score for vascular risk was calculated by summing these variables, yielding a range of 0-6 for the vascular risk composite score. Summed scores for vascular risk factors have been used in previous studies that used a self-report format (Yochim, Mast, \& Lichtenberg, 2003; Holley \& Mast, 2007).

Self-Rated Health

Perceived health status was measured by asking participants: "In general, would you say your health is....(circle one) Excellent, Very Good, Good, Fair or Poor." Multiple studies in the gerontology literature have demonstrated this item's relation to mortality and other health outcomes (see review, Idler \& Benyamini, 1997). Screening Measure for Parkinson's disease

This measure is essentially a check list of symptoms that have been associated with Parkinson's disease (PD) in research studies. Participants either screen positive or negative for PD.

$\underline{\text { Depression }}$

Geriatric Depression Scale (GDS)

The Geriatric Depression Scale (GDS) is a self-report measure consisting of 30 statements reflecting depressive symptoms that older adults frequently report (Brink, 1982). The response format is dichotomized; participants simply answer "yes" or "no" in 
order to indicate their agreement with each item. The 30 -item version of the GDS has demonstrated excellent internal consistency with a Cronbach's $\alpha$ of .94 and excellent reliability (split-half $=.94 ;($ Yesavage et al., 1982). Sheikh \& Yesavage (Sheikh \& Yesavage, 1986) developed a 15-item short form that is highly correlated with the original 30 -item version $(\mathrm{r}=.84)$ and was used in this study to assess both participant and informant depressive symptoms. A cut-score of 5 has been recommended for classifying individuals as depressed versus non-depressed (Hermann et al., 1996).

\section{Cognitive Variables}

\section{North American Adult Reading Test (NAART)}

The North American Adult Reading Test (NAART) was used to provide an estimate of premorbid IQ. For the NAART, participants read aloud 61 irregularly pronounced words, and their score is based on the number of words they correctly pronounce. The NAART has demonstrated excellent reliability as estimated by a Cronbach's $\alpha$ of .93 in one sample (Uttl, 2002). Correlations with the Wechsler Adult Intelligence Scale - Revised (WAIS-R) and the NAART were .75 for the Full Scale IQ, .83 for Verbal IQ, and .40 for Performance IQ (Blair \& Spreen, 1989).

Dementia Rating Scale - Version 2 (DRS-2)

The Dementia Rating Scale - 2 (DRS-2) is a measure of global cognitive functioning that has demonstrated utility in detecting dementia (Jurica et al., 2001). In addition to a score for overall cognitive functioning, the DRS-2 has subscales for attention, initiation/perseveration, conceptualization, construction, and memory abilities. One-week test-retest reliability for the DRS-2 total score was .97 while the subscales testretest reliabilities ranged from .61 to .94 . The DRS-2 has acceptable levels of convergent 
and divergent validity with other neuropsychological tests commonly used in assessing individuals for dementia.

Frontal Assessment Battery (FAB)

The Frontal Assessment Battery (FAB) is a brief, valid measure of frontal lobe functions (Dubois et al., 2000). The FAB includes items that measure inhibitory control, motor series programming, verbal fluency, autonomy with regard to environmental cues, sensitivity to interference, and abstract reasoning. Participants are asked to carry out tasks such as naming all of the words that they can think of that begin with a specific letter and demonstrating a sequence of hand gestures. The FAB has good internal consistency (Cronbach's $\alpha=.78$ ) and discriminant validity (correctly categorized $89.1 \%$ of cases in a sample including healthy controls and patients with frontal lobe dysfunction; Dubois et al., 2000).

Hopkins Verbal Learning Test-Revised (HVLT-R)

The Hopkins Verbal Learning Test is a widely used neuropsychological test of verbal learning and memory with established normative data, reliability, and validity (Brandt \& Benedict, 2001). Participants are read a list of 12 words. After the examiner has read the entire list, participants are asked to say the words that they remember. The process is repeated over two more trials. Then is a time delay of $20-25$ minutes, at the end of which participant long-term recall is assessed by free recall and recognition tasks. Letter-Number Sequencing ( $L N-S e q)$

Letter-number sequencing ( $\mathrm{LN}-\mathrm{Seq})$ is a subtest from the Wechsler Adult Intelligence Scale - Version III that measures working memory (Wechsler, 1997; Kaufman \& Lichtenberger, 2006; Lezak et al., 2004). In the LN-Seq subtest, progressively longer sequences of letters interspersed with numbers are orally presented 
to participants. After hearing the letter-number sequence, participants must mentally reorganize the numbers and letters in the sequence and then orally present all the numbers in ascending order followed by all of the letters in alphabetical order.

\section{$\underline{\text { Social Relations Measures }}$}

\section{Convoy Measure}

The size of participants' affective networks was measured using the hierarchical mapping technique described by Antonucci (Antonucci, 1986). Participants are given a diagram with three concentric circles. The word "You" is written in the center of the three circles. Participants are told, "this is you in the middle" (Kahn \& Antonucci, 1980). Participants are instructed to think of "people who are important in your life right now" and write each person's initials into the circle that best represents how close they feel to that person (Antonucci, 1986). Participants are told to place "those people to whom you feel so close that it is hard to imagine life without them" into the innermost circle. For the middle circle, participants are instructed to write the initials of "people to whom you may not feel quite that close but who are still important to you." For the outermost circle, participants are instructed to write the initials of the "people whom you haven't already mentioned but who are close enough and important enough in your life that they should be placed in your personal network." Total network size is determined by adding up the number of people in the diagram (Antonucci, 1986; Antonucci et al., 2002). The concentric circle diagram has been employed in many studies, including those making cross-cultural comparisons, and is considered a valid measure of affective network size. (Antonucci \& Akiyama, 1987; Antonucci, 1986; Antonucci et al., 2002; Brissette et al., 2000).

Interpersonal Support Evaluation List-Short Form 
The Interpersonal Support Evaluation List - Short Form (ISEL) was used to measure perceived social support. The six items on the short form of the ISEL were taken from the full version of the ISEL and reflect three functions of social support: tangible support (i.e., instrumental support), belonging (i.e., how well one identifies with one's social network), and appraisal support (i.e. informational support). Participants rate each item on a 4-point scale; possible responses include definitely false, probably false, probably true, and definitely true. The full version of the ISEL has been shown to correlate moderately with other scales of social support (Cohen et al., 1985). The sixitem ISEL-SF has demonstrated good internal consistency ( $\alpha=0.73 ;$ (Williamson $\&$ Schulz, 1992).

The Positive and Negative Social Exchange Measure

The Positive and Negative Social Exchange Measure was used to measure the frequency of positive and negative social exchanges experienced by participants in the past month. This 24 -item self-report measure contains 12 items that measure the frequency of positive social exchanges and 12 items that measure the frequency of negative social exchanges. Each item begins with the phrase, "In the past month, how often did the people you know...?" Participants respond using a 5-point Likert scale ranging from 0 (never) to 4 (very often). Positive exchange domains measured by the positive exchange items include informational support, instrumental support, emotional support, and companionship. Negative exchange domains measured by the negative exchange items include unwanted advice or intrusion, failure to provide help, unsympathetic or insensitive behavior, and rejection or neglect (Newsom, 2005). Composite scales for negative and positive social exchanges both have very good internal consistency, with $\alpha=.90$ for each (Newsom et al., 2005). The negative social exchange 
subcale (PANSE - NSE) was used in the current study to measure frequency of negative social exchanges in primary participants. Higher scores indicate greater frequency of negative social exchanges.

Peer Report Social Functioning Scale (prSFS)

The Peer-Report Social Functioning Scale (prSFS) includes 38 items that represent behaviors considered socially-inappropriate, socially appropriate, or stereotyping and prejudicial (Henry et al., 2009). An informant of the participant completes the measure with regard to the primary participant's behaviors. The instructions are, "Below are statements about particular topics of conversation. How often does do the following things?" Items for the prSFS are based on previous research concerning socially disturbing behaviors displayed by some older adults as well as research with focus groups conducted specifically for the prSFS development (Henry et al., 2009). Eight of the items on the scale are filler items that were added to increase the opportunity for informants to report positive aspects of the primary participants and to decrease the sense of guilt that informants may feel from reporting negative qualities about the primary participants. Informants use a 4-point scale (never, rarely, occasionally, frequently) to reflect how often the primary participants engage in a particular behavior. Subscales for social inappropriateness, social appropriateness, and stereotyping and prejudicial behavior have demonstrated excellent internal consistency, with Cronbach's alpha coefficients of $.87, .92$, and .75 , respectively. The composite measure that represents overall social functioning also demonstrated excellent internal consistency ( $\alpha=.94$; Henry et al., 2009), and was the variable for social functioning used in the current study. Higher raw scores on the composite measure indicate better social functioning. Significant correlations of the prSFS with a laboratory experiment in which 
socially-inappropriate and prejudicial behaviors were provoked provide additional evidence of validity for the prSFS (Henry et al., 2009).

\section{$\underline{\text { Awareness Measures }}$}

Multiple methods of assessment of the construct awareness were used per Clare's $(2004 ; 2005)$ recommendation.

Participant-Informant Discrepancies on the Memory Functioning Scale of the Memory Awareness Rating Scale - Revised (MARS-MFS)

The Memory Functioning Scale of the Memory Awareness Rating Scale Revised (MARS-MFS) measures subjective memory functioning. The scale was designed for use with patients who have Alzheimer's disease, but has been used with individuals who do not have diagnosis of dementia as well (Clare et al., 2002). Participants are asked how they would manage in certain situations in which they would need to rely on their memory. Scores range from 0 (never) to 4 (always). Discrepancy scores are calculated between parallel participant and informant versions. The MARSMFS also has very good psychometric properties. Internal consistency was excellent, with $\alpha=.93$. One-week test-retest reliability with participant self-rating was .91 and with informant rating of the participant was .9. The MARS-MFS also demonstrated adequate criterion validity, as it's correlations with other measures of awareness ranged from -.56 to -.74 .

Participant-Informant Discrepancies on the Peer Report Social Functioning Scale(prSFS)

A parallel self-report version of the prSFS was created and given to participants so that discrepancy scores could be calculated with respect to awareness of interpersonal functioning. Although this was a novel use of this scale, comparison between informant 
report and participant report on domains of function (i.e. IADLs, memory) is common throughout the awareness literature (see reviews, Clare et al., 2005a; Clare, 2004a). Prediction of Performance Scores on the HVLT-R and Letter-Number Sequencing Calculation of discrepancy scores between participants' predictions of how well they will do on cognitive tasks versus their actual performance on those tasks is common in the awareness literature (O'Keeffe et al., 2007; Green et al., 1993; Cosentino \& Stern, 2005; Clare, 2004a; Clare et al., 2005a). For the two tasks, participants were presented with standard directions and then asked, "How well do you think you will do on this task?" Participants were asked to rate how well they thought they would be able to do the task using the following 5-point response scale (0-4): very poor (0), poor (1), alright (2), good (3), and very good (4); this 5-point scale has been used in other measures of awareness (Clare, 2002). Using the normed scores on the actual performance measures, participants' actual performance was recoded according to the above scale. The HVLT-R Trial 1 score was used as the standard for short-term memory and the LN-Seq Total score was used as the standard for working memory. Scores 2 standard deviations (SDs) below the mean were classified as "very poor" and were recoded as 0 . Scores between 1 and 2 SDs below the mean were classified as "poor" and were recoded as 1 . Scores within 1 SD of the mean were assigned a score of 2 . Scores between 1 and 2 SDs above the mean were assigned a score of 3 . Scores above 3 SDs of the mean were assigned a score of 4. Then actual performance was subtracted from predictions of performance to obtain prediction awareness scores. Positive scores were hypothesized to reflect higher levels of unawareness. A similar method was successfully used in a recent study (Graham et al., 2005).

Postdiction of Performance Scores on the HVLT-R and Letter-Number Sequencing 
Calculation of discrepancy scores between participants' actual scores on cognitive tasks and their immediate assessment of their performance is hypothesized to indicate online monitoring ability. Following the administration of the tasks above, participants were asked to rate their performance on a five-point response scale (0-4): very poor $(0)$, poor (1), alright (2), good (3), and very good (4), which has been used effectively in other postdiction measures of awareness (Clare et al., 2002). Transformed, norm-based scores which represent participants' actual cognitive performances were used to calculate discrepancies. HVLT-R Total Recall (immediate recall over three trials) was used as the standard for postdiction of memory, while LN-Seq Total score was used as the standard for working memory. Actual performance was subtracted from postdiction assessments of performance to obtain postdiction awareness scores. Positive scores were hypothesized to reflect higher levels of unawareness and difficulties with online monitoring. A similar method was successfully used in a recent study (Graham et al., 2005).

\section{Theory of Mind}

Reading the Mind in the Eyes Test-Revised (EYES)

The Reading the Mind in the Eyes Test-Revised (EYES) is a 36-item measure that was created to detect subtle disturbances in social cognition. EYES has been identified as a social-perceptual measure of ToM (Tager-Flusberg \& Sullivan, 2000) that involves the identification of complex mental states, which integrate emotions, beliefs, and intentions. Before the introduction of the stimuli, participants are asked to read over a glossary of mental state terms that are used on the test. They are then encouraged to consult the glossary during EYES if there are any mental state terms of which they are uncertain. Examples of mental state terms used on EYES include "irritated," 
"depressed," and "accusing." During EYES, participants are shown a photograph of a person's eye region and four similarly, emotionally-valenced complex mental state words. Out of these four words, participants must select the word that best describes the mental state that is being expressed by the person in the photograph. In the current study, each item on EYES was presented on an $81 / 2 \times 11$ piece of paper. Participants were asked to verbally indicate or point to their answer, which was recorded by the examiner. The total EYES score is the total number of correct answers. Scores above 13 indicate better than chance performance (Baron-Cohen et al., 2001). Although groups of healthy adults administered less complex tests of ToM often demonstrate ceiling effects, the EYES scores of healthy adults have demonstrated a normal distribution (Baron-Cohen et al., 2001).

Validity for EYES has been established by the test's ability to discriminate clinical groups with social deficits from healthy groups or other clinical groups (Craig et al., 2004; Baron-Cohen et al., 2001; Gregory et al., 2002). EYES has successfully discriminated adults with high-functioning autism or Asperger's disorder from normal controls and was inversely correlated with a measure of autistic traits that included items assessing social skills and communicative abilities (Baron-Cohen et al., 2001). EYES also predicted social functioning better than traditional neuropsychological tests in patients with schizophrenia (Bora et al., 2006). An older version of the test that was not as sensitive as the revised version also found differences in performance between participants diagnosed with fvFTD and those diagnosed with Alzheimer's disease or healthy older adults (Gregory et al., 2002) and between healthy adults and patients with fvFTD who scored above the cut-point for dementia on a test of global cognitive functioning (Torralva et al., 2009). 


\section{Faux Pas Test}

The Faux Pas Test (Stone et al., 1998; Gregory et al., 2002) contains 10 stories in which a character commits a social faux pas and 10 control stories in which characters interact without a faux pas occurring. The Faux Pas Test requires participants to represent two mental states: the mental state of the person committing the faux pas and the mental state of the other person in the story, who may feel disturbed by the faux pas. Validity for the Faux Pas test has been established through its utility in detecting clinical groups characterized by poor social functioning. Patients with fvFTD (Gregory et al., 2002), bilateral lesions in the orbito-frontal cortex (Stone et al., 1998), and Asperger's syndrome (Zalla et al., 2009) tend to perform more poorly on the Faux Pas Test compared to healthy controls. Additionally, the Faux Pas Test has correlated with other measures of ToM (Gregory et al., 2002).

For the Faux Pas Test, the stories were read aloud by the examiner and a copy was also placed in front of the participant for reference in order to reduce task demands on working memory. After each vignette was read, participants were asked, "Did anyone say something they shouldn't have said or something awkward?" If the participant indicated that a faux pas occurred in the vignette, then the examiner probed the depth of the participant's understanding of the faux pas with standard follow-up questions. For each of the 20 vignettes, examiners also asked two control questions that tested participant comprehension of the story. Index scores were prorated in order to control for comprehension difficulties. In other words, if individuals missed the control questions for a vignette, all questions related to that vignette were thrown out and index scores were calculated based only on vignettes in which individuals correctly answered the control questions (Gregory et al., 2002, Stone et al., 1998). 
Studies have used different methods to calculate Faux Pas Test index scores, and the test authors recommend examining different indices (Gregory et al., 2002; Stone et al., 1998; Torralva et al., 2007; Torralva et al., 2009; MacPherson et al., 2002). Consistent with other studies (Gregory et al., 2002; Torralva et al., 2007), the current study examined the proportion of correct hits on faux pas stories (FP HITS) and the proportion of correct rejections of control stories (FP REJECTIONS). A Faux Pas Composite score (FP Composite); which combined FP HITS, responses to two faux pas understanding follow-up questions, and FP REJECTIONS; was calculated, as this index has been used in prior studies and has been found to significantly differentiate patients with fvFTD from patients with Alzheimer's disease and healthy controls (Gregory et al., 2002; Torralva et al., 2007). The two faux pas understanding follow-up questions were: 1) "Why shouldn't he/she have said it or why was it awkward?" and 2) "Why do you think he/she said it?"

\section{Procedures}

Persons responding to advertisements were provided with a description of the study over the telephone and invited to participate. Those who agreed to participate and who met the inclusion criteria had the option of participating in the study within their own home or at another mutually agreed upon location, such as the researcher's lab or a senior center, that offered relatively private, quiet, and well-lit testing conditions. Fiftythree participating pairs $(67.9 \%)$ elected to participate within a home environment and 25 (32.1\%) participating pairs elected to participate on the university campus.

Before data collection began, both the participant and the informant were informed about the study, the likely benefits of participation, and the possible risks of participation. If individuals had difficulty reading, self-report measures were read to 
them. On average, primary participants completed the study in 144 minutes $(\mathrm{SD}=28$ minutes) and informants completed the study in 27 minutes ( $S D=9$ minutes). Thirty primary participants also participated in the informant role.

In order to maintain confidentiality, participants were assigned an ID number. Informant responses were coded under the primary participants' ID numbers. Scoring of the measures was carried out by trained researchers. Although one research assistant was trained to score each participant's Faux Pas Test, another trained researcher independently scored stratified random selections across the sample in order to establish interrater reliability and manage scoring drift. Using this method, interrater reliability was calculated to be $r=.97$. Scores and demographic information were entered into a database and stored in a locked filing cabinet.

\section{Data Analysis}

Statistical analyses were carried out using PASW and AMOS versions 18.0. Alpha was set at .05 for all analyses. Descriptive data analyses were completed first. As noted above, the two primary hypotheses concerned the utility of ToM measures in predicting social relations and awareness. The hypothesis regarding ToM and the social variables was examined initially using bivariate correlations and $t$ tests. Cognitive and demographic variables were also included in the correlational analyses in order to determine whether they significantly accounted for variance in any of the primary variables of interest; they were only included in subsequent analyses if bivariate correlations indicated a significant relationship with primary variables. Path analysis was planned to test the hypothesized model depicted in Figure 1 between ToM and the social variables. $T$ tests were used to compare participants performing in the impaired range on 
ToM measures with participants performing in the non-impaired range with regard to the social relations variables.

The hypotheses regarding the relationship between ToM and unawareness of ability were similarly explored with bivariate correlations and $t$ tests along with select demographic and cognitive variables. The model depicted in Figure 2 was tested using path analysis. $T$ tests were used to compare participants performing in the impaired range on ToM measures with participants performing in the non-impaired range with regard to the awareness variables.

Three participants had one item missing on the PANSE-NSE or prSFS. Person mean substitution was used to impute the missing data in these cases (Hawthorne \& Elliott, 2005). Cases in which more than one item was missing and summary or index scores could not be calculated were generally not included in analyses involving those variables.

As parametric statistics were planned, the primary variables (ToM, awareness, social relations) were explored for their consistency with statistical assumptions and to screen for outliers. Several transformations were applied to the data due to significant skewness $(z>2.58)$, ceiling effects, or the presence of outliers (Field, 2005). These transformations and the meaning of the subsequent scores are detailed in Table 3 , which also provides a reference for acronyms and abbreviations used in the study. As noted in the table, square root transformations were applied to the following variables: FP Composite score, EYES score, prSFS Social Functioning Composite score, convoy measure of total network size, and negative social exchanges. A natural log transformation was applied to the ISEL (perceived social support) score. A reciprocal transformation was applied to the CMI and visual acuity scores. Attempted square root, 
logarithmic, and reciprocal transformations of the memory awareness score for the MARS-MFS failed due to the presence of an extreme outlier. The outlying case was then removed from analyses involving the MARS-MFS awareness score, which corrected the problems with the distribution of this variable.

Gregory et al. (2002) defined impairment on the EYES, FP Composite score, FP HITS, and Faux Pas REJECTIONS as proportion scores that fell 1.5 standard deviations below the mean of the healthy control group. Using the cut-scores established by Gregory et al. (2002), the current sample was classified as impaired versus non-impaired on the Faux Pas variables. As Gregory et al. (2002) used an older version of EYES in their study, their recommended cut-score was not used in the current study for EYES. However, their recommended methods were used, as a cut-score 1.5 standard deviations below the current sample's raw EYES mean was used to define impairment on EYES in the current study.

\section{Statistical Power}

1. Hypotheses related to social relations:

As shown in Table 2, selected effect sizes from published studies concerning the relationship of ToM with different measures of social functioning across different populations suggested medium to large effect sizes. Though effect sizes that isolated the relationship between ToM and social functioning in older adults were not available, two studies have been performed using multiple regression. The first study tested ToM as a mediator between age and participation in prosocial activities, but found that ToM was not a mediator in the relationship and reported no relevant statistical results (Henry et al., 2009). The second study found that social cognition (ToM and emotion identification from faces) accounted for $38 \%$ of the variance in social intimacy in nursing home 
residents with and without cognitive impairment $(\mathrm{N}=40)$ after controlling for gender, age, education, global cognitive functioning, and working memory (Washburn et al., 2003). When emotion identification was controlled for as well, ToM accounted for an additional $8 \%$ of the variance. This indicates a large effect size $\left(f^{2}=0.33\right)$.

\section{Hypotheses related to unawareness of ability}

As noted in the introduction, there have been two studies involving awareness and patients with AD (Cuerva et al., 2001; Caoile, 2002). One study reported no association with 39 patients with $\mathrm{AD}$, but used a ToM measure that appears to rely heavily on working memory (Cuerva et al., 2001). Because that study did not control for working memory in their analysis, it is possible that ToM may have been significantly confounded with working memory ability. The other study, which examined individual differences in ToM performance across 17 participants with $\mathrm{AD}$ and 18 healthy controls, found that the relationship between ToM and insight into ability was significant with $r=-.645$, which is a large effect size (Caoile, 2002). However, this study did not control for possible confounding variables such as overall cognitive ability. No other studies appear to have investigated this link directly. Studies that support the relationship between ToM and unawareness into ability level, such as studies of insight in patients with fvFTD (who perform poorly on ToM tasks), suggest that low levels of ToM will produce profound deficits in awareness and indicate a large effect size. Because the first study of unawareness and ToM found no relationship, however, the more conservative medium effect size is more appropriate for these analyses.

\section{Sample Size}

In path analysis, sample size is usually determined based on the number of free parameters estimated. However, there is debate regarding the optimal number of cases 
per estimated parameter in order to achieve adequate power to reject the null hypothesis while avoiding Type I error, which is more likely to occur in path analysis with very large sample sizes. Bollen (Bollen, 1989) has suggested that three cases per free parameter are necessary, whereas Bentler (Bentler, 1993) is more conservative and recommends at least 5 cases per free parameter. The model depicted in Figure 1 contains 15 free parameters. Thus, for the social relations and ToM model, the smallest adequate sample size was between 45 ( $3 \times 15$; Bollen, 1989) and 75 (5 x 15; Bentler, 1993). The model of ToM and awareness depicted in Figure 2 contains 21 free parameters and requires a sample size that is at least between $63(3 \times 21$; Bollen, 1989) and $105(5 \times 21$; Bentler, 1993). Based on these guidelines, the current sample of 78 was likely adequate to test the model of ToM and social relations, but may have lacked sufficient power to adequately test the model of ToM and awareness. 


\section{RESULTS}

\section{Demographics and Characterization of sample}

A reference with study abbreviations and guidelines for interpreting variables that underwent transformation for analyses is found in Table 3. The demographic characteristics of the primary participants and their informants are presented in Table 4. The mean age of primary participants was 68.79 years old $(\mathrm{SD}=7.75$ years), with $62.8 \%$ of the sample below the age of 70 years and $84.6 \%$ of the sample below the age of 80 years. The mean age of informants was 59.33 years, with informant ages ranging from 21 years to 87 years. Slightly more than half $(57.9 \%)$ of informants were 60 or more years old. As can be seen in Table 4, primary participants and informants tended to identify themselves as non-Hispanic White ( $92.3 \%$ and $88.5 \%$, respectively) and female (70.5\% and $75.6 \%$, respectively). The sample was almost evenly divided between married/partnered and non-married participants, with $43.6 \%$ of primary participants and $47.4 \%$ of informants reporting that they were married or partnered. Relatively high socioeconomic status (SES) characterized an unusually high portion of the sample, as $56.5 \%$ of primary participants and $53.3 \%$ of informants reported having at least a bachelor's degree and approximately $40 \%$ of both participants and informants reported a household income greater than $\$ 60,000$ per year. The sample was also very healthy, as the majority of primary participants $(88.5 \%)$ and informants $(88.2 \%)$ rated their health as good, very good, or excellent. More objective measures of health, such as the CMI and 
vascular risk composite score also indicated low levels of illness in primary participants. On average, primary participants reported $<1(\mathrm{M}=0.75, \mathrm{SD}=1.2)$ comorbid health condition on the CMI, with $61.3 \%$ reporting no health conditions. Similarly, primary participants reported a mean of $1.03(\mathrm{SD}=1.1)$ vascular risk conditions, with $71.8 \%$ of the sample reporting 0-1 vascular risk conditions. Notably, 4 participants reported having a history of cerebrovascular accident (stroke), with the mean time since stroke 19.8 months ( $\mathrm{SD}=18.6$ months) prior to the study. Using the screening measure for Parkinson's disease (PD), $48(61.5 \%)$ of the primary participants screened negative for PD and $29(37.2 \%)$ of the primary participants screened positive for PD. The group screening positive for PD reported significantly higher levels of comorbidity $(t(72)=$ $2.20, \mathrm{p}=.03)$ and rated their health more poorly $(\mathrm{t}(75)=2.9, \mathrm{p}<.01)$ than the group screening negative for PD. Bivariate correlations indicated that cumulative vascular risk was significantly associated with both primary participant self-rating of health $(r=-.452$, $p<.001)$ and comorbid health conditions $(r=.354, p<.01)$, while self-rating of health and the CMI were not significantly associated with one another in this sample.

Both primary participants and informants tended to report a low level of depressive symptoms. The mean GDS score (possible range of 0-15) for primary participants was $1.51(95 \% \mathrm{CI}[1.17,1.92])$, with only 4 primary participants $(5.2 \%)$ endorsing a significant level of depressive symptoms, as determined by endorsement of more than 5 items (Hermann et al., 1996). The mean GDS score for informants was 1.10 (95\% CI $[0.79,1.44])$, with only 3 informants $(3.9 \%)$ endorsing a significant level of depressive symptoms.

As can be seen in Table 5, the sample of primary participants in the current study was characterized by slightly higher than average cognitive functioning. With the 
exception of the measure of verbal IQ (NAART), all scores on cognitive measures were adjusted for age. There were two participants $(2.6 \%)$ who obtained raw scores for global cognitive functioning (DRS-2) that were at or below the cut-off score of 123 for dementia (Jurica et al., 2001). When these two scores were adjusted for age and education, they indicated the presence of cognitive impairment.

The relationship between the participants and their informants is detailed in Table 6. Most informants were likely peers of primary participants, as $42.9 \%$ categorized themselves as friends or siblings and $26 \%$ categorized themselves as spouses. Approximately $20 \%$ of the informants were the child or children-in-law of primary participants. On average, informants knew primary participants for 30.19 years $(\mathrm{SD}=$ 19.22). For the majority of the sample, the frequency of contact was high, with $88.4 \%$ of informants reporting interaction at least multiple times per week with primary participants.

\section{Characterization of Performance on Theory of Mind (ToM) Variables}

Means and confidence intervals for the two primary ToM measures, the Faux Pas Test and EYES, are displayed in Tables 7 and 8, along with comparison data from recent studies utilizing these measures with non-clinical, older adult samples. While the mean value for EYES in the current study appears slightly above the mean EYES scores in the comparison studies, the current sample is also younger. As can be seen in Table 8 , the FP Composite proportion score for the current study appears much lower than the FP composite proportion score from the study by Gregory et al. (2002), which was based on only 10 participants - who were younger on average than the participants in the current study. The bivariate correlation between the EYES test and the FP Composite score was not significant $(\mathrm{r}=.10, \mathrm{p}>.05)$. 
The scores for FP HITS and FP REJECTIONS appear similar between the current study and the two comparison studies. As a reminder, the FP HITS score refers to correct identification of stories with a faux pas as containing faux pas, while the FP REJECTIONS score refers to correct identification of a story without a faux pas as not containing a faux pas. In the current study, 61 participants correctly identified $100 \%$ of the stories on the Faux Pas test as containing a faux pas (FP HITS), while 17 participants scored less than $100 \%$ correct for FP HITS. With regard to FP REJECTIONS, 46 participants correctly rejected $100 \%$ of stories on the Faux Pas Test that did not contain a Faux Pas, while 32 participants scored less than $100 \%$ correct. As scores for FP HITS and FP REJECTIONS demonstrated significant ceiling effects, their inclusion in subsequent analyses was limited.

As noted in the Methods section, impairment on the ToM measures was also examined based on previously published criteria (Gregory et al., 2002). Note that while the cut-scores for the Faux Pas test indices were taken from a study comparing patients with dementia and healthy controls, the cut-score for the EYES test used in the current study was based on the raw mean and standard deviation (1.5 SD below the mean) of the current sample, as cut scores were not available in the literature for the revised version of the EYES test. Thus, the term impairment is used for simplicity with regard to both Faux Pas test and EYES performance in the current study, but may actually indicate relatively low performance within the current sample with regard to EYES performance.

Eight participants scored in the impaired range on the EYES test, two participants scored in the impaired range for FP HITS, and ten participants scored in the impaired range for FP REJECTIONS. Twenty-four participants scored in the impaired range on the FP Composite score, and impairment on this index was examined further, given the 
relatively low rates of impairment on FP HITS and FP REJECTIONS, which collectively make up 50\% of the FP Composite score. For the first follow-up question (Why shouldn't he/she have said it or why was it awkward?), $52.6 \%$ of the sample obtained $100 \%$ correct and $74.4 \%$ obtained $90 \%$ or more correct. For the second follow-up question (Why do you think he/she said it?), $2.6 \%$ of the sample achieved $100 \%$ correct and $67.9 \%$ of the sample achieved $50 \%$ or less correct. Across participants, $48.4 \%$ of responses to the explanation question were correct. Thus, performance on the second follow-up question, which concerns attribution and explanation of behavior, appears to at least partially explain the lower FP Composite scores in the current study compared to extant studies as well as the greater numbers of participants in the current study who were categorized as impaired on the FP Composite score compared to the other ToM measures of impairment.

Impairment on one ToM index did not necessarily predict impairment on other ToM indices (EYES and FP Composite: $\left(\chi^{2}(1)=1.55, \mathrm{p}=0.21\right.$; EYES and FP REJECTIONS $\left(\chi^{2}(1)=1.18, p=0.28\right)$. Only 4 participants $(5.1 \%)$ performed in the impaired range on a Faux Pas Test index and EYES. One participant (1.3\%) performed in the impaired range across all four ToM impairment indices, one participant (1.3\%) performed in the impaired range across three ToM impairment indices (EYES, FP Composite, and FP REJECTIONS), and eight participants (10.2\%) performed in the impaired range on two ToM impairment indices. As only two participants met criteria for impairment on FP HITS, chi-square analysis was not appropriate. However, there was no apparent pattern of impairment for the two participants scoring in the impaired range on FP HITS, as one of the participants scored in the impaired range across all ToM measures, while the other scored in the impaired range on the closely-related FP 
Composite score only. One of the participants scored in the impaired range ( $\mathrm{T}$ score $=$ 21) on the HVLT-R Delayed Recall. Both participants were in their early 60's, had at least a college education, and performed in at least the average range on other cognitive measures.

\section{Characterization of Performance on Social Relations Variables}

The social relations variables are detailed in Tables 9 and 10. As shown in Table 9, primary participants' social networks contained a mean of 24.60 individuals (based on transformed data). On average, primary participants reported low levels of negative social exchanges and high levels of social support, and informants tended to rate primary participants as exhibiting relatively high levels of social functioning. As shown in Table 10 , higher levels of perceived social support were associated with larger social networks and reduced frequency of negative social exchanges. The informant-rated measure of social functioning (prSFS) was not significantly associated with the other social relations measures, which were completed by the primary participants themselves.

\section{Characterization of Performance on Awareness Variables}

As displayed in Table 11, mean discrepancy scores were minimal across the awareness measures, with primary participants tending to slightly underestimate their performance or functioning on average. Given the larger range of possible discrepancy scores on the MARS-MFS and prSFS, the likelihood of obtaining a discrepancy score of 0 was much lower than on the performance-based measures. Thus, a larger portion of the sample is categorized as underestimating or overestimating performance on the informant-based measures. The transformed discrepancy scores were used in subsequent analyses. 
Bivariate correlations were used to test the relationships between the awareness variables, and the results are depicted in Table 12. The two informant-based measures of awareness (prSFS and MARS-MFS) were significantly positively associated $(\mathrm{r}=.28, \mathrm{p}<$ .05 ), indicating that individuals who overestimated social functioning were also likely to overestimate memory functioning. Primary participant and informant ratings of social functioning were not significantly associated $(\mathrm{r}=-.18, \mathrm{p}=.12)$. Informant ratings of primary participant memory on the MARS-MFS were not significantly related to primary participant ratings on the MARS-MFS $(r=.16, p=.17)$ or actual memory performance on the HVLT-R $(r=0, p>.05)$, whereas primary participant ratings of memory performance on the MARS-MFS were significantly related to actual memory performance on the HVLT-R $(\mathrm{r}=-.31, \mathrm{p}<.01)$. Although primary participant and informant ratings were not correlated on either the MARS-MFS or prSFS, primary participant ratings and informant ratings across the measures were similarly correlated ( $\mathrm{r}$ $=.25, \mathrm{p}<.05 ; \mathrm{r}=-.25, \mathrm{p}<.05$, respectively (correlation for informant ratings is negative due to transformed variable)), which may indicate response style. The performancebased measures of awareness were significantly correlated within the cognitive domains (predictions and postdictions were correlated on the two cognitive measures), but otherwise, the performance-based measures were not correlated with one another or with either of the informant-based measures of awareness. As shown in Tables 12 and 13, the performance-based measures of awareness were also significantly associated with the associated cognitive variable used to gauge actual performance as well as between the prediction awareness and postdiction awareness scores based on each measure. Regarding the actual ratings of performance, the HVLT-R prediction ratings were not significantly associated with performance $(r=.08, \mathrm{p}>.05)$, but the HVLT-R postdiction 
ratings were associated with performance $(\mathrm{r}=.52, \mathrm{p}<.001)$. Both the LN-Seq prediction and postdiction ratings were significantly associated with performance $(\mathrm{r}=$ $.44, \mathrm{p}<.001, \mathrm{r}=.30, \mathrm{p}<.01$, respectively). Associations between Primary Variables, Demographics, Health, and Depression The impact of key demographic variables, such as gender and ethnicity, on the primary variables (ToM, awareness, and social relations) was tested with $t$ tests. The performance-based memory awareness scores significantly differed according to gender (Table 14). On average, men tended to overestimate memory performance, while females tended to underestimate memory performance (Table 14). Gender did not differentiate scores on the other primary variables and was not associated with impaired versus non-impaired performance on the ToM measures.

Although the majority of the sample identified themselves as non-Hispanic White with regard to ethnicity, ethnicity was cautiously considered by comparing performance on primary study variables, as well as demographic and cognitive variables, between African-American primary participants $(n=5)$ and non-Hispanic White $(n=72)$ primary participants using $t$ tests. Significant results are displayed in Table 15. As shown in the table, FP Composite scores were significantly lower for the African-American group compared to the non-Hispanic White group. Significantly, 4 out of 5 of the AfricanAmerican participants scored in the impaired range with the FP Composite score $\left(\chi^{2}(1\right.$, $\mathrm{N}=77)=5.94, \mathrm{p}=.02$ ). The impairment scores for FP REJECTIONS and EYES did not demonstrate a significant association with ethnicity $\left(\chi^{2}(1, N=77)=3.45, p>.05 ; \chi^{2}(1\right.$, $\mathrm{N}=77)=0.53, \mathrm{p}>.05$, respectively). The African-American group also overpredicted memory performance on the HVLT-R Prediction awareness measure compared to the non-Hispanic White group, which underpredicted performance on average. $T$ tests 
comparing the non-Hispanic White group and African-American group on demographic and cognitive measures revealed significant differences in self-ratings of health between the two groups, with African-American participants rating their health significantly worse than non-Hispanic White participants. Differences in level of education and verbal IQ between the African-American group and the non-Hispanic White group also approached significance, with the African-American group reporting lower levels of education and obtaining slightly lower verbal IQ scores compared to non-Hispanic Whites.

The relationships between age, education level, depression level, health variables, and ToM, awareness, and social relations were tested using bivariate correlations and are depicted in Tables 10,12, and 16. Greater memory awareness as measured by HVLT-R postdiction awareness score was significantly associated with higher levels of education, but education was not significantly associated with any of the other primary variables. Older age was also significantly associated with poorer performance on the EYES test ( $r$ $=.33, \mathrm{p}<.01$ ), but was not associated with the FP Composite score, any of the social relations variables, or any of the awareness variables.

Regarding health, greater medical comorbidity was associated with poorer performance on the Faux Pas Test $(r=.24, p<.05)$. Lower levels of vascular risk were associated with larger social networks $(r=-.42, p<.01)$, higher levels of perceived social support $(\mathrm{r}=.25, \mathrm{p}<.01)$, and better social functioning $(\mathrm{r}=.24, \mathrm{p}<.05)$. Primary participant self-rating of health was also associated with higher levels of perceived social support $(r=-.27, p<.05) . \quad$ PD screening status did not differentiate scores on any of the primary variables.

Despite relatively low endorsement of depressive symptoms across the sample, depressive symptoms in primary participants were significantly correlated with all social 
relations measures. Specifically, higher levels of depressive symptoms in primary participants were associated with smaller social network size $(r=-.30, p<.01)$, higher frequency of negative social exchanges $(r=.27, p<.05)$, lower levels of perceived social support $(\mathrm{r}=.38, \mathrm{p}<.01)$, and lower levels of social functioning $(\mathrm{r}=.24, \mathrm{p}<.05)$. Neither ToM nor any of the awareness measures were significantly associated with depressive symptoms in primary participants with correlational analyses. However, the difference between the impaired and non-impaired participants on the EYES test approached significance with regard to depressive symptoms $(\mathrm{t}(76)=-1.89, \mathrm{p}=0.06)$, with the impaired group reporting fewer depressive symptoms $(\mathrm{M}=0.66,95 \% \mathrm{CI}$ $[0,1.79])$ compared to the non-impaired group $(\mathrm{M}=1.64,95 \% \mathrm{CI}[1.26,2.08])$. Associations between Primary Variables and Cognition

Tables 17-19 display bivariate correlations between the primary variables, visual acuity, and cognitive variables. As shown in Table 17, all of the cognitive measures were significantly associated with one another. Regarding the ToM measures, the EYES test was significantly associated with visual acuity $(r=.27, p<.05)$ and all measures of cognition, with the exception of the FAB. Essentially, better performance across cognitive measures was predictive of better performance on EYES. The Faux Pas Test was not significantly associated with any of the cognitive measures or with visual acuity. $T$ tests comparing cognitive functioning between the impaired and non-impaired groups on the ToM measures found similar results with regard to EYES, but also indicated that the impaired groups on both EYES and FP REJECTIONS obtained lower scores on the FAB (see Table 20). Additionally, the impaired group on the FP Composite score had a significantly lower verbal IQ than the non-impaired group (see Table 20). 
Regarding the social relations variables (see Table 18), larger social network size was significantly associated with better global cognitive functioning $(\mathrm{r}=.28, \mathrm{p}<.05)$, better memory $(\mathrm{r}=-.33, \mathrm{p}<.01)$, and better working memory $(\mathrm{r}=.28, \mathrm{p}<.05)$. Greater perceived social support was significantly associated with better global cognition $(\mathrm{r}=$ $.24, \mathrm{p}<.05$ ), and better social functioning was significantly associated with better memory $(r=-.27, p<.05)$.

For the awareness variables (results displayed in Table 19), neither informantbased memory awareness nor social functioning awareness were significantly associated with any of the cognitive variables included in the study. Overprediction as measured by the HVLT-R prediction awareness score was associated with poorer global cognitive functioning $(\mathrm{r}=-.23, \mathrm{p}<.05)$, poorer memory $\mathrm{r}=.55, \mathrm{p}<.01)$, and poorer frontal lobe functioning $(\mathrm{r}=.31, \mathrm{p}<.01)$. None of the other performance-based measures of awareness were significantly associated with other cognitive variables.

\section{Hypothesis 1:}

Hypothesis 1 stated that ToM ability would predict social relations, and the hypothesis was tested with bivariate correlations, $t$ tests, and path analysis. As can be seen in Table 21, bivariate correlations did not support a significant relationship between ToM and any of the social relations variables. $T$ tests comparing impaired versus nonimpaired performance on ToM measures also did not indicate that ToM is related to social relations. Because ethnicity was associated with FP Composite performance and there were few minority participants who participated in the study, the correlational analyses were repeated excluding all ethnicities except for non-Hispanic White participants. The analyses including only the non-Hispanic White participants remained non-significant. 
The model depicting the relationship between ToM and social relations that is shown in Figure 1 was tested using path analysis with all participant data. As suggested by the correlational analyses and depicted in Figure 3, ToM ability did not predict social relations as there were no direct effects for either of the ToM variables on any of the social relations variables. The model was a poor fit for the data $\left(\chi^{2}(6)=26.33, p<.001\right.$; $\left.\chi^{2} / \mathrm{df}=4.39 ; \mathrm{CFI}=0 ; \mathrm{NFI}=.17, \mathrm{IFI}=.21, \mathrm{TLI}=-2.06, \mathrm{RMSEA}=0.21\right)$. More than $90 \%$ of the variance in each of the social relations variables was unexplained by the model.

\section{Hypothesis 2:}

Hypothesis 2 stated that ToM ability would predict problems with awareness of cognitive and social abilities. The hypothesis was tested with bivariate correlations, $t$ tests, and path analysis. As can be seen in Table 22, the sole significant correlation between ToM and awareness was found between the FP Composite score and the MARSMFS awareness score $(r=-.25, \mathrm{p}<.05)$. However, this relationship was not in the predicted direction, as better FP Composite scores were associated with overestimation of memory function (i.e. less awareness).

Because ethnicity differentiated Faux Pas performance and the HVLT-R-based awareness measures and because minority participation was low in the study, the correlational analyses were repeated excluding all ethnicities except for non-Hispanic White participants $(n=72)$. The results were similar, except that the FP Composite score was no longer significantly associated with memory awareness as measured by the MARS-MFS $(\mathrm{r}=-.21, \mathrm{p}=.09, \mathrm{n}=71)$, and the FP Composite Score was significantly associated with working memory awareness (LN-Seq Postdiction Awareness; $r=-.25, p$ $=.03, \mathrm{n}=70$ ). Similar to memory awareness, this correlation was in the opposite 
direction, with better FP Composite scores associated with overestimation of working memory performance on the Letter-Number Sequencing subtest.

$T$ tests were also used to test whether impairment on ToM measures significantly impacted scores for awareness. The results, which are displayed in Table 23 , found significant differences in memory awareness, as measured by the MARS-MFS, between the impaired and non-impaired groups on the FP Composite score and FP REJECTIONS. An examination of the means for both measures of impairment indicates that while the impaired groups did not overestimate their memory function as hypothesized, their estimations were far less accurate than the non-impaired groups. In other words, the impaired group significantly underestimated their memory functioning compared to the non-impaired group, which demonstrated more accuracy in the estimations. Differences between the impaired and non-impaired groups on EYES also approached significance with regard to prediction of social awareness (prSFS), and the means for the discrepancy scores for each group also suggest a tendency toward underprediction in the impaired group. While the performance-based measures of awareness did not demonstrate significant differences according to the presence of impairment, two relationships approached significance. Differences between the impaired and non-impaired groups on FP REJECTIONS approached significance with regard to memory awareness on the HVLT-R Postdiction Awareness measure. Examination of the means indicated that the differences were in the hypothesized direction, with the impaired group overestimating their performance and the non-impaired group providing more accurate estimates of performance, on average. Differences between the impaired and non-impaired groups on EYES also approached significance for the LN-Seq Prediction Awareness measure. However, the means for the impaired and non-impaired groups, while approaching a 
significant difference, indicated that both groups underestimated performance on average, with the non-impaired group less accurate than the impaired group on average.

The model depicting the relationship between ToM and awareness that is shown in Figure 2 was tested using path analysis with all ethnicities included. As suggested by the correlational analyses and depicted in Figure 4, ToM ability only predicted MARSMFS awareness scores. The model was a poor fit for the data $\left(\chi^{2}(15)=73.14, \mathrm{p}<.001\right.$; $\chi^{2} / \mathrm{df}=4.88 ; \mathrm{GFI}=.81, \mathrm{CFI}=.07 ; \mathrm{NFI}=.19, \mathrm{IFI}=.23, \mathrm{TLI}=-.74, \mathrm{RMSEA}=0.23$ ). While the model explained $7.9 \%$ of the variance in MARS-MFS scores, the model failed to account for at least $95 \%$ of the variance in the each of the other awareness variables. 


\section{DISCUSSION}

The current study aimed to establish empirical links between ToM and two conceptually-related constructs, social relations and awareness, in a sample of community dwelling older adults. Despite the use of empirically validated measures for the three primary constructs, the hypotheses were generally not supported by the data. Neither ToM measure predicted the social relations variables using correlational analysis, and impairment on ToM tests did not significantly impact social relations scores. The results suggested potential links between awareness and ToM, but the findings were mixed, with one hypothesized association that only approached significance and other significant associations in the opposite direction of the original hypothesis. Possible explanations for the results are discussed in the sections below, along with the implications of the study findings. First, issues related to ToM that span both hypotheses are discussed, followed by the implications of the findings related to each main hypothesis. For reference purposes, Table 24 provides an overview of basic associations between all the ToM indices and most study variables.

What is the meaning and clinical relevance of impairment on ToM tests in communitydwelling older adults?

Both of the measures of ToM that were used in the current study are theorized to measure advanced ToM abilities, and scores on these measures may reflect subtle differences in ToM across healthy older adults. Prior studies with patients with fvFTD 
and healthy controls have found significant differences between the groups on all ToM indices (EYES, FP REJECTIONS, FP HITS, and FP Composite) used in the current study (Gregory et al., 2002; Torralva et al., 2007). EYES and the Faux Pas Test were not significantly associated with one another in the current study. The lack of association between the two ToM measures is consistent with the findings of Gregory et al. (2002), but inconsistent with the findings of Torralva et al. (2007). Notably, both studies compared ToM performance in healthy controls and patients with fvFTD, and the Gregory et al. study included patients with $\mathrm{AD}$ as well. In the Gregory et al. study, the Faux Pas Test correlated with other ToM tests, but the EYES test did not. Although both tests are considered measures of ToM, the EYES test has been related to socioperceptual ability, while the Faux Pas test supposedly measures integration of cognitive and emotional information within a social context (Tager-Flusberg et al., 2000; Stone et al., 1998; Shamay-Tsoory et al., 2007). In sum, because EYES and the Faux Pas Test are thought to measure slightly different aspects of advanced ToM, they may not always correlate.

Comparisons of mean FP Composite scores and EYES scores with previous samples of community-dwelling older adults suggest that the current sample performed similarly with regard to EYES, FP HITS, and FP REJECTIONS. However, the mean FP Composite score for the current study was one standard deviation lower than the mean of one of the comparison studies (Gregory et al., 2002). Notably, the comparison study by Gregory et al. (2002) used a much smaller sample $(n=10)$ that was also ten years younger on average than the current sample (Table 8). On the other hand, the current sample had higher levels of education than the healthy controls in the Gregory et al. study (mean = 12.1 years, $\mathrm{SD}=1.5$ years), but greater ToM impairment was found in the current sample 
than in the healthy controls in the Gregory et al. study. While age may explain the lower scores on the FP Composite measure, the current study's findings may also indicate the presence of subtle ToM deficits in community-dwelling older adults.

This is the first study to examine the presence of ToM impairment (defined as performance 1.5 standard deviations below the mean) in community-dwelling older adults. Notably, the two clinical studies of older adults that utilized both EYES and the Faux Pas Test compared patients with fvFTD to "healthy controls" who were matched for age and education. Only one of these studies compared impaired vs. non-impaired performance on the ToM measures (Gregory et al., 2002), and that study found no impairment in the control group on either ToM test, which may be related to the stringent screening of control participants for clinical studies in order to categorize them as "healthy." In community-dwelling samples, researchers have shown that older adults tend to perform worse on EYES compared to younger adults, but the findings comparing older adults and younger adults on the Faux Pas Test have been mixed (see Table 1).

The current study adds to the literature with the finding of impairment on ToM tests in community-dwelling older adults without a formal diagnosis of dementia and with relatively normal cognitive performance. Some level of impairment on ToM was expected across the sample based on the likelihood that some participants would have experienced changes in brain regions (e.g. medial and ventromedial areas of prefrontal cortex) that are thought to underlie ToM ability (Raz \& Rodrigue, 2006; Gregory et al, 2002; Gallagher et al., 2000; Rowe et al., 2001; Baird et al., 2006; Saxe \& Powell, 2006; Stuss et al., 2001). Consistent with these expectations, impairment on ToM measures was found across participants, with $10 \%-30 \%$ of the sample demonstrating impairment on each of the following ToM indices: EYES, FP REJECTIONS, and the FP Composite 
score, which includes questions related to faux pas understanding. Impairment was defined by Gregory et al. (2002) as performance 1.5 standard deviations below the mean of their healthy controls. It is possible that the rates of impairment on ToM in the current study would have been significantly lower if the more typical cut-off for impairment - 2 standard deviations below the mean of the normative sample - was used. Though age effects were not found within the current sample, it is important to note that the standard of impairment used for the FP Composite score was derived from healthy controls participating in a clinical study and they were approximately 10 years younger on average than the primary participants in the current study. These findings suggest that research to establish age-based normative data may be useful in delineating impairment on ToM tests in older adults.

Participants meeting criteria for impairment varied across the ToM indices, with only $12.8 \%$ of the sample demonstrating impairment on more than one ToM index. Varying patterns of impairment may be related to true differences in the aspect of ToM being measured by each index or may be explained by differences in general cognitive processes needed to carry out each ToM task. FP HITS demonstrated the least impairment, with only 2 participants scoring in the impaired range. Importantly, a study comparing adult patients with Asperger's Syndrome (AS) to healthy controls on the Faux Pas Test found no differences in FP HITS between the groups, but significant differences in FP REJECTIONS, with the AS group more likely to incorrectly identify a faux pas as occurring in a story without a faux pas (Zalla et al., 2009). FP REJECTIONS may strongly indicate ToM-specific impairment, as patients with AS have been noted to have ToM-specific impairment in the absence of other general cognitive impairment (BaronCohen, 2001). At the same time, however, the impaired group on FP REJECTIONS in 
the current study also had significantly lower FAB performance, indicating that frontal lobe dysfunction may at least partially account for the poorer scores on FP REJECTIONS. Certainly, more research is needed to clarify whether differences in general cognitive processes contribute to performance on each index.

The FP Composite scores demonstrated very high levels of impairment, with $30 \%$ of the sample falling in the impaired range. The means for the FP Composite score also appeared much lower for the current sample compared to those of the healthy controls in Gregory et al. (2002). The high rates of impairment were most likely related to high rates of incorrect responses to the explanation/attribution question (e.g., "Why did he/she say it?"). Relatively high rates of correct responses were found for FP HITS, FP REJECTIONS, and identification of the faux pas, but only $48.4 \%$ of responses across the sample were correct for the explanation/attribution question.

Although an analysis of the explanation/attribution question was not carried out in the current study, the literature suggests that non-clinical samples may exhibit some difficulty with this question. For example, one study that found differences on the Faux Pas Test between older adults and younger adults noted that the older adults demonstrated particularly poor performance on the questions related to faux pas understanding (Wang et al., 2006). Zalla et al. (2009) carried out a detailed study of the responses to the explanation/attribution question with adult patients with AS and healthy controls. While only $39.3 \%$ of the explanation/attribution questions were answered correctly by the AS group, the control group (mean age $=27.8$ years, $\mathrm{SD}=4.5$ years) answered $78.7 \%$ of the explanation/attribution questions correctly. The authors' analysis of the errors on this question found that both the AS group and the control group erroneously attributed the faux pas to a character's psychological traits $(15.9 \%$ and $10 \%$, 
respectively), but significant differences between error categories were found between the AS group and the control group in attribution of faux pas to internal psychological states (emotions, sensations, etc.; $15.9 \%$ and 6.7\%, respectively) and to malicious intentions $(9.8 \%$ and $0.7 \%$, respectively).

Because the attribution/explanation question appeared to severely impact the rates of impairment on the FP Composite score in the non-clinical sample used in the current study, more research is needed to better understand the utility of this question, the types of errors committed by community-dwelling older adults, and whether these errors are related to ToM-specific deficits or can be attributed to variability in other cognitive processes. With regard to the latter, one study found that older adults were more likely than middle-aged adults to make the fundamental attribution error (i.e. correspondence bias), which is when internal, stable causes are used to explain another individual's behavior and logical, situational factors are largely ignored (Follett \& Hess, 2002). In that study, middle-aged adults also made the fundamental attribution error (though at lower rates than older adults), indicating that it is a relatively normal error throughout adulthood. Complexity in cognitive operations was found to account for some of the variance in the fundamental attribution error in both the middle-aged adult and older adult groups, suggesting a role for general cognitive processes that could also account for some of the variability on the explanation/attribution question in the current study. In a conceptual paper, Andrews (2001) discussed the fundamental attribution error and ToM research, suggesting that attribution processes rely on ToM abilities. What is unclear from the current study is whether the poor performance of the current sample on the explanation/ attribution question represents normal or abnormal functioning, whether it can be attributed to general cognitive processes, and whether it indicates subtle, but 
meaningful differences in ToM. With these issues in mind, the results of the study in relation to the two main hypotheses will be discussed.

ToM Does Not Predict Social Relations in Community-Dwelling Older Adults

ToM was not significantly associated with social relations in the current study.

As a group, the sample appeared to be socially active with good interpersonal relationships, reporting high levels of function across the social relations measures, as shown in Table 9. The sample reported having larger social networks than past samples using the Convoy measure (Antonucci \& Akiyama, 1987; Antonucci et al., 2002). For example, a study published in 2002 (Antonucci et al.) found that the average network size for U.S. males was 6.82 individuals $(\mathrm{SD}=2.95)$ and for U.S. females was 7.07 individuals $(\mathrm{SD}=2.92)$, while the current sample had an average network size above 20 (see Table 9). Informants' reports of participants' social functioning on the prSFS also indicated good social functioning, but were more consistent with another sample of community-dwelling older adults with which the measure was used in the past (Henry et al., 2009). The relatively high overall social functioning and low variability in social relations observed in the current sample may have limited the results linking ToM with social functioning.

The social relations construct was well-represented in the current study, as the measures used were based on both informant report and self-report. Though the measures represented different facets of social relations, the three self-report measures demonstrated associations with one another, but not with the informant-based measure. Although it is important to consider that individuals with deficits on ToM may not accurately report their social functioning (Eslinger et al., 2005), ToM was also not associated with informant report, and the current study found that primary participants 
had relatively good awareness. However, the lack of association between the informantbased social functioning measure and the self-report social measures along with the finding that the informants' reports of participants' memory functioning did not relate to participants' actual memory scores on cognitive testing, suggests questionable accuracy with regard to informants' ratings of participants' memory and possibly social functioning. Thus, some of the social relations measures used in the current study may be more valid than others.

ToM is considered a social-cognitive construct; such constructs refer to cognitive processes that allow human beings to understand their social world and interact effectively with others (Washburn et al., 2003). Empirical support for the link between ToM and social relations comes from the finding that ToM impairment is highly prevalent in clinical samples with prominent social deficits but relatively intact performance on traditional cognitive tests (Gregory et al., 2002; Baron-Cohen et al., 1999). While evidence directly linking measures of social relations to ToM is limited, a few studies have found a significant relationship between the two constructs in clinical samples (Frith et al., 1994; Brune et al., 2007, Bora et al., 2006), in samples of normally developing children (Eggum et al., 2011, Watson et al., 1999, \& Astington \& Jenkins, 1995), and in a sample of older nursing home residents (Washburn et al., 2003). Thus, research increasingly suggests a valid role for ToM in predicting social relationships and behavior in some groups.

The current study did not find a significant association between ToM and multiple measures of social relations in community-dwelling older adults, which is consistent with Bailey et al., 2008, who also did not find a direct connection between ToM (EYES) and social functioning in community-dwelling older adults. Even the use of cut-scores to 
indicate ToM impairment did not significantly differentiate older adults with regard to social network size, perceived social support, negative social exchanges, and social functioning. Furthermore, although the sample size was not large, the correlations between ToM and social relations variables were so small that the likelihood of Type II error appears low. Thus, the current study is consistent with extant research suggesting that existing ToM measures, which presumably should demonstrate an association with social relations given their purported measurement of a social-cognitive construct, may have limited validity and usefulness for predicting social functioning in communitydwelling older adults.

Cross-sectional associations between ToM and social relations may be more discernible in clinical samples which demonstrate ToM-specific deficits. The common factor across clinical studies that link ToM and social relations is evidence of different underlying brain function compared to the average adult. For example, an fMRI study of ToM found that high functioning patients with AS recruited different brain areas compared to healthy controls when completing ToM tasks (Baron-Cohen et al., 1999). Presumably, the brain areas impacted during child development and in clinical samples include areas that are required for ToM-specific ability, such as the amygala and the medial and orbital areas of the prefrontal cortex (Stuss et al., 2001; Baron-Cohen et al., 1999). While the average older adult may perform more poorly on some ToM tests compared to younger adults, the poor or impaired performance of some older adults may be attributable to declines in general cognitive processes rather than a ToM-specific deficit associated with damage to underlying brain areas necessary for ToM. Thus, community-dwelling older adults may lack the ToM-specific deficits that appear to impact social relationships in clinical samples. As a result, community-dwelling older 
adults' poor performances on ToM tests may not predict problems in social functioning. Future research should continue to focus on establishing links between ToM and social relations in clinical samples of older adults that appear to have ToM-specific impairment.

It is also possible that ToM ability may actually decline in normally aging individuals, but in a less-pronounced manner than in clinical samples. At the same time, social ability could be bolstered to some extent by intact general cognitive processes. For example, AS patients have succeeded in identifying faux pas by applying well-learned social rules, even though they ultimately exhibit more difficulty with attribution and empathy compared to age-matched controls (Zalla et al., 2009). In the current study, ToM impairment may be marking subtle declines in brain processes and associated social functioning that are too subtle to be detected by these measures of social relations. Thus, alternative methods of measuring the nuances of social behavior, such as observational techniques, may be more likely to expose any subtle differences in social interactions detected by the ToM measures. Moreover, longitudinal studies of how ToM changes over time and whether it predicts future impairment in social relations could help clarify the validity of ToM tests for predicting social functioning in community-dwelling samples of older adults.

A final conclusion that may be drawn from the social relations analyses in the current study is that variability in social relations in most community-dwelling older adults may be better explained by factors other than ToM ability. For example, in the current study, social relations variables were associated with measures of health, depression, global cognitive functioning, memory, and working memory, and these findings are consistent with findings from other studies (Barnes et al., 2004a; Antonucci et al., 1997; Russell et al., 1991; Seeman \& Chen, 2002). Any future studies of ToM 
and social relations in either clinical samples or community-dwelling older adults will need to consider the role that these factors may play.

\section{Associations Between ToM and Awareness Were Mixed}

Awareness of ability level is important throughout the lifespan in order for an individual to judge whether participation in activities is likely to be successful and safe. Although clinical samples of older adults with dementing disorders may demonstrate significant lack of awareness of their deficits, non-clinical samples have also been noted to demonstrate problems with awareness (Neary et al., 1998; Auchus et al., 1994; Graham et al, 2005). Despite numerous studies, the clinical correlates of unawareness are not well-defined (see reviews, Aalten et al., 2005; Clare, 2004a). ToM and awareness emerge at the same time during childhood and have been linked in patients with schizophrenia (Gopnik \& Meltzoff, 1994; Happe, 2003; Bora et al., 2007; Langdon \& Ward, 2009). Empirical associations have not yet been established between Tom and awareness in other clinical samples with notable deficits in both domains (e.g. patients with fvFTD), though such links are strongly suggested by extant literature (Gregory et al., 2002; Neary et al., 1998). ToM and awareness are also thought to share overlapping neural substrates (Saxe et al., 2006; Vogeley et al., 2001), which suggests that damage to brain areas that impact ToM performance may also impact awareness, even in community-dwelling older adults without dementia.

The results from the current study indicated that the primary participants demonstrated very good awareness on average (Table 11). Significant associations were found between primary participant ratings of memory and working memory function and actual performance on cognitive testing. Thus, evidence for impaired awareness was lacking in the current sample. Importantly, the excellent accuracy of the primary 
participants in the current study differentiates them from clinical samples that demonstrate overall poor awareness and greater variability on awareness measures (Eslinger et al, 2005; Williamson, 2010). Although ToM impairment was noted in the current study, the lack of impairment in awareness may have limited the results.

Similar to the discussion of social relations and ToM, clinical samples with noted deficits in both ToM and awareness may be the most likely populations to establish links between ToM and awareness. There are three main reasons why community-dwelling older adults may demonstrate ToM impairment without accompanying awareness deficits. First, ToM-specific deficits may be present, but ToM may not actually be required for awareness. Second, ToM may be required for awareness, but poor performance on ToM tests may reflect poor general cognitive functioning rather than specific deficits in ToM in community-dwelling older adults. Third, ToM tests may be detecting an underlying neurological process that has not yet impacted awareness, but will impact awareness in the future as the underlying changes progress. Continued research into the correlates of awareness as well as longitudinal study of ToM tests and awareness in community-dwelling older adults will help to clarify the relationship between these two constructs.

The current study hypothesized that individuals performing more poorly on ToM tests would be more likely to overestimate their cognitive and social abilities, but very limited support was found for the hypothesis. The extant literature suggests that overestimation of abilities is more common in older adult clinical samples that demonstrate ToM-specific deficits and also may be more clinically relevant with regard to safety and caregiver distress (Banks \& Weintraub, 2008; Souchay et al., 2003; Rankin et al., 2005, Rymer et al., 2002). In the current study, ToM impairment (FP 
REJECTIONS) approached significance $(\mathrm{p}=.052)$ with regard to its ability to predict online-monitoring of memory performance (HVLT-R Postdiction Awareness), with the impaired group overestimating their performance compared to the non-impaired group.

Postdiction measures of awareness are thought to tap online monitoring ability. The fact that a postdiction measure of awareness came closest to demonstrating the hypothesized relationship between ToM and awareness in the current study is important in the context of mounting evidence that postdiction measures have been found to demonstrate the greatest utility in capturing the gross awareness deficits exhibited by patients with fvFTD (Eslinger et al., 2005; O'Keeffe et al., 2007). O'Keeffe and associates (2007) found that patients with FTD demonstrated significantly less adjustment in their ratings following performance compared to other clinical older adult groups (corticobasal degeneration, progressive supranuclear palsy), though all groups demonstrated unawareness on some measures compared to controls. Additionally, while patients with $\mathrm{AD}$ may demonstrate unawareness, they appear to adjust their postdiction ratings according to their actual performance (Stewart et al., 2010). For example, one study found that participants with $\mathrm{AD}$ overestimated their performance on a cognitive task before the task and 1 hour after the task, but were able to provide accurate estimates immediately after the task, consistent with intact online monitoring (Stewart et al., 2010). Evidence that patients with fvFTD may demonstrate greater difficulties with online monitoring compared to other clinically impaired older adults groups combined with the current findings (i.e., association between online monitoring of memory awareness and ToM) suggests that future research should focus on possible associations between ToM and online monitoring measures of awareness. 
Although poorer ToM performance was expected to predict overestimation, the results of the current study surprisingly indicated that ToM also predicted underestimation. Two significant associations were found that suggested that poorer ToM ability was associated with underestimation of memory and working memory. This finding is based on two different types of awareness measurement: an informant-based measure of awareness (MARS-MFS Awareness) and a performance-based measure of awareness (LN-Seq Postdiction Awareness).

While extant studies have not suggested that lower levels of ToM ability should be associated with underestimation, healthy controls have been found to underestimate their positive qualities (Rankin, 2005). Other studies have found that cognitive complaints or underestimation of performance were related to mood and general mental health factors (Okonkwo et al., 2008; Cargin et al., 2008), though no evidence was found for this in the current sample, which may be related to the relatively low rates of depressive symptoms.

One problem in drawing the conclusion that ToM may predict underestimation in older adults is that much of the evidence relies on informant-based ratings of awareness, which may have dubious accuracy. In the current study, the informants' ratings of primary participants' memory abilities were not significantly correlated with primary participants' actual performance on cognitive testing, but the primary participants' selfratings of memory were significantly correlated with actual memory performance. This suggests that the primary participants may have provided more accurate estimates than the informants on the MARS-MFS awareness measure. This would imply that the negative discrepancy scores that were obtained between informants' ratings and primary 
participants' ratings were produced by informants' overestimating primary participants' memory ability.

Problems with the accuracy of informant reports have been noted across the awareness literature (see review, Clare, 2004; Okwonko et al., 2008). For example, in a study of financial capacity comparing patients with Mild Cognitive Impairment (MCI) and healthy controls, $31.9 \%$ of the MCI patients' informants overestimated the patients' ability (Okwonko et al., 2008). Research has suggested that accuracy of informant ratings may depend on whether the informant resides with the primary participant, the type of relationship between the informant and primary participant, the informant's cognitive ability, and how disturbed the informant is by primary participant behavior (Clare, 2004; Ready, 2004). In the current study, primary participants and informants knew one another for a long time and saw one another frequently, but only $27.3 \%$ of the primary participants and informants lived together. Thus, it is possible that poor informant accuracy in the current study may be related to inadequate proximity or frequency of contact with informants and that very close proximity is necessary for accurate informant ratings in community-dwelling older adults. The need for proximity may be more important with community-dwelling older adults compared to clinical samples because community-dwelling older adults are typically not impaired and any cognitive difficulties that they exhibit on testing or in their daily lives may be more subtle and related to other factors (i.e. illness, fatigue, depression, etc.). Future studies of awareness may demonstrate better accuracy in informant ratings by limiting who can serve in the informant role and by including factors such as informant cognitive functioning and disturbance measures into study designs. Additionally, more research 
regarding what factors contribute to informant accuracy would likely help both clinicians and researchers.

The findings regarding underestimation and ToM also appeared to be influenced by ethnicity, as the association between memory awareness (MARS-MFS Awareness) and the FP Composite score was no longer significant when African-American and Hispanic participants were removed from the analysis. While the loss of statistical significance may be attributable to a loss of power resulting from the decreased sample size, the role of ethnicity is highlighted by the finding that the association of underestimation of working memory and poorer ToM performance was only significant when the African-American and Hispanic participants were removed from the analysis. As ethnicity was only associated with the FP Composite and was not associated with either of the awareness variables, it is likely that the changes in the significant associations may be related to variability in the Faux Pas Test that is associated with ethnicity, which will be discussed further below.

\section{Clinical Application of ToM Tests}

In general, more normative data is needed if ToM tests are to be used for clinical purposes. The finding of impairment on the ToM measures in this community sample is particularly relevant in that both of the ToM measures included in the current study have been recommended as part of a larger neuropsychological testing battery for detecting executive and social deficits in early frontotemporal dementia (Torralva et al., 2009). The clinical research essentially suggests that healthy patients will perform at ceiling or at least consistently above impairment levels on ToM measures, but this was not the case in this relatively high functioning community sample of older adults. 
As noted above, the lack of strong support for the hypotheses regarding ToM, awareness, and social functioning may be related to a lack of ToM-specific impairment in community-dwelling older adults or confounds introduced by variability in general cognitive processes. An absence of ToM-specific impairment in community-dwelling older adults may suggest that ToM as a construct has limited validity and usefulness for predicting social functioning and awareness in this population. As noted in the introduction to this paper, the phenomenon of poorer ToM performance in communitydwelling older adults compared to younger adults has been attributed by some authors to problems with general cognitive processes, such as memory and executive functioning, rather than a specific deficit in ToM (McKinnon \& Moscovich, 2007; German \& Hehman, 2006). The current study provides mixed support regarding the role of general cognitive processes with ToM, as the EYES test was highly correlated with cognitive measures but the Faux Pas Test was not. However, when impairment across the Faux Pas indices was considered, the impaired group demonstrated significantly lower levels of frontal lobe functioning and estimates of verbal IQ, suggesting that these factors likely contributed to impaired scores in some participants. The results suggest that general cognitive processes were likely involved in impairment on both ToM measures in the current study. Thus, future research is needed to ascertain the contribution of general cognitive processes in older adult ToM performance on advanced ToM measures and to guide improvements to ToM tests in order to increase specificity for ToM impairment.

A final issue that relates to using ToM measures in clinical work with older adults regards the association between ethnicity and the Faux Pas Test. AfricanAmericans in the current sample were overrepresented in the impairment category on the 
Faux Pas Composite score, with $80 \%$ of African-Americans performing in the impaired range compared to $27.7 \%$ of Non-Hispanic Whites performing in the impaired range. This may be because Faux Pas performance was associated with the lower ratings of health, slightly lower verbal IQ scores (approached significance), or lower levels of education (approached significance) in the African-American group compared to the nonHispanic White group. Although there is very little literature about African-American performance on ToM tests, one study of low-income preschoolers found that European children outperformed African-American children on ToM tests (Curenton, 2004). This may reflect cultural differences, as what is considered a faux pas may vary across cultures, and explanations of faux pas may vary according to ethnic groups' sociocultural histories. This may reflect a bias in ToM tests toward European cultural norms. Studies with the Faux Pas Test in older adults have generally either not included AfricanAmericans or have not reported the ethnicities of their participants (MacPherson et al., 2002; Stone et al., 1998; Gregory et al., 2002; Torralva et al., 2007; Torralva et al., 2009). In recognition of the importance of providing participants with culturally appropriate stimuli, Wang et al. (2006) modified the stories in the Faux Pas Test for use with Chinese participants.

\section{Limitations and Future Directions}

Several limitations and future directions for research have already been discussed, but there are others that must be noted. First, the sample was healthy, relatively financially well-off, and more educated than the general population (United States Census Bureau, 2011). These factors were relevant for several reasons. Lower vascular risk predicts lower rates of small vessel brain disease and other damage to neural circuitry (Knopman et al., 2011), higher levels of education are believed to increase cognitive 
reserve (see review, Stern, 2002), and greater income may increase access to resources associated with better health (Ettner, 1996). Essentially, factors such as health, income, and education, which may impact underlying neural integrity, may have resulted in the current sample having better cognitive and social functioning compared to the majority of their same-age peers. Thus, the sample characteristics in the current study may impact the generalizability of the results. As discussed above, however, the finding of impaired performance on ToM measures is particularly relevant within the context of the sample's good health and general cognitive functioning.

Although an effort was made to recruit a representative sample, lower income participants were less likely to participate. This may be related to general difficulties in recruiting some groups to participate in research, but also may have been related to the combination of the volunteer-basis of study participation, the need for an informant, and the relatively significant time commitment for participation. In the current study, the latter two issues were necessary in order to answer study questions, but future studies would likely benefit by paying participants for their time.

The method that was used to compute awareness on the performance-based measures (HVLT-R and LN-Seq Prediction \& Postdiction awareness measures) was similar to the method used in an existing study (Graham et al., 2005), but collapsing the actual scores into broad ranges based on standard deviations may have contributed to a loss of critical variability in the awareness scores. In a methodological improvement in the awareness literature, Williamson et al. (2010) provided brief education on normative distributions and percentiles to three groups: participants with frontotemporal dementia, participants with AD, and healthy controls. A graphic depiction of the normal curve, which depicted human figures, was presented to participants to use in providing estimates 
of their functioning in different domains. Participants' estimates were then easily converted into percentile scores, and the difference between the actual performance percentile and the estimated percentile could be calculated. Notably, the percentile estimates were highly correlated with a verbal rating scale (poor, fair, good, etc.) similar to the scale used in the current study, which suggested that the percentile method was just as good as the verbal rating scales with regard to reliability of estimates. While more research is needed to further validate the percentile-estimate method, it appears promising, as it may increase the precision of awareness measurement without the dampening of variability that occurs when actual performance scores are collapsed into ranges.

As noted above, awareness and ToM present measurement challenges, and there are other measures of these constructs available to researchers. Although the selected measures for the current study were chosen based on the strength of their empirical support, it is possible that other measures of these constructs would demonstrate the hypothesized results because other measures of these constructs may tap more relevant aspects or may have better clinical utility in older adults. Thus, future studies of ToM and awareness may wish to incorporate alternative measures of the constructs.

Both Type I and Type II error must be considered with regard to interpreting results from the current study. With regard to Type I error, analyses in the current study involved multiple comparisons, but maintained an alpha level at .05. The choice to maintain alpha at .05 was based on the need to balance factors associated with Type I and Type II error, as well as a consideration of the relative novelty of the research. However, because of the high number of comparisons in the current study, there is a possibility that some of the significant associations were products of Type I error. Thus, replication of 
the results will be important for establishing the reliability of the findings. Consideration of Type II error is particularly germane to the analyses of ToM and awareness, as the current study may have lacked power to detect differences as a result of the modest sample size. The suggested sample size based on power analyses combined with the finding of borderline significant correlations between ToM and awareness indicate that the study sample was likely too small to detect moderate effects. Slightly larger sample sizes may be necessary to detect potential associations between awareness and ToM in future studies.

Although excellent interrater reliability was found on the Faux Pas Test, one possible explanation for the lower scores among the two questions related to faux pas understanding is that the raters were more strict than other researchers in their scoring of these questions. The scoring guidance available in the testing manual and throughout the literature appears slightly mixed and may indicate that researchers have approached Faux Pas Test scoring with varying degrees of adherence to the manual (Stone et al., 1998; Gregory et al., 2002; Zalla et al., 2009, MacPherson et al., 2002; Torralva et al., 2007). Certainly, better standardization with regard to scoring the Faux Pas Test as well as better normative data for both EYES and the Faux Pas Test is required in order to meet clinical standards.

In sum, the current study did not find a significant relationship between ToM and social relations and only found limited support for a relationship between ToM and awareness in community-dwelling older adults. As discussed above, the findings may have been impacted by confounds from general cognitive processes, limitations of the measures, and sample characteristics. Increased specificity of ToM measurement along with the establishment of normative data and standardized scoring criteria for ToM 
measures will likely improve future studies involving ToM. Refinement of awareness measurement, observational measurement of social functioning, replication with larger samples, research in clinical samples, and research into the longitudinal relationship of ToM, awareness, and social functioning may clarify any relationship between the three constructs. 


\section{REFERENCES}

Aalten, P., van Valen, E., Clare, L., Kenny, G., \& Verhey, F. (2005). Awareness in dementia: A review of clinical correlates. Aging \& Mental Health, 9, 414-422.

Andrews, P. W. (2001). The psychology of social chess and the evolution of attribution mechanisms: explaining the fundamental attribution error. Evolution and Human Behavior, 22, 11-29.

Antonucci, T. C. (1986). Hierarchical mapping technique. Generations: Journal of the American Society on Aging, 10, 10-12.

Antonucci, T. C. (2001). Social relations: An examination of social networks, social support, and sense of control. In J.E. Birren \& K.W. Schaie (Eds.), Handbook of the Psychology of Aging (5th ed.). (pp. 427-453). San Diego, CA: Academic Press .

Antonucci, T. C. \& Akiyama, H. (1987). Social networks in adult life and a preliminary examination of the convoy model. Journal of Gerontology, 42, 519-527.

Antonucci, T. C., Akiyama, H., \& Lansford, J. E. (1998). Negative effects of close social relations. Family Relations, 47, 379-384.

Antonucci, T. C., Lansford, J. E., Akiyama, H., Smith, J., Baltes, M. M., Takahashi, K. et al. (2002). Differences between men and women in social relations, resource deficits, and depressive symptomatology during later life in four nations. Journal of Social Issues, 58, 767-783. 
Antonucci, T. C., Fuhrer, R., \& Dartigues, J. F. (1997). Social relations and depressive symptomatology in a sample of community-dwelling French older adults. Psychology and Aging, 12, 189-195.

Astington, J. W. \& Jenkins, J. M. (1995). Theory of mind development and social understanding. Cognition \& Emotion, 9, 151-165.

Auchus, A. P., Goldstein, F. C., Green, J., \& Green, R. C. (1994). Unawareness of cognitive impairments in Alzheimer's disease. Neuropsychiatry, Neuropsychology, \& Behavioral Neurology, 7, 25-29.

Bailey, P. E. \& Henry, J. D. (2008). Growing Less Empathic With Age: Disinhibition of the Self-Perspective. Journals of Gerontology Series B: Psychological Sciences and Social Sciences, 63, 219-226.

Bailey, P. E., Henry, J. D., \& von Hippel, W. (2008). Empathy and social functioning in late adulthood. Aging \& Mental Health, 12, 499-503.

Baird, A., Dewar, B. K., Critchley, H., Dolan, R., Shallice, T., \& Cipolotti, L. (2006). Social and emotional functions in three patients with medial frontal lobe damage including the anterior cingulate cortex. Cognitive Neuropsychiatry, 11, 369-388.

Banks, S. \& Weintraub, S. (2008). Self-awareness and self-monitoring of cognitive and behavioral deficits in behavioral variant frontotemporal dementia, primary progressive aphasia and probable alzheimer's disease. Brain and Cognition, 67, $58-68$.

Barnes, L. L., de Leon, C. F. M., Wilson, R. S., Bienias, J. L., \& Evans, D. A. (2004a). Social resources and cognitive decline in a population of older African Americans and whites. Neurology, 63, 2322-2326. 
Barnes, L. L., De Leon, C. F. M., Bienias, J. L., \& Evans, D. A. (2004b). A Longitudinal Study of Black-White Differences in Social Resources. Journals of Gerontology: Series B: Psychological Sciences and Social Sciences, 59B, S146-S153.

Baron-Cohen, S., Jolliffe, T., Mortimore, C., \& Robertson, M. (1997). Another advanced test of theory of mind: evidence from very high functioning adults with autism or Asperger syndrome. Journal of Child Psychology \& Psychiatry \& Allied Disciplines, $38,813-822$.

Baron-Cohen, S., Wheelwright, S., Hill, J., Raste, Y., \& Plumb, I. (2001). The "Reading the Mind in the Eyes" Test revised version: a study with normal adults, and adults with Asperger syndrome or high-functioning autism. Journal of Child Psychology \& Psychiatry \& Allied Disciplines, 42, 241-251.

Baron-Cohen, S., Leslie, A. M., \& Frith, U. (1985). Does the autistic child have a "theory of mind"? Cognition, 21, 37-46.

Baron-Cohen, S., O'Riordan, M., Stone, V., Jones, R., \& Plaisted, K. (1999). Recognition of faux pas by normally developing children with asperger syndrome or highfunctioning autism. Journal of Autism and Developmental Disorders, 29, 407 418.

Baron-Cohen, S., Ring, H., Wheelwright, S., Bullmore, E., Brammer, M., Simmons, A., \& Williams, S. (1999). Social Intelligence in the normal and autistic brain: an fMRI study. European Journal of Neuroscience, 11, 1891 - 1898.

Bath, P. A. \& Deeg, D. (2005). Social engagement and health outcomes among older people: Introduction to a special section. European Journal of Ageing, 2, 24-30. 
Beland, F., Zunzunegui, M. V., Alvarado, B., Otero, A., \& del Ser, T. (2005).

Trajectories of cognitive decline and social relations. Journals of Gerontology:

Series B: Psychological Sciences and Social Sciences, 60B, 320-330.

Bentler, P. M. (1993). EQS: Structural Equations Program Manual. Los Angeles:

BMDP Statistical Software.

Berkman, L. F. \& Syme, S. L. (1979). Social networks, host resistance, and mortality: a nine-year follow-up study of Alameda County residents. American Journal of Epidemiology, 109, 186-204.

Berkman, L. F., Glass, T., Brissette, I., \& Seeman, T. E. (2000). From social integration to health: Durkheim in the new millennium. Social Science \& Medicine, 51, 843857.

Blair, J. R. \& Spreen, O. (1989). Predicting premorbid IQ: A revision of the National Adult Reading Test. Clinical Neuropsychologist, 3, 129-136.

Bollen, K. A. (1989). Structural Equations with Latent Variables. New York: John Wiley.

Bora, E., Eryavuz, A., Kayahan, B., Sungu, G., \& Veznedaroglu, B. (2006). Social functioning, theory of mind and neurocognition in outpatients with schizophrenia; mental state decoding may be a better predictor of social functioning than mental state reasoning. Psychiatry Research, 145, 95-103.

Bora, E., Sehitoglu, G., Aslier, M., Atabay, I., \& Veznedaroglu, B. (2007). Theory of mind and unawareness of illness in schizophrenia: Is poor insight a mentalizing deficit? European Archives of Psychiatry and Clinical Neuroscience, Vol.257, 104-111. 
Boustani, M., Peterson, B., Hanson, L., Harris, R., \& Lohr, K. N. (2003). Screening for Dementia in Primary Care: A Summary of the Evidence for the U.S. Preventive Services Task Force. Annals of Internal Medicine, 138, 927.

Bozeat, S., Gregory, C. A., Ralph, M. A., \& Hodges, J. R. (2000). Which neuropsychiatric and behavioural features distinguish frontal and temporal variants of frontotemporal dementia from Alzheimer's disease? Journal of Neurology, Neurosurgery \& Psychiatry, 69, 178-186.

Brandt, J., \& Benedict, R.H.B. (2001). Hopkins Verbal Learning Test-Revised. Lutz, FL: Psychological Assessment Resources.

Brink, T. L. (1982). Screening tests for geriatric depression. Clinical Gerontologist, 1 , $37-43$.

Brissette, I., Cohen, S., \& Seeman, T. E. (2000). Measuring social integration and social networks, Social Support Measurement and Intervention: A Guide for Social Scientists. 53-85.

Brune, M. (2005). "Theory of Mind" in Schizophrenia: A Review of the Literature. Schizophrenia Bulletin, 31, 21-42.

Brune, M., bdel-Hamid, M., Lehmkamper, C., \& Sonntag, C. (2007). Mental state attribution, neurocognitive functioning, and psychopathology: What predicts poor social competence in schizophrenia best? Schizophrenia Research, 92, 151-159.

Brune, M. \& Brune-Cohrs, U. (2006). Theory of mind--evolution, ontogeny, brain mechanisms and psychopathology. Neuroscience \& Biobehavioral Reviews, 30 , $437-455$

Caoile, J. D. (2002). Theory of mind, empathy, and insight in alzheimer's disease. Dissertation. 
Cargin, J. W., Collie, A., Masters, C., \& Maruff, P. (2008). The nature of cognitive complaints in healthy older adults with and without objective memory decline. Journal of Clinical and Experimental Neuropsychology, Vol.30, 1-13.

Carstensen, L. L. (1992). Social and emotional patterns in adulthood: Support for socioemotional selectivity theory. Psychology and Aging, 7, 331-338.

Carstensen, L. L., Isaacowitz, D. M., \& Charles, S. T. (1999). Taking time seriously: A theory of socioemotional selectivity. American Psychologist, 54, 165-181.

Charlson, M. E., Pompei, P., Ales, K. L., \& MacKenzie, C. R. (1987). A new method of classifying prognostic comorbidity in longitudinal studies: development and validation. Journal of Chronic Diseases, 40, 373-383.

Clare, L. (2004a). Awareness in early-stage Alzheimer's disease: a review of methods and evidence. British Journal of Clinical Psychology, 43, 2-96.

Clare, L. (2004b). The construction of awareness in early-stage Alzheimer's disease: a review of concepts and models. British Journal of Clinical Psychology, 43, 2-75.

Clare, L., Markova, I., Verhey, F., \& Kenny, G. (2005a). Awareness in dementia: A review of assessment methods and measures. Aging \& Mental Health, 9, 394413.

Clare, L. (2002). Developing awareness about awareness in early-stage dementia: The role of psychosocial factors. Dementia: The International Journal of Social Research and Practice, 1, 295-312.

Clare, L. (2003). Managing threats to self: Awareness in early stage Alzheimer's disease. Social Science \& Medicine, 57, 1017-1029. 
Clare, L., Markova, I., Verhey, F., \& Kenny, G. (2005b). Awareness in dementia: A review of assessment methods and measures. Aging \& Mental Health, 9, 394413.

Clare, L., Wilson, B. A., Carter, G., Roth, I., \& Hodges, J. R. (2002). Assessing awareness in early-stage Alzheimer's disease: Development and piloting of the Memory Awareness Rating Scale. Neuropsychological Rehabilitation, 12, 341362.

Cohen, S., Gottlieb, B. H., \& Underwood, L. G. (2001). Social relationships and health: Challenges for measurement and intervention. Advances in Mind-Body Medicine, 17, 129-141.

Cohen, S., Mermelstein, R., Kamarck, T., \& Hoberman, H. M. (1985). Measuring the functional components of social support. In I.G.Sarason \& B. R. Sarason (Eds.), Social Support: Theory, Research, and Applications (pp. 73-94).

Cosentino, S. \& Stern, Y. (2005). Metacognitive theory and assessment in dementia: Do we recognize our areas of weakness? Journal of the International Neuropsychological Society, 11, 910-919.

Craig, J. S., Hatton, C., Craig, F. B., \& Bentall, R. P. (2004). Persecutory beliefs, attributions and theory of mind: Comparison of patients with paranoid delusions, Asperger's syndrome and healthy controls. Schizophrenia Research, 69, 29-33.

Cuerva, A. G., Sabe, L., Kuzis, G., Tiberti, C., Dorrego, F., \& Starkstein, S. E. (2001). Theory of mind and pragmatic abilities in dementia. Neuropsychiatry, Neuropsychology, \& Behavioral Neurology, 14, 153-158.

Curenton, S. M. (2004). The association between narratives and theory of mind for lowincome preschoolers. Early Education and Development, Vol.15, 121-145. 
DeBettignies, B. H., Mahurin, R. K., \& Pirozzolo, F. J. (1990). Insight for impairment in independent living skills in Alzheimer's disease and multi-infarct dementia. Journal of Clinical and Experimental Neuropsychology, 12, 355-363.

Dubois, B. M., Slachevsky, A. M., Litvan, I. M., \& Pillon, B. P. (2000). The FAB: A frontal assessment battery at bedside. Neurology, 55, 1621-1626.

DuPertuis, L. L., Aldwin, C. M., \& Bosse, R. (2001). Does the source of support matter for different health outcomes? Findings from the Normative Aging Study. . Journal of Aging and Health, 13, 494-510.

Eggum, N. D., Eisenberg, N., Kao, K., Spinrad, T. L., Bolnick, R., Hofer, C. et al. (2011). Emotion understanding, theory of mind, and prosocial orientation: Relations over time in early childhood. The Journal of Positive Psychology, Vol.6, 4-16.

Eslinger, P. J., Dennis, K., Moore, P., Antani, S., Hauck, R., \& Grossman, M. (2005). Metacognitive deficits in frontotemporal dementia. Journal of Neurology, Neurosurgery \& Psychiatry, 76, 1630-1635.

Ettner, S. L. (1996). New evidence on the relationship between income and health. Journal of Health Economics, 15, 67-85.

Evers, K., Kilander, L., \& Lindau, M. (2007). Insight in frontotemporal dementia: Conceptual analysis and empirical evaluation of the consensus criterion 'loss of insight' in frontotemporal dementia. Brain and Cognition, 63, 13-23.

Field, A. (2005). Discovering Statistics Using SPSS ( $2^{\text {nd }}$ ed.). London: Sage Publications Ltd.

Field, D. \& Minkler, M. (1988). Continuity and change in social support between youngold and old-old or very-old age. Journals of Gerontology, 43, 100-106. 
Follett, K. \& Hess, T. M. (2002). Aging, cognitive complexity, and the fundamental attribution error. The Journals of Gerontology: Series B: Psychological Sciences and Social Sciences, Vol.57B, P312-P323.

Frith, C. D. \& Frith, U. (1999). Interacting minds--a biological basis. Science, 286, 16921695.

Frith, U., Happe, F., \& Siddons, F. (1994). Autism and theory of mind in everyday life. Social Development, Vol.3, 108-124.

Gallagher, H. L., Happe, F., Brunswick, N., Fletcher, P. C., Frith, U., \& Frith, C. D. (2000). Reading the mind in cartoons and stories: an fMRI study of 'theory of mind' in verbal and nonverbal tasks. Neuropsychologia, 38, 11-21.

German, T. P. \& Hehman, J. A. (2006). Representational and executive selection resources in 'theory of mind': Evidence from compromised belief-desire reasoning in old age. Cognition, 101, 129-152.

Gopnik, A. \& Meltzoff, A. N. (1994). Minds, bodies, and persons: Young children's understanding of the self and others as reflected in imitation and theory of mind research. 166-186.

Graham, D. P., Kunik, M. E., Doody, R., \& Snow, A. L. (2005). Self-reported awareness of performance in dementia. . Cognitive Brain Research, 25, 144-152.

Green, J., Goldstein, F. C., Sirockman, B. E., \& Green, R. C. (1993). Variable awareness of deficits in Alzheimer's disease. Neuropsychiatry, Neuropsychology, \& Behavioral Neurology, 6, 159-165.

Gregory, C., Lough, S., Stone, V., Erzinclioglu, S., Martin, L., Baron-Cohen, S. et al. (2002). Theory of mind in patients with frontal variant frontotemporal dementia 
and Alzheimer's disease: theoretical and practical implications. Brain, 125, 752764.

Gregory, C. A., Serra-Mestres, J., \& Hodges, J. R. (1999). Early diagnosis of frontal variant of frontotemporal dementia: How sensitive are standard neuroimaging and neuropsychologic tests? Neuropsychiatry, Neuropsychology, \& Behavioral Neurology, 12, 128-135.

Guise, K., Kelly, K., Romanowski, J., Vogeley, K., Platek, S. M., Murray, E. et al. (2007). The anatomical and evolutionary relationship between self-awareness and Theory of mind. Human Nature, 18, 132-142.

Gurung, R. A. R., Taylor, S. E., \& Seeman, T. E. (2003). Accounting for changes in social support among married older adults: Insights from the MacArthur Studies of Successful Aging. Psychology and Aging, 18, 487-496.

Happe, F. (2003). Theory of mind and the self. Annals of the New York Academy of Sciences, 1001, 134-144.

Happe, F. G. E. (1994). An advanced test of theory of mind: Understanding of story characters' thoughts and feelings by able autistic, mentally handicapped, and normal children and adults. Journal of Autism and Developmental Disorders, 24, 129-154.

Happe, F. G. E., Winner, E., \& Brownell, H. (1998). The getting of wisdom: Theory of mind in old age. Developmental Psychology, 34, 358-362.

Hawthorne, G. \& Elliott, P. (2005). Imputing cross-sectional missing data: Comparison of common techniques. Australian and New Zealand Journal of Psychiatry, Vol.39, 583-590. 
Henry, J. D., von Hippel, W., \& Baynes, K. (2009). Social inappropriateness, executive control, and aging. . Psychology and Aging, 24, 239-244.

Herrmann, N., Mittman, N., Silver, I. L., \& Shulman, K. I. (1996). A validation study of the Geriatric Depression Scale short form. International Journal of Geriatric Psychiatry, Vol.11, 457-460.

Holley, C.K. \& Mast, B.T. (2007). The effects of widowhood and vascular risk factors on late-life depression. Am J Geriatr Psychiatry, 15, 1-9.

Hsu, H. C. (2007). Does social participation by the elderly reduce mortality and cognitive impairment? Aging \& Mental Health, 11, 699-707.

Idler, E. L. \& Benyamini, Y. (1997). Self-rated health and mortality: a review of twentyseven community studies. Journal of Health \& Social Behavior, 38, 21-37.

Jurica, P. J., Leitten, C. L., \& Mattis, S. (2001). Dementia Rating Scale-2. Psychological Assessment Resources.

Kahn, R. L. \& Antonucci, T. C. (1980). Convoys over the life course: attachment, roles, and social support. Life-Span Development and Behavior, 3, 254-283.

Kaufman, A. S. \& Lichtenberger, E. O. (2006). Assessing adolescent and adult intelligence (3rd ed.).

Keightley, M. L., Winocur, G., Burianova, H., Hongwanishkul, D., \& Grady, C. L. (2006). Age Effects on Social Cognition: Faces Tell a Different Story. Psychology and Aging, 21, 558-572.

Knopman, D. S. M., Penman, A. D. M., Catellier, D. J. D., Coker, L. H. P., Shibata, D. K. M., Sharrett, A. R. M. et al. (2011). Vascular risk factors and longitudinal changes on brain MRI: The ARIC study. Neurology, 76, 1879-1885. 
Lang, F. R. \& Carstensen, L. L. (1994). Close emotional relationships in late life: Further support for proactive aging in the social domain. . Psychology and Aging, 9, 315324.

Langdon, R., Coltheart, M., Ward, P. B., \& Catts, S. V. (2002). Disturbed communication in schizophrenia: The role of poor pragmatics and poor mind-reading. . Psychological Medicine, 32, 1273-1284.

Langdon, R. \& Ward, P. (2009). Taking the perspective of the other contributes to awareness of illness in schizophrenia. Schizophrenia Bulletin, Vol.35, 1003-1011.

Lezak, M. D., Howieson, D. B., \& Loring, D. W. (2004). Neuropsychological Assessment. (Fourth ed.). New York: Oxford University Press, Inc.

Liu, D., Wellman, H. M., Tardif, T., \& Sabbagh, M. A. (2008). Theory of mind development in Chinese children: A meta-analysis of false-belief understanding across cultures and languages. . Developmental Psychology, 44, 523-531.

Lough, S. \& Hodges, J. R. (2002). Measuring and modifying abnormal social cognition in frontal variant frontotemporal dementia. . Journal of Psychosomatic Research, $53,639-646$.

Lough, S., Kipps, C. M., Treise, C., Watson, P., Blair, J. R., \& Hodges, J. R. (2006). Social reasoning, emotion and empathy in frontotemporal dementia. . Neuropsychologia, 44, 950-958.

MacPherson, S. E., Phillips, L. H., \& Della Sala, S. (2002). Age, executive function and social decision making: A dorsolateral prefrontal theory of cognitive aging. Psychology and Aging, 17, 598-609. 
Mangone, C. A., Hier, D. B., Gorelick, P. B., \& Ganellen, R. J. (1991). Impaired insight in Alzheimer's disease. Journal of Geriatric Psychiatry and Neurology, 4, 189193.

Maylor, E. A., Moulson, J. M., Muncer, A. M., \& Taylor, L. A. (2002). Does performance on theory of mind tasks decline in old age. British Journal of Psychology, 93, 465-485.

McDaniel, K. D., Edland, S. D., \& Heyman, A. (1995). Relationship between level of insight and severity of dementia in Alzheimer disease. Alzheimer Disease \& Associated Disorders, 9, $101-104$.

McKinnon, M. C. \& Moscovitch, M. (2007). Domain-general contributions to social reasoning: Theory of mind and deontic reasoning re-explored. Cognition, 102, 179-218.

Michon, A., Deweer, B., Pillon, B., \& Agid, Y. (1994). Relation of anosognosia to frontal lobe dysfunction in Alzheimer's disease. Journal of Neurology, Neurosurgery \& Psychiatry, 57, 805-809.

Milders, M., Ietswaart, M., Crawford, J. R., \& Currie, D. (2006). Impairments in Theory of Mind Shortly After Traumatic Brain Injury and at 1-Year Follow-Up. Neuropsychology, 20, 400-408.

Milligan, K., Astington, J. W., \& Dack, L. A. (2007). Language and theory of mind: Meta-analysis of the relation between language ability and false-belief understanding. . Child Development, 78, 622-646.

Moore, C. A. \& Lichtenberg, P. A. (1996). Neuropsychological prediction of independent functioning in a geriatric sample: A double cross-validational study. Rehabilitation Psychology, 41, 115-130. 
Morris, J. C. \& Cummings, J. (2005). Mild cognitive impairment (MCI) represents earlystage Alzheimer's disease. Journal of Alzheimer's Disease, 7, 235-239.

Neary, D., Snowden, J. S., Gustafson, L., Passant, U., Stuss, D., Black, S. et al. (1998). Frontotemporal lobar degeneration: A consensus on clinical diagnostic criteria. Neurology, 51, 1546-1554.

Newsom, J. T., Nishishiba, M., Morgan, D. L., \& Rook, K. S. (2003). The relative importance of three domains of positive and negative social exchanges: A longitudinal model with comparable measures. Psychology and Aging, 18, 746754.

Newsom, J. T., Rook, K. S., Nishishiba, M., Sorkin, D. H., \& Mahan, T. L. (2005). Understanding the relative importance of positive and negative social exchanges: Examining specific domains and appraisals. Journals of Gerontology Series BPsychological Sciences and Social Sciences, 60, 304-312.

O'Keeffe, F. M., Murray, B., Coen, R. F., Dockree, P. M., Bellgrove, M. A., Garavan, H. et al. (2007). Loss of insight in frontotemporal dementia, corticobasal degeneration and progressive supranuclear palsy. . Brain: A Journal of Neurology, 130, 753-764.

Okonkwo, O. C., Wadley, V. G., Griffith, H. R., Belue, K., Lanza, S., Zamrini, E. Y. et al. (2008). Awareness of deficits in financial abilities in patients with mild cognitive impairment: Going beyond self-informant discrepancy. . American Journal of Geriatric Psychiatry, 16, 650-659.

Orrell, M., Butler, R., \& Bebbington, P. (2000). Social factors and the outcome of dementia. International Journal of Geriatric Psychiatry, 15, 515-520. 
Pardini, M. \& Nichelli, P. F. (2009). Age-related decline in mentalizing skills across adult life span. Experimental Aging Research, 35, 98-106.

Perner, J. \& Wimmer, H. (1985). "John thinks that Mary thinks that...": Attribution of second-order beliefs by 5- to 10-year-old children. Journal of Experimental Child Psychology, 39, 437-471.

Petersen, R. C., Stevens, J. C., Ganguli, M., Tangalos, E. G., Cummings, J. L., \& DeKosky, S. T. (2001). Practice parameter: Early detection of dementia: Mild cognitive impairment (an evidence-based review). . Neurology, 56, 1133-1142.

Phillips, L. H., MacLean, R. D. J., \& Allen, R. (2002). Age and the understanding of emotions: Neuropsychological and sociocognitive perspectives. Journals of Gerontology: Series B: Psychological Sciences and Social Sciences, 57B, 526530.

Pinquart, M. \& Sorensen, S. (2000). Influences of socioeconomic status, social network, and competence on subjective well-being in later life: A meta-analysis. Psychology and Aging, 15, 187-224.

Premack, D. \& Woodruff, G. (1978). Does the chimpanzee have a theory of mind? Behavioral and Brain Sciences, 1, 515-526.

Pushkar, D., Basevitz, P., Arbuckle, T., Nohara-LeClair, M., Lapidus, S., \& Peled, M. (2000). Social behavior and off-target verbosity in elderly people. Psychology and Aging, 15, 361-374.

Rankin, K. P., Baldwin, E., Pace-Savitsky, C., Kramer, J. H., \& Miller, B. L. (2005). Self awareness and personality change in dementia. Journal of Neurology, Neurosurgery \& Psychiatry, 76, 632-639. 
Raz, N. \& Rodrigue, K. M. (2006). Differential aging of the brain: Patterns, cognitive correlates and modifiers. Neuroscience \& Biobehavioral Reviews, 30, 730-748.

Reis, H. T., Clark, M. S., \& Holmes, J. G. (2004). Perceived Partner Responsiveness as an Organizing Construct in the Study of Intimacy and Closeness. Handbook of Closeness and Intimacy, 201-225.

Ready, R. E., Ott, B. R., \& Grace, J. (2004). Validity of Informant Reports About AD and MCI Patients' Memory. Alzheimer Disease \& Associated Disorders, 18, 11 16.

Rook, K. S. (2001). Emotional health and positive versus negative social exchanges: A daily diary analysis. Applied Developmental Science, 5, 86-97.

Rook, K. S. (2003). Exposure and reactivity to negative social exchanges: A preliminary investigation using daily diary data. Journals of Gerontology: Series B: Psychological Sciences and Social Sciences, 58B, 100-111.

Rowe, A. D., Bullock, P. R., Polkey, C. E., \& Morris, R. G. (2001). "Theory of mind" impairments and their relationship to executive functioning following frontal lobe excisions. Brain, 124, 600-616.

Russell, D. W. \& Cutrona, C. E. (1991). Social support, stress, and depressive symptoms among the elderly: Test of a process model. Psychology and Aging, Vol.6, 190201.

Rymer, S., Salloway, S., Norton, L., Malloy, P., Correia, S., \& Monast, D. (2002). Impaired awareness, behavior disturbance, and caregiver burden in Alzheimer disease. . Alzheimer Disease \& Associated Disorders, 16, 248-253. 
Saltzman, J., Strauss, E., Hunter, M., \& Archibald, S. (2000). Theory of mind and executive functions in normal human aging and Parkinson's disease. Journal of the International Neuropsychological Society, 6, 781-788.

Sarason, B. R., Shearin, E. N., Pierce, G. R., \& Sarason, I. G. (1987). Interrelations of social support measures: Theoretical and practical implications. Journal of Personality and Social Psychology, 52, 813-832.

Saxe, R., Moran, J. M., Scholz, J., \& Gabrieli, J. (2006). Overlapping and nonoverlapping brain regions for theory of mind and self reflection in individual subjects. Social Cognitive and Affective Neuroscience, 1, 229-234.

Saxe, R. \& Powell, L. J. (2006). It's the Thought That Counts: Specific Brain Regions for One Component of Theory of Mind. Psychological Science, 17, 692-699.

Schaie, K. W. (1994). The Course of Adult Development. American Psychologist, 49, 304-313.

Schroepfer, T. A. (2008). Social relationships and their role in the consideration to hasten death. The Gerontologist, 48, 612-621.

Seeman, T. \& Chen, X. (2002). Risk and protective factors for physical functioning in older adults with and without chronic conditions: MacArthur studies of successful aging. The Journals of Gerontology: Series B: Psychological Sciences and Social Sciences, Vol.57B, S135-S144.

Seltzer, B., Vasterling, J. J., Yoder, J., \& Thompson, K. A. (1997). Awareness of deficit in Alzheimer's disease: Relation to caregiver burden. The Gerontologist, 37, 20 24. 
Shamay-Tsoory, S. G. \& haron-Peretz, J. (2007). Dissociable prefrontal networks for cognitive and affective theory of mind: A lesion study. Neuropsychologia, 45, 3054-3067.

Sheikh, J. I. \& Yesavage, J. A. (1986). Geriatric Depression Scale (GDS): Recent evidence and development of a shorter version. Clinical Gerontologist, 5, 165173.

Slessor, G., Phillips, L. H., \& Bull, R. (2007). Exploring the specificity of age-related differences in theory of mind tasks. Psychology and Aging, 22, 639-643.

Smith, C. A., Henderson, V. W., McCleary, C. A., Murdock, G. A., \& Buckwalter, J. G. (2000). Anosognosia and Alzheimer's disease: The role of depressive symptoms in mediating impaired insight. Journal of Clinical and Experimental Neuropsychology, 22, 437-444.

Snowden, J. S., Neary, D., \& Mann, D. A. (2002). Frontotemporal dementia. . British Journal of Psychiatry, 180, 140-143.

Souchay, C., Isingrini, M., Pillon, B., \& Gil, R. (2003). Metamemory Accuracy in Alzheimer's Disease and Frontotemporal Lobe Dementia. Neurocase, Vol.9, 482493.

Stern, Y. (2002). What is cognitive reserve? Theory and research application of the reserve concept. Journal of the International Neuropsychological Society, Vol.8, $448-460$.

Stewart, G., McGeown, W. J., Shanks, M. F., \& Venneri, A. (2010). Anosognosia for memory impairment in Alzheimer's disease. Acta Neuropsychiatrica, Vol.22, 180-187. 
Stone, V. E., Baron-Cohen, S., \& Knight, R. T. (1998). Frontal lobe contributions to theory of mind. Journal of Cognitive Neuroscience, 10, 640-656.

Stone, V. E., Baron-Cohen, S., Calder, A., Keane, J., \& Young, A. (2003). Acquired theory of mind impairments in individuals with bilateral amygdala lesions. Neuropsychologia, 41, 209-220.

Stuss, D. T., Gallup, G. G., Jr., \& Alexander, M. P. (2001). The frontal lobes are necessary for 'theory of mind'. Brain, 124, 279-286.

Stuss, D. T. \& Levine, B. (2002). Adult clinical neuropsychology: lessons from studies of the frontal lobes. Annu.Rev.Psychol, 53, 401-433.

Stuss, D. T. (1991). Disturbance of self-awareness after frontal system damage. In G.P. Prigatano D.L. Schacter (Eds.), Awareness of Deficit After Brain Injury: Clinical and Theoretical Issue, (pp. 63-83). New York: Oxford University Press.

Stuss, D. T. \& Anderson, V. (2004). The frontal lobes and theory of mind:

Developmental concepts from adult focal lesion research. Brain and Cognition, $55,69-83$.

Sullivan, S. \& Ruffman, T. (2004). Social understanding: How does it fare with advancing years? British Journal of Psychology, 95, 1-18.

Tager-Flusberg, H. \& Sullivan, K. (2000). A componential view of theory of mind: Evidence from Williams syndrome. Cognition, 76, 59-89.

Torralva, T., Roca, M., Gleichgerrcht, E., Bekinschtein, T., \& Manes, F. (2009). A neuropsychological battery to detect specific executive and social cognitive impairments in early frontotemporal dementia. Brain, 132, 1299-1309. 
Torralva, T., Kipps, C. M., Hodges, J. R., Clark, L., Bekinschtein, T., Roca, M. et al. (2007). The relationship between affective decision-making and theory of mind in the frontal variant of fronto-temporal dementia. . Neuropsychologia, 45, 342-349.

Uekermann, J., Channon, S., \& Daum, I. (2006). Humor processing, mentalizing, and executive function in normal aging. . Journal of the International Neuropsychological Society, 12, 184-191.

United States Census Bureau. (2011). Educational Attainment by State: $1990-2008$. Retrieved May 1, 2011, from http://www.census.gov/compendia/statab/2011/tables/11s0229.pdf.

Uttl, B. (2002). North American Adult Reading Test: Age norms, reliability, and validity. Journal of Clinical and Experimental Neuropsychology, 24, 1123-1137.

Vanderhorst, R. K. \& McLaren, S. (2005). Social relationships as predictors of depression and suicidal ideation in older adults. Aging \& Mental Health, 9, 517525.

Verdon, C. M., Fossati, P., Verny, M., Dieudonne, B., Teillet, L., \& Nadel, J. (2007). Social cognition: An early impairment in dementia of the Alzheimer type. Alzheimer Disease \& Associated Disorders, 21, 25-30.

Vogeley, K., Bussfeld, P., Newen, A., Herrmann, S., Happe, F., Falkai, P. et al. (2001). Mind reading: neural mechanisms of theory of mind and self-perspective. Neuroimage, 14, t-81.

von Hippel, W. \& Dunlop, S. M. (2005). Aging, Inhibition, and Social Inappropriateness. . Psychology and Aging, 20, 519-523. 
von Hippel, W., Silver, L. A., \& Lynch, M. E. (2000). Stereotyping against your will: The role of inhibitory ability in stereotyping and prejudice among the elderly. Personality and Social Psychology Bulletin, 26, 523-532.

Wang, Y. F. \& Su, Y. J. (2006). Theory of mind in old adults: The performance on Happe's stories and faux pas stories. Psychologia, 49, 228-237.

Washburn, A. M., Sands, L. P., \& Walton, P. J. (2003). Assessment of social cognition in frail older adults and its association with social functioning in the nursing home. The Gerontologist, 43, 203-212.

Watson, A. C., Nixon, C. L., Wilson, A., \& Capage, L. (1999). Social interaction skills and theory of mind in young children. . Developmental Psychology, 35, 386-391.

Wechsler, D. (1997). WAIS-III administration and scoring manual. San Antonio, TX: The Psychological Corporation.

West, R. L. (1996). An application of prefrontal cortex function theory to cognitive aging. Psychological Bulletin, 120, 272-292.

World Health Organization. International statistical classification of diseases, injuries and causes of death, tenth revision. Geneva: WHO; 1993.

Williamson, C., Alcantar, O., Rothlind, J., Cahn-Weiner, D., Miller, B. L., \& Rosen, H. J. (2010). Standardised measurement of self-awareness deficits in FTD and AD. Journal of Neurology, Neurosurgery \& Psychiatry, Vol.81, 140-145.

Williamson, G. M. \& Schulz, R. (1992). Physical illness and symptoms of depression among elderly outpatients. . Psychology and Aging, 7, 343-351.

Wimmer, H. \& Perner, J. (1983). Beliefs about beliefs: Representation and constraining function of wrong beliefs in young children's understanding of deception. Cognition, 13, 103-128. 
Wolf, P. A., D'Agostino, R. B., Belanger, A. J., \& Kannel, W. B. (1991). Probability of stroke: a risk profile from the Framingham Study. Stroke, 22, 312-318.

Woo, J., Goggins, W., Sham, A., \& Ho, S. C. (2005). Social determinants of frailty. Gerontology, 51, 402-408.

Yesavage, J. A., Brink, T. L., Rose, T. L., Lum, O., Huang, V., Adey, M. et al. (1982). Development and validation of a geriatric depression screening scale: a preliminary report. Journal of Psychiatric Research, 17, 37-49.

Yochim, B., Mast, B.T., \& Lichtenberg, P.A. (2003). Cerebrovascular risk factors and depressed mood in inner city older adults. Clinical Psychologist, 7, 11-20.

Zaitchik, D., Koff, E., Brownell, H., Winner, E., \& Albert, M. (2004). Inference of mental states in patients with Alzheimer's disease. Cognit.Neuropsychiatry, 9, 301-313.

Zaitchik, D., Koff, E., Brownell, H., Winner, E., \& Albert, M. (2006). Inference of beliefs and emotions in patients with Alzheimer's disease. Neuropsychology, 20, 11-20.

Zalla, T., Sav, A. M., Stopin, A., Ahade, S., \& Leboyer, M. (2009). Faux pas detection and intentional action in Asperger syndrome. A replication on a French sample. Journal of Autism and Developmental Disorders, 39, 373-382. 
Table 1

\begin{tabular}{|c|c|c|c|c|c|}
\hline Study (First author, year) & $\mathrm{N}$ (mean age in years) & ToM Test(s) & Other Tests & Main Results & Limits \\
\hline Happé et al., 1998 & $\begin{array}{l}\text { OA: } 19(9 \text { men, } 10 \text { women; } \\
\text { mean age }=73) \\
\text { YA: } 67(33 \text { men, } 34 \\
\text { women })(\text { mean age }=21)\end{array}$ & Strange Stories Test & & $\begin{array}{l}\text { Interaction of age and story } \\
\text { type (control \& ToM) } \mathrm{F}(1, \\
82)=14.59, \mathrm{p}<.001 \\
\text { Post-hoc comparisons } \\
\text { reveal OA performed } \\
\text { better on ToM stories than } \\
\text { YA } \mathrm{t}(84)=4.18, \mathrm{p}<.001\end{array}$ & $\begin{array}{l}\text { 1) Older group had high } \\
\text { education } 12-18 \text { years ( } \mathrm{m}= \\
14 \text { years, } 7 \text { months) which } \\
\text { may affect the } \\
\text { generalizability of the } \\
\text { results. 2) No measure of } \\
\text { general intelligence. 3) } \\
\text { Scores may have been } \\
\text { confounded with memory } \\
\text { as participants were not } \\
\text { permitted to review } \\
\text { vignettes. }\end{array}$ \\
\hline Saltzman et al., $2000^{*}$ & $\begin{array}{l}\text { OA: } 8(3 \text { male, } 5 \text { female; } \\
\text { mean age }=71.61, \mathrm{SD}= \\
9.42) \\
\text { YA: } 9(3 \text { male, } 6 \text { female; } \\
\text { mean age }=20.87, \mathrm{SD}= \\
2.53)\end{array}$ & $\begin{array}{l}\text { Strange Stories; Droodles; } \\
\text { Spy Model Task; Knower/ } \\
\text { Guesser Task }\end{array}$ & Executive measures & $\begin{array}{l}\text { 1) OA group and YA } \\
\text { group had similar } \\
\text { performance on all ToM } \\
\text { tasks, with the exception of } \\
\text { the Knower/Guesser task, } \\
\text { on which the OA group } \\
\text { performed significantly } \\
\text { below the YA group (t }(9) \\
=-2.330, \mathrm{p}=.022) \text {. 2) The } \\
\text { Knower/Guesser task was } \\
\text { the most highly correlated } \\
\text { with measures of executive } \\
\text { functioning. }\end{array}$ & $\begin{array}{l}\text { 1) Small sample size. 2) } \\
\text { The one measure that } \\
\text { found age differences may } \\
\text { rely heavily on executive } \\
\text { functioning. } 3 \text { ) the other } \\
\text { measures used } \\
\text { demonstrated ceiling } \\
\text { effects. }\end{array}$ \\
\hline
\end{tabular}




\begin{tabular}{|c|c|c|c|c|c|}
\hline Study (First author, year) & $\mathrm{N}$ (mean age in years) & ToM Test(s) & Other Tests & Main Results & Limits \\
\hline $\begin{array}{l}\text { Maylor, } 2002 \\
\text { Experiment } 1\end{array}$ & $\begin{array}{l}\text { YA: } 25(15 \text { males, } 10 \\
\text { females; mean age }=19, \\
\mathrm{SD}=3.7) \\
\text { YOA: } 25(9 \text { males, } 16 \\
\text { females; mean age }=67.2 \text {, } \\
\mathrm{SD}=4.8) \\
\text { OOA: } 25(6 \text { males, } 19 \\
\text { females; mean age }=81, \\
\mathrm{SD}=3.3)\end{array}$ & $\begin{array}{l}\text { Strange Stories + } 3 \text { new } \\
\text { stories }\end{array}$ & $\begin{array}{l}\text { Speed, Vocabulary } \\
\text { Intelligence measures }\end{array}$ & $\begin{array}{l}\text { 1) ANOVA found } \\
\text { significant differences on } \\
\text { ToM tasks with no } \\
\text { memory load regarding } \\
\text { age group }(\mathrm{F}(2,72)= \\
21.21, \mathrm{p}<.0001) \text {. Post hoc } \\
\text { comparisons revealed that } \\
\text { YA \& YOA performed } \\
\text { better on ToM tasks } \\
\text { without a memory load } \\
\text { than the OOA. } \\
\text { 2) ANOVA on ToM with } \\
\text { memory load was } \\
\text { significant F }(2,72)=9.52 \text {, } \\
\text { p }<.0005) \text {. Post hoc } \\
\text { comparisons revealed that } \\
\text { YA performed better on } \\
\text { tasks with a memory load } \\
\text { than both OOA \& YOA. }\end{array}$ & $\begin{array}{l}\text { 1) Use of stimuli that have } \\
\text { not been validated. } \\
\text { 2) Control tasks may differ } \\
\text { from ToM tasks regarding } \\
\text { inference complexity. }\end{array}$ \\
\hline $\begin{array}{l}\text { Maylor, } 2002 \text { Experiment } \\
2\end{array}$ & $\begin{array}{l}\text { YA: } 30(14 \text { males, } 16 \\
\text { females; mean age }=21.2 \text {, } \\
\mathrm{SD}=2.5) \\
\text { OA: } 30(13 \text { males, } 17 \\
\text { females; mean age }=80.6 \text {, } \\
\mathrm{SD}=4.7)\end{array}$ & $\begin{array}{l}\text { Strange Stories - no } \\
\text { memory load }\end{array}$ & $\begin{array}{l}\text { Vocabulary } \\
\text { Spced; } \\
\text { Executive function } \\
\text { measures }\end{array}$ & $\begin{array}{l}\text { 1) Relationship between } \\
\text { ToM and executive } \\
\text { functioning was mediated } \\
\text { by age. Relationship } \\
\text { disappeared when age was } \\
\text { partialled out. 2) } \\
\text { ANCOVA using } \\
\text { education, vocabulary, } \\
\text { speed, executive } \\
\text { functioning as covariates } \\
\text { found an interaction } \\
\text { between story type (control } \\
\text { vs. ToM) and age: F(1,53) } \\
=4.23, \text { p<.05. 3) } \\
\text { Crystallized ability } \\
\text { markers, such as education } \\
\text { and vocabulary, predicted } \\
\text { ToM performance. }\end{array}$ & $\begin{array}{l}\text { 1) Only one measure of } \\
\text { ToM was used. 2) Control } \\
\text { tasks may differ from ToM } \\
\text { tasks regarding inference } \\
\text { complexity. }\end{array}$ \\
\hline
\end{tabular}




\begin{tabular}{|c|c|c|c|c|c|}
\hline Study (First author, year) & $\mathrm{N}$ (mean age in years) & ToM Test(s) & Other Tests & Main Results & Limits \\
\hline MacPherson, 2002 & $\begin{array}{l}\text { YA: } 30(15 \text { men, } 15 \\
\text { women; mean age }=50.3 \text {, } \\
\text { SD }=5.7) \\
\text { MA: } 30(15 \text { men, } 15 \\
\text { women; mean age }=50.3 \text {, } \\
\text { SD }=5.7) \\
\text { OA: } 30(15 \text { men, } 15 \\
\text { women; mean age }=69.9 \text {, } \\
\mathrm{SD}=5.5)\end{array}$ & Faux Pas Task & $\begin{array}{l}\text { Executive tasks; Gambling } \\
\text { task, Emotion } \\
\text { Identification task; } \\
\text { memory tasks. }\end{array}$ & $\begin{array}{l}\text { The ToM task did not } \\
\text { demonstrate age effects } \\
\text { (MANCOVA, Wilk's } \Lambda= \\
86, F(10,162)=1.26, \eta_{\mathrm{p}}^{2} \\
=.07 .07 . \\
\text { Age effect was found for } \\
\text { emotion identification, but } \\
\text { this effect disappeared } \\
\text { when memory ability was } \\
\text { used as a covariate. }\end{array}$ & $\begin{array}{l}\text { 1) Only one ToM task was } \\
\text { used. }\end{array}$ \\
\hline $\begin{array}{l}\text { Phillips, MacLean, \& } \\
\text { Allen, } 2002\end{array}$ & $\begin{array}{l}\text { YA: } 30(11 \text { men, } 19 \\
\text { women; mean age }=29.9, \\
\mathrm{SD}=7.1) \\
\text { OA: } 30(15 \text { men, } 15 \\
\text { women; mean age }=69.2 \text {, } \\
\mathrm{SD}=6.1)\end{array}$ & $\begin{array}{l}\text { Reading the Mind in the } \\
\text { Eyes Task }\end{array}$ & $\begin{array}{l}\text { Measures of fluid and } \\
\text { crystallized intelligence, } \\
\text { Empathy, Emotion } \\
\text { Identification tasks }\end{array}$ & $\begin{array}{l}\text { YA performed } \\
\text { significantly better on the } \\
\text { ToM task after controlling } \\
\text { for education and fluid and } \\
\text { crystallized intelligence } \\
\left(\mathrm{F}(1,55)=5.61, \mathrm{p}<.05, \eta_{\mathrm{p}}{ }^{2}\right. \\
=.09) .\end{array}$ & $\begin{array}{l}\text { 1) Only one ToM measure } \\
\text { was used. 2) Performance } \\
\text { on this task may rely on } \\
\text { visuospatial processes } \\
\text { which may decline with } \\
\text { age. }\end{array}$ \\
\hline Sullivan \& Ruffman, 2004 & $\begin{array}{l}\text { YA: } 24(13 \mathrm{M}, 11 \mathrm{~W} ; \text { mean } \\
\text { age }=30, \mathrm{SD}=7.5) \\
\text { OA: } 24(8 \mathrm{M}, 16 \mathrm{~W} ; \text { mean } \\
\text { age }=73 \text { years, } \mathrm{SD}=6.0)\end{array}$ & $\begin{array}{l}\text { Strange Stories; } \\
\text { Video Task }\end{array}$ & $\begin{array}{l}\text { Measures of fluid and } \\
\text { crystallized intelligence. }\end{array}$ & $\begin{array}{l}\text { 1) YA performed } \\
\text { significantly better than } \\
\text { older adults on ToM } \\
\text { stories }(t(46)=4.56 \text {, } \\
p<.001) .2 \text { ) The effect of } \\
\text { age } x \text { story type (ToM vs. } \\
\text { control) disappeared when } \\
\text { fluid abilities were } \\
\text { controlled for } F(1,45)= \\
2.49, p=.12 \text {. }\end{array}$ & $\begin{array}{l}\text { 1) Group differences on } \\
\text { control stories almost } \\
\text { significant } \mathrm{t}(46)=1.82 \text {, } \\
\mathrm{p}<.08 \text {. Thus, with more } \\
\text { power differences may be } \\
\text { found, which would then } \\
\text { indicate that older adults } \\
\text { would demonstrate an age } \\
\text { effect for both control and } \\
\text { ToM conditions, and not } \\
\text { just ToM. 2) Sample was } \\
\text { primarily white, middle } \\
\text { class, limiting } \\
\text { generalizability. }\end{array}$ \\
\hline
\end{tabular}




\begin{tabular}{|c|c|c|c|c|c|}
\hline Study (First author, year) & $\mathrm{N}$ (mean age in years) & ToM Test(s) & Other Tests & Main Results & Limits \\
\hline German \& Hehman, 2006 & $\begin{array}{l}\text { YA: } 27(9 \mathrm{M} 18 \mathrm{~F} ; \text { mean } \\
\text { age }=19.51, S D=1.51) \\
\text { OA: } 20(1 \mathrm{M}, 19 \mathrm{~F} ; \text { mean } \\
\text { age }=78.22, S D=8.27)\end{array}$ & $\begin{array}{l}\text { New vignettes were } \\
\text { created in which ToM and } \\
\text { the control condition were } \\
\text { more evenly matched. }\end{array}$ & $\begin{array}{l}\text { Crystallized and fluid } \\
\text { intelligence measures; } \\
\text { executive function } \\
\text { measures focusing on } \\
\text { response inhibition }\end{array}$ & $\begin{array}{l}\text { Performance on ToM tasks } \\
\text { was not significantly } \\
\text { different in YA vs. OA } \\
\text { groups } F(1,45)=0.66 \\
\text { p }>.05 .\end{array}$ & $\begin{array}{l}\text { 1) The measures used were } \\
\text { created and were not } \\
\text { piloted. Though they } \\
\text { seemed to be } \\
\text { improvement, more studies } \\
\text { would be needed to } \\
\text { determine their reliability } \\
\text { and validity. } \\
\text { 2) Gender differences on } \\
\text { the tasks would influence } \\
\text { the generalizability of } \\
\text { results. }\end{array}$ \\
\hline Wang \& Su, 2006 & $\begin{array}{l}\text { YA: } 30(26 \mathrm{M}, 4 \mathrm{~F} ; \text { mean } \\
\text { age }=69.93, \mathrm{SD}=3.73) \\
\text { OA: } 30(26 \mathrm{M}, 4 \mathrm{~F} ; \text { mean } \\
\text { age }=21.6, \mathrm{SD}=1.5)\end{array}$ & $\begin{array}{l}\text { Strange Stories; } \\
\text { Faux Pas stories(1 from } \\
\text { Stone et al. 2003, } 2 \text { newly } \\
\text { constructed) }\end{array}$ & $\begin{array}{l}\text { Crystallized and fluid } \\
\text { intelligence measures; IQ }\end{array}$ & $\begin{array}{l}\text { OA demonstrated worse } \\
\text { performance on the Faux } \\
\text { Pas test than YA }(\mathrm{t}(58)=- \\
2.25, \mathrm{p}<.05, \text { but no } \\
\text { differences were found } \\
\text { between the older and } \\
\text { younger groups on the } \\
\text { Strange stories. }\end{array}$ & $\begin{array}{l}\text { 1) Cultural norms (study } \\
\text { was done in China. 2) } \\
\text { Possibly invalid measures } \\
\text { 3) Memory may be } \\
\text { confounded with } \\
\text { performance as } \\
\text { participants were not } \\
\text { allowed to refer back to } \\
\text { stories before answering } \\
\text { questions. 4) Men may } \\
\text { perform more poorly on } \\
\text { ToM tasks than women, } \\
\text { which would affect the } \\
\text { generalizability of the } \\
\text { results. }\end{array}$ \\
\hline
\end{tabular}




\begin{tabular}{|c|c|c|c|c|c|}
\hline Study (First author, year) & $\mathrm{N}$ (mean age in years) & ToM Test(s) & Other Tests & Main Results & Limits \\
\hline $\begin{array}{l}\text { Uekermann, Channon, \& } \\
\text { Daum, } 2006\end{array}$ & $\begin{array}{l}\text { YA: } 32(12 \mathrm{M}, 10 \mathrm{~F} ; \text { mean } \\
\text { age }=24.15, \mathrm{SD}=0.73) \\
\text { MA: } 29(10 \mathrm{M}, 19 \mathrm{~F} ; \text { mean } \\
\text { age }=49, \mathrm{SD}=0.96) \\
\text { OA: } 26(12 \mathrm{M}, 14 \mathrm{~F} ; \text { mean } \\
\text { age }=67.46, \mathrm{SD}=1.26)\end{array}$ & Joke Task & $\begin{array}{l}\text { Abbreviated IQ measures, } \\
\text { Depression, Executive } \\
\text { measures }\end{array}$ & $\begin{array}{l}\text { ANOVA demonstrated } \\
\text { significant difference in } \\
\text { ToM performance across } \\
\text { groups }(\mathrm{F}(2,84)=14.22 \text {, } \\
\mathrm{p}<.0001) \text {. Post hoc } \\
\text { analyses demonstrated that } \\
\text { the older adults group } \\
\text { performed significantly } \\
\text { worse on ToM tasks } \\
\text { compared to both the YA } \\
\text { and MA groups. }\end{array}$ & $\begin{array}{l}\text { Possible cohort effects and } \\
\text { clear ceiling effects for } \\
\text { humor processing task. }\end{array}$ \\
\hline Keightley et al., 2006 & $\begin{array}{l}\text { YA: } 30(15 \mathrm{M}, 15 \mathrm{~F} ; \text { mean } \\
\text { age }=25.7, \mathrm{SD}=5.1) \\
\text { OA: } 30(15 \mathrm{M}, 15 \mathrm{~F} ; \text { mean } \\
\text { age }=72.5, \mathrm{SD}=7.8)\end{array}$ & $\begin{array}{l}\text { Strange Stories } \\
\text { Single Cartoon Task }\end{array}$ & $\begin{array}{l}\text { Global Cognitive } \\
\text { functioning, Vocabulary, } \\
\text { working memory, fluency, } \\
\text { selective attention and } \\
\text { inhibition, sequencing \& } \\
\text { visual search, memory, } \\
\text { personality, emotion } \\
\text { processing of faces and } \\
\text { words, trait measures }\end{array}$ & $\begin{array}{l}\text { OA and YA did not } \\
\text { demonstrate ToM- specific } \\
\text { differences on either ToM } \\
\text { task, though they did } \\
\text { perform more poorly on } \\
\text { comprehension questions } \\
\text { compared to YA. } \\
\text { Performance on ToM tasks } \\
\text { was not predicted by } \\
\text { personality in either young } \\
\text { or old adults (Keightley et } \\
\text { al., 2006) }\end{array}$ & $\begin{array}{l}\text { Only } 8 \text { ToM items were } \\
\text { used ( } 4 \text { ToM cartoons, } 4 \\
\text { ToM stories) and a } \\
\text { relatively small sample } \\
\text { size was used. Both of } \\
\text { these may have limited } \\
\text { power to detect } \\
\text { differences. }\end{array}$ \\
\hline
\end{tabular}




\begin{tabular}{|c|c|c|c|c|c|}
\hline Study (First author, year) & $\mathrm{N}$ (mean age in years) & ToM Test(s) & Other Tests & Main Results & Limits \\
\hline $\begin{array}{l}\text { McKinnon \& Moscovitch, } \\
2007\end{array}$ & $\begin{array}{l}\text { YA: } 12(\text { gender N/A; } \\
\text { mean age }=78.18, S D= \\
\text { N/A }) \\
\text { OA: } 12(\text { gender N/A; mean } \\
\text { age }=20.16, S D=N / A)\end{array}$ & $\begin{array}{l}\text { Vignettes including faux } \\
\text { pas, first-order ToM } \\
\text { questions, and second- } \\
\text { order ToM questions. }\end{array}$ & $\begin{array}{l}\text { Deontic selection task; } \\
\text { working memory tasks }\end{array}$ & $\begin{array}{l}\text { OA performed worse than } \\
\text { YA only on second-order } \\
\text { questions }(\mathrm{F}(1,11)=1.96 \text {, } \\
\mathrm{p}>.05) \text {, but not on first- } \\
\text { order questions }(\mathrm{F}(1,11)= \\
1.96, \mathrm{p}>.05) \text {. } \\
\text { Working memory supports } \\
\text { ToM functioning. }\end{array}$ & $\begin{array}{l}\text { High education in OA } \\
\text { group }(\mathrm{M}=15.90 \text { years of } \\
\text { education) } \\
\text { Created their own } \\
\text { vignettes based on faux pas } \\
\text { stories and strange stories. } \\
\text { No non-ToM control } \\
\text { condition, so the } \\
\text { conclusion cannot be } \\
\text { drawn that the deficits } \\
\text { observed are specific ToM } \\
\text { deficits; rather, they may } \\
\text { be working memory } \\
\text { deficits. }\end{array}$ \\
\hline Slessor, 2007 & $\begin{array}{l}\text { OA: } 40(15 \text { male, } 25 \\
\text { female; mean age }=66.95 \text {, } \\
S D=4.31) \\
\text { YA: } 40(12 \text { male, } 28 \\
\text { female; mean age }=20.08 \text {, } \\
S D=4.64)\end{array}$ & $\begin{array}{l}\text { Strange Stories; } \\
\text { Videos Task; } \\
\text { Reading the Mind in the } \\
\text { Eyes Task }\end{array}$ & Mill Hill Vocabulary Test & $\begin{array}{l}\text { Age differences on verbal } \\
\text { ToM for Strange Stories } \\
\text { task: ANOVA } \\
\text { demonstrated no effects of } \\
\text { age on ToM } F(1,78)<1, \eta_{\mathrm{p}}{ }^{2} \\
=.00 \text {. } \\
\text { ANCOVA (controlling for } \\
\text { vocabulary) on verbal } \\
\text { ToM demonstrated effects } \\
\text { of age: } F(1,77)=11.24 \text {, } \\
\text { p }<.01 . \\
\text { Age differences were } \\
\text { found for the visual tasks, } \\
\text { but not between the ToM } \\
\text { and control tasks. Across } \\
\text { visual tasks, both age } \\
\text { groups performed better on } \\
\text { the ToM tasks than on the } \\
\text { control tasks. }\end{array}$ & $\begin{array}{l}\text { OAs had superior } \\
\text { vocabulary compared to } \\
\text { YAs. } \\
\text { Did not control for } \\
\text { executive functioning. } \\
\text { Control condition for } \\
\text { visual tasks was to guess } \\
\text { the age range of characters } \\
\text { ( } 40-50 \text { years vs. } 50-60 \\
\text { years). This may not be a } \\
\text { well-matched control } \\
\text { condition. }\end{array}$ \\
\hline
\end{tabular}




\begin{tabular}{|c|c|c|c|c|c|}
\hline Study (First author, year) & $\mathrm{N}$ (mean age in years) & ToM Test(s) & Other Tests & Main Results & Limits \\
\hline Bailey, 2008 & $\begin{array}{l}\text { OA: } 49(16 \text { male, } 33 \\
\text { female; mean age }=70.4, \\
\mathrm{SD}=5.51) \\
\text { YA: } 80(23 \text { male, } 57 \\
\text { female; mean age }=20.8 \text {, } \\
\mathrm{SD}=1.13)\end{array}$ & Eyes task & $\begin{array}{l}\text { EQ (Empathy Quotient) } \\
\text { Questionnaire } \\
\text { Prosocial subscale of the } \\
\text { Social Functioning Scale. }\end{array}$ & $\begin{array}{l}\text { OA performed worse than } \\
\text { YA on EYES task } t(127)= \\
7.61, d=1.35) \\
\text { OA reported lower levels } \\
\text { of cognitive empathy (but } \\
\text { not affective empathy) } \\
\text { compared to YA (t }(127)= \\
2.45, d=0.44) \\
\text { OA reported lower levels } \\
\text { of social participation } \\
\text { compared to YA ( }(127)= \\
3.48, d=.62) \\
\text { Cognitive empathy (as } \\
\text { measured by EQ) partially } \\
\text { mediated relationship } \\
\text { between age and social } \\
\text { functioning. EYES did not } \\
\text { demonstrate mediation } \\
\text { between age and social } \\
\text { functioning. } \\
\text { Analysis of EYES test } \\
\text { determined no difference } \\
\text { in performance for OA vs. } \\
\text { YA on items of different } \\
\text { emotional valence. } \\
\text { Authors conclude age is } \\
\text { associated with reduced } \\
\text { capacity for cognitive } \\
\text { empathy, but not affective } \\
\text { empathy. }\end{array}$ & $\begin{array}{l}\text { Causality cannot be } \\
\text { determined due to cross- } \\
\text { sectional design. }\end{array}$ \\
\hline
\end{tabular}




\begin{tabular}{|c|c|c|c|c|c|}
\hline Study (First author, year) & $\mathrm{N}$ (mean age in years) & ToM Test(s) & Other Tests & Main Results & Limits \\
\hline Bailey \& Henry, 2008 & $\begin{array}{l}\text { OA: } 33(11 \text { male, } 22 \\
\text { female); mean age }=72.2 \text {, } \\
S D=5.56) \\
\text { YA: } 36(11 \text { male, } 25 \\
\text { female; mean age }=19.5, \\
S D=2.10)\end{array}$ & $\begin{array}{l}\text { Reality-known video task } \\
\text { (high inhibition of self- } \\
\text { perspective FB task) } \\
\text { Reality Unknown video } \\
\text { task (low inhibition FB } \\
\text { task) } \\
\text { EYES task }\end{array}$ & $\begin{array}{l}\text { Speed, memory, measures } \\
\text { of inhibitory control } \\
\text { (Stroop test, Hayling } \\
\text { Sentence Completion Test) }\end{array}$ & $\begin{array}{l}\text { OA performed worse on } \\
\text { EYES test compared to } \\
\text { YA } t(67)=-4.38, d=1.04) \\
\text { OA performed worse than } \\
\text { YA on high inhibition FB } \\
\text { task } \\
\text { OA demonstrated worse } \\
\text { performance on high } \\
\text { inhibition FB task } \\
\text { compared to their } \\
\text { performance on low } \\
\text { inhibition FB task, while } \\
\text { YA demonstrated no } \\
\text { differences in performance } \\
\text { on the two tasks. } \\
\text { Stroop task, but not } \\
\text { Hayling task, mediated age } \\
\text { and performance on high- } \\
\text { inhibition FB task. } \\
\text { Hayling task, but not } \\
\text { Stroop task, mediated age } \\
\text { and performance on the } \\
\text { Eyes task. }\end{array}$ & $\begin{array}{l}\text { Cross-sectional limits } \\
\text { causality. }\end{array}$ \\
\hline
\end{tabular}




\begin{tabular}{|c|c|c|c|c|c|}
\hline Study (First author, year) & $\mathrm{N}$ (mean age in years) & ToM Test(s) & Other Tests & Main Results & Limits \\
\hline Pardini, 2009 & $\begin{array}{l}\text { YA (Young Adults): } 30 \\
(15 \text { male, } 15 \text { female); Age } \\
\text { range }=20-25 \text { years } \\
\text { EMA (Early Middle Age) } \\
30 \text { (15 male, } 15 \text { female); } \\
\text { Age range }=45-55 \text { years } \\
\text { LMA (Late Middle Age) } \\
30 \text { ( } 16 \text { males, } 14 \text { females); } \\
\text { Age range }=55-65 \text { years } \\
\text { OA (Old Age) } 30(13 \\
\text { males, } 17 \text { females); Age } \\
\text { range }=70-75 \text { years }\end{array}$ & Revised Eyes Test & $\begin{array}{l}\text { Inclusion criteria: MMSE } \\
>27 \text { and no errors on } \\
\text { CLOX test. }\end{array}$ & $\begin{array}{l}\text { Significant age differences } \\
\text { were found for ToM }(\mathrm{F}(3 \text {, } \\
116)=24.5 \\
4 \text { contrasts indicated } \\
\text { poorer performance on } \\
\text { EYES test for each older } \\
\text { group: } \\
\text { YA>LMA } \\
\text { YA> older adults } \\
\text { EMA >LMA } \\
\text { LMA >older adults }\end{array}$ & $\begin{array}{l}\text { No other variables known } \\
\text { to influence ToM were } \\
\text { used as controls. } \\
\text { Cross-sectional study; } \\
\text { cohort effects could be } \\
\text { influencing data. }\end{array}$ \\
\hline Verdon, 2007 & $\begin{array}{l}\mathrm{OA}: \mathrm{N}=20(8 \mathrm{M}, 12 \mathrm{~F} \\
\text { mean age }=82, \text { education } \\
\text { level }=15 \mathrm{y}) \\
\text { YA: } \mathrm{N}=20(9 \mathrm{M}, 11 \mathrm{~F}) \\
\text { mean age }=27, \text { education } \\
16 \mathrm{y})\end{array}$ & Cartoon Task & $\begin{array}{l}\text { MMSE; Verbal Memory } \\
\text { Task }\end{array}$ & $\begin{array}{l}\text { Performance on ToM tasks } \\
\text { was not significantly } \\
\text { different in YA vs. OA } \\
\text { groups. }\end{array}$ & $\begin{array}{l}\text { 1) Expressive language } \\
\text { abilities were not tested, } \\
\text { but are an important } \\
\text { element of test } \\
\text { performance on the } \\
\text { cartoon task used. 3) } \\
\text { Depression, anxiety, and } \\
\text { psychotic disorders were } \\
\text { excluded. Exclusions may } \\
\text { limit the generalizability of } \\
\text { the results. }\end{array}$ \\
\hline \multicolumn{6}{|c|}{$\begin{array}{l}\text { OA }=\text { Older adults } \\
\text { YA = Younger Adults } \\
\text { YOA = Young-old adults } \\
\text { OOA = Old old adults } \\
\text { WCST = Wisconsin Card Sorting Test } \\
\text { *Also included an additional group of } 11 \text { patients with Parkinson's disease; not reported in this table. } \\
\text { **Also included an additional group of } 20 \text { patients with Alzheimer's disease; not reported in this table. }\end{array}$} \\
\hline
\end{tabular}


Table 2.

Effect sizes regarding ToM and different social variables

\begin{tabular}{llll}
\hline $\begin{array}{l}\text { Sample characteristics \& } \\
\text { reference }\end{array}$ & Social Construct(s) & Effect Size & $\mathrm{N}$ \\
\hline $\begin{array}{l}\text { Schizophrenia } \\
\text { (Bora et al., 2006) }\end{array}$ & $\begin{array}{l}\text { Overall Social Functioning } \\
\text { Interpersonal Communication }\end{array}$ & $\begin{array}{l}\mathrm{r}=.46 \\
\mathrm{r}=.49\end{array}$ & 50 \\
$\begin{array}{l}\text { Schizophrenia } \\
\text { (Brune et al., 2007) }\end{array}$ & Problematic Social Behaviors & $\mathrm{r}=-.69$ & 38 \\
$\begin{array}{l}\text { College Students } \\
\text { (Baron-Cohen et al., }\end{array}$ & $\begin{array}{l}\text { social skills } \\
\text { communicative abilities }\end{array}$ & $\begin{array}{l}\mathrm{r}=.27 \\
\mathrm{r}=.25\end{array}$ & 103 \\
$\begin{array}{l}\text { 6-year-old children, } \\
\text { normally developing } \\
\text { (Watson et al., 1999) }\end{array}$ & $\begin{array}{l}\text { Social skills as rated by } \\
\text { teachers }\end{array}$ & $\mathrm{r}=.35$ & 26 \\
\hline
\end{tabular}


Table 3

Abbreviations and study variables, including transformations of key variables and their subsequent meaning

\begin{tabular}{|c|c|c|}
\hline Abbreviation/Label & Full Name/Description & $\begin{array}{l}\text { Meaning of HIGHER } \\
\text { TRANSFORMED scores for } \\
\text { subsequent analyses }\end{array}$ \\
\hline AD & Alzheimer's disease & \\
\hline ADLs & Activities of daily living & \\
\hline AS & Asperger's Syndrome & \\
\hline CMI & Charlson Comorbidity Index & $\begin{array}{l}\text { Lower levels of medical } \\
\text { comorbidity } \mathrm{b}, \mathrm{h}\end{array}$ \\
\hline Convoy & Convoy Measure & Larger social networks ${ }^{\mathrm{f}}$ \\
\hline DRS-2 & Dementia Rating Scale - Version 2 & \\
\hline EYES & Reading the Eyes in the Mind Test-Revised & Lower ToM ability ${ }^{\mathrm{a}, \mathrm{e}, \mathrm{f}}$ \\
\hline FAB & Frontal Assessment Battery & Poorer frontal lobe functioning ${ }^{\mathrm{a}, \mathrm{f}}$ \\
\hline FP Composite & Faux Pas Test Composite & Lower ToM ability ${ }^{\mathrm{a}, \mathrm{e}, \mathrm{f}}$ \\
\hline FP HITS & $\begin{array}{l}\text { Faux Pas Test Hits (correctly identifying a story with a } \\
\text { faux pas as containing a faux pas) }\end{array}$ & \\
\hline FP REJECTIONS & $\begin{array}{l}\text { Faux Pas Test Rejections (correctly identifying stories } \\
\text { without a faux pas as not containing a faux pas) }\end{array}$ & \\
\hline fMRI & Functional magnetic resonance imaging & \\
\hline fvFTD & Frontal variant frontotemporal dementia & \\
\hline GDS & Geriatric Depression Scale & More depressive symptoms ${ }^{\mathrm{b}, \mathrm{d}, \mathrm{g}}$ \\
\hline HVLT-R & Hopkins Verbal Learning Test - Revised & \\
\hline HVLT-R Prediction Awareness & $\begin{array}{l}\text { Discrepancy between predicted performance on the } \\
\text { HVLT-R and actual performance }\end{array}$ & \\
\hline
\end{tabular}




\begin{tabular}{|c|c|c|}
\hline Abbreviation/Label & Full Name/Description & $\begin{array}{l}\text { Meaning of HIGHER } \\
\text { TRANSFORMED scores for } \\
\text { subsequent analyses }\end{array}$ \\
\hline HVLT-R Postdiction Awareness & $\begin{array}{l}\text { Discrepancy between postdicted performance on the } \\
\text { HVLT-R and actual performance }\end{array}$ & \\
\hline HVLT-R Delayed Recall & $\begin{array}{l}\text { Hopkins Verbal Learning Test - Revised, Delayed } \\
\text { Recall }\end{array}$ & Poorer memory $^{\mathrm{a}, \mathrm{f}}$ \\
\hline IADLs & Instrumental Activities of Daily Living & \\
\hline$\overline{\text { ISEL }}$ & Interpersonal Support Evaluation List-Short Form & Lower level of social support ${ }^{\mathrm{a}, \mathrm{g}}$ \\
\hline LN-Seq & Letter-Number Sequencing subtest & \\
\hline LN-Seq Prediction Awareness & $\begin{array}{l}\text { Discrepancy between predicted performance on LN- } \\
\text { Seq and actual performance }\end{array}$ & \\
\hline LN-Seq Postdiction Awareness & $\begin{array}{l}\text { Discrepancy between postdicted performance on LN- } \\
\text { Seq and actual performance }\end{array}$ & \\
\hline MARS-MFS & $\begin{array}{l}\text { Memory Functioning Scale of the Memory Awareness } \\
\text { Rating Scale - Revised. }\end{array}$ & \\
\hline MARS-MFS Awareness & $\begin{array}{l}\text { Discrepancy between informant and primary participant } \\
\text { ratings of primary participant memory on the MARS- } \\
\text { MFS }\end{array}$ & \\
\hline MARS-MFS Informant Ratings & $\begin{array}{l}\text { Informant Ratings of Primary Participant's memory on } \\
\text { the MARS-MFS }\end{array}$ & $\begin{array}{l}\text { Lower levels of memory in the } \\
\text { primary participant }{ }^{\mathrm{a}, \mathrm{f}}\end{array}$ \\
\hline $\begin{array}{l}\text { MARS-MFS Primary } \\
\text { Participant Ratings }\end{array}$ & $\begin{array}{l}\text { Memory Functioning Scale of the Memory Awareness } \\
\text { Rating Scale - Revised, Primary participants' self- } \\
\text { report of memory }\end{array}$ & \\
\hline MCI & Mild Cognitive Impairment & \\
\hline NAART & North American Adult Reading Test & \\
\hline
\end{tabular}




\begin{tabular}{|c|c|c|}
\hline Abbreviation/Label & Full Name/Description & $\begin{array}{l}\text { Meaning of HIGHER } \\
\text { TRANSFORMED scores for } \\
\text { subsequent analyses }\end{array}$ \\
\hline PANSE-NSE & $\begin{array}{l}\text { Positive and Negative Social Exchange measure - } \\
\text { Negative Social Exchange subscale }\end{array}$ & $\begin{array}{l}\text { Greater frequency of negative social } \\
\text { exchanges }\end{array}$ \\
\hline PD & Parkinson's disease & \\
\hline $\mathbf{P P}$ & Primary Participant & \\
\hline prSFS & $\begin{array}{l}\text { Peer Report Social Functioning Scale - the informant } \\
\text { ratings of primary participant social functioning }\end{array}$ & Lower levels of social functioning ${ }^{a_{\text {s }}}$ \\
\hline prSFS awareness score & $\begin{array}{l}\text { Discrepancy between primary participant \& Informant } \\
\text { ratings of primary participant social functioning on the } \\
\text { Peer Report Social Functioning Scale }\end{array}$ & $\begin{array}{l}\text { Lower levels of awareness \& } \\
\text { overestimation of social } \\
\text { functioning }{ }^{\mathrm{b}, \mathrm{f}}\end{array}$ \\
\hline $\begin{array}{l}\text { prSFS primary participant } \\
\text { rating }\end{array}$ & $\begin{array}{l}\text { Primary participant's self-report of their social } \\
\text { functioning on the Peer Report Social Functioning } \\
\text { Scale }\end{array}$ & \\
\hline SST & Socioemotional Selectivity Theory & \\
\hline ToM & Theory of Mind & \\
\hline Vascular Risk & Vascular Risk & Higher levels of vascular risk ${ }^{b, f}$ \\
\hline Visual Acuity & Visual Acuity & Better visual acuity ${ }^{\mathrm{a}, \mathrm{h}}$ \\
\hline $\begin{array}{l}{ }^{a} \text { Required a preliminary linear } \\
{ }^{b} \text { Required a preliminary linear } \\
{ }^{c} 100 \% \text { correct group versus le } \\
{ }^{d} \text { tranformation completed on b } \\
{ }^{e} \text { Note that the raw score, in wh } \\
\text { f Square Root transformation } \\
{ }^{g} \text { Natural Log transformation } \\
{ }^{h} \text { Reciprocal transformation }\end{array}$ & $\begin{array}{l}\text { sformation to reverse skew from negative to positive. } \\
\text { sformation to make all scores positive. } \\
\text { in } 100 \% \text { correct group. } \\
\text { rimary participant and informant scores } \\
\text { igher scores indicate better ToM, was used for comparis }\end{array}$ & $n$ with extant studies \\
\hline
\end{tabular}


Table 4

Characteristics of Primary Participants and Informants

\begin{tabular}{|c|c|c|}
\hline Characteristic & Primary Participants & Informants \\
\hline Age (years) & Mean $=68.79(\mathrm{SD}=7.75)$ & $\begin{array}{l}\text { Mean }=59.33 \\
(\mathrm{SD}=15.77)^{\mathrm{a}}\end{array}$ \\
\hline \multicolumn{3}{|l|}{ Gender } \\
\hline Male & $23(29.5 \%)$ & $18(23.1 \%)$ \\
\hline Female & $55(70.5)$ & $59(75.6 \%)$ \\
\hline \multicolumn{3}{|l|}{ Ethnicity } \\
\hline Non-Hispanic White & $72(92.3 \%)$ & $69(88.5 \%)$ \\
\hline African American & $5(6.4 \%)$ & $6(7.7 \%)$ \\
\hline Hispanic & $1(1.3 \%)$ & $2(2.6 \%)$ \\
\hline \multicolumn{3}{|l|}{ Education } \\
\hline Less than $12^{\text {th }}$ grade & $1(1.3 \%)$ & $3(3.9 \%)^{b}$ \\
\hline High School graduate (or GED) & $6(7.7 \%)$ & $8(10.4 \%)$ \\
\hline Partial College/Specialized & $27(34.6 \%)$ & $25(32.5 \%)$ \\
\hline \multicolumn{3}{|l|}{ Training } \\
\hline College Graduate & $16(20.5 \%)$ & $21(27.3 \%)$ \\
\hline Graduate Training & $28(35.9 \%)$ & $20(26.0 \%)$ \\
\hline \multicolumn{3}{|l|}{ Marital Status } \\
\hline Married/Partnered & $34(43.6 \%)$ & $36(47.4 \%)^{\mathrm{a}}$ \\
\hline Not Married & $44(56.4 \%)$ & $40(52.6 \%)$ \\
\hline \multicolumn{3}{|l|}{ Employment Status } \\
\hline Employed & $31(39.8 \%)$ & $40(52.0 \%)^{b}$ \\
\hline Retired/Unemployed & $47(60.2 \%)$ & $37(48.0 \%)$ \\
\hline \multicolumn{3}{|l|}{ Income } \\
\hline$<\$ 20,000$ & $12(17.9 \%)^{\mathfrak{c}}$ & $10(15.2 \%)^{\mathrm{d}}$ \\
\hline$\$ 20,000-\$ 59,999$ & $27(40.3 \%)$ & $29(43.9 \%)$ \\
\hline$\geq \$ 60,000$ & $28(41.8 \%)$ & $27(40.9 \%)$ \\
\hline \multicolumn{3}{|l|}{ Health Self-Rating } \\
\hline Poor or Fair & $9(11.5 \%)$ & $9(11.8 \%)^{\mathrm{a}}$ \\
\hline Good, Very Good, or Excellent & $69(88.5 \%)$ & $67(88.2 \%)$ \\
\hline
\end{tabular}

${ }^{a}$ Data available for 76 informants; ${ }^{b}$ Data available for 77 informants;

${ }^{c}$ Data available for 67 primary participants; ${ }^{d}$ Data available for 66 informants 
Table 5

Cognitive variables - Means and 95\% confidence intervals (or standard deviations)

\begin{tabular}{|c|c|c|c|c|c|}
\hline Construct & Measure & n & Mean & $\begin{array}{l}\text { Standard } \\
\text { Deviation }^{\mathrm{a}}\end{array}$ & $\begin{array}{l}\text { 95\% Confidence } \\
\text { Interval }\end{array}$ \\
\hline Verbal IQ & NAART $^{c}$ & 78 & $107.88^{\mathrm{c}}$ & 10.49 & $105.51-110.24$ \\
\hline \multirow[t]{2}{*}{ Global Cognitive Functioning } & $\begin{array}{l}\text { DRS-2 Total Scaled } \\
\text { Score }^{\mathrm{e}}\end{array}$ & 77 & $11.17^{\mathrm{e}}$ & 2.41 & $10.62-11.72$ \\
\hline & $\begin{array}{l}\text { (DRS-2 Total raw } \\
\text { score) }\end{array}$ & 77 & 138.44 & 4.99 & $137.31-139.57$ \\
\hline Memory & $\begin{array}{l}\text { HVLT-R Delayed } \\
\text { Recall T-Score }^{\mathrm{d}}\end{array}$ & 76 & $55.57^{\mathrm{d}}$ & & $52.92-57.97$ \\
\hline Frontal lobe functioning & FAB Total T-Score $^{d}$ & 78 & $59.43^{\mathrm{d}}$ & & $57.16-61.43$ \\
\hline Working Memory & $\begin{array}{l}\text { Letter-Number } \\
\text { Sequencing Total T- } \\
\text { Score }^{\mathrm{d}}\end{array}$ & 77 & $55.99^{\mathrm{d}}$ & 9.27 & $53.88-58.09$ \\
\hline \multicolumn{6}{|c|}{$\begin{array}{l}{ }^{a} \text { Not reported for transformed variables } \\
{ }^{b} \text { Based on transformed score } \\
{ }^{c} \text { Standard Score }(\text { mean }=100, \text { standard deviation }=15) \\
d^{d} \text {-score }(\text { mean }=50, \text { standard deviation }=10) \\
{ }^{e} \text { Scaled Score }(\text { mean }=10, \text { standard deviation }=3)\end{array}$} \\
\hline
\end{tabular}


Table 6

Characteristics Regarding the Relationships of Primary Participants and Informants ${ }^{\mathrm{a}}$

Characteristic

n $(\%)$

Mean (SD)

Informants Roles/Relationships with

Primary Participants

Spouse

$20(26.0 \%)$

Friend/Sibling

$33(42.9 \%)$

Child/Child-in-law

$16(20.8 \%)$

Other

$8(10.4 \%)$

Duration of the Informants' Relationship

with Primary Participants in years

$30.19(19.22)$

Frequency of Informants seeing/talking

with Primary Participants

Lives with Primary Participant

$21(27.3 \%)$

Daily

$23(29.9 \%)$

Several Times per Week

$24(31.2 \%)$

Once a week - monthly

$9(11.7 \%)$

${ }^{a}$ Data available for 77 pairs 
Table 7

EYES Test-Mean EYES Test scores in Recent Studies with older adults

\begin{tabular}{|c|c|c|c|c|c|}
\hline Study & $\mathbf{n}$ & Mean age (SD) & Mean & $\begin{array}{l}\text { Standard } \\
\text { Deviation }^{\mathrm{a}}\end{array}$ & $\begin{array}{l}95 \% \\
\text { Confidence } \\
\text { Interval } \\
\end{array}$ \\
\hline Current Study & 78 & $68.8(7.75)$ & 25.95 & & 24.8 .26 .9 \\
\hline data) (non-transformed & 78 & $68.8(7.75)$ & 25.41 & 4.7 & \\
\hline Bailey et al., 2008 & 49 & $70.4(5.5)$ & 21.2 & 6.3 & \\
\hline Bailey \& Henry, 2008 & 33 & $72.2(5.6)$ & 23.4 & 3.8 & \\
\hline Pardini et al., $2009^{b}$ & 30 & $\mathrm{~b}$ & 21.6 & 2.2 & \\
\hline
\end{tabular}


Table 8

Faux Pas Test Composite, FP HITS, and FP REJECTIONS scores in recent studies with older adults without clinical diagnosis

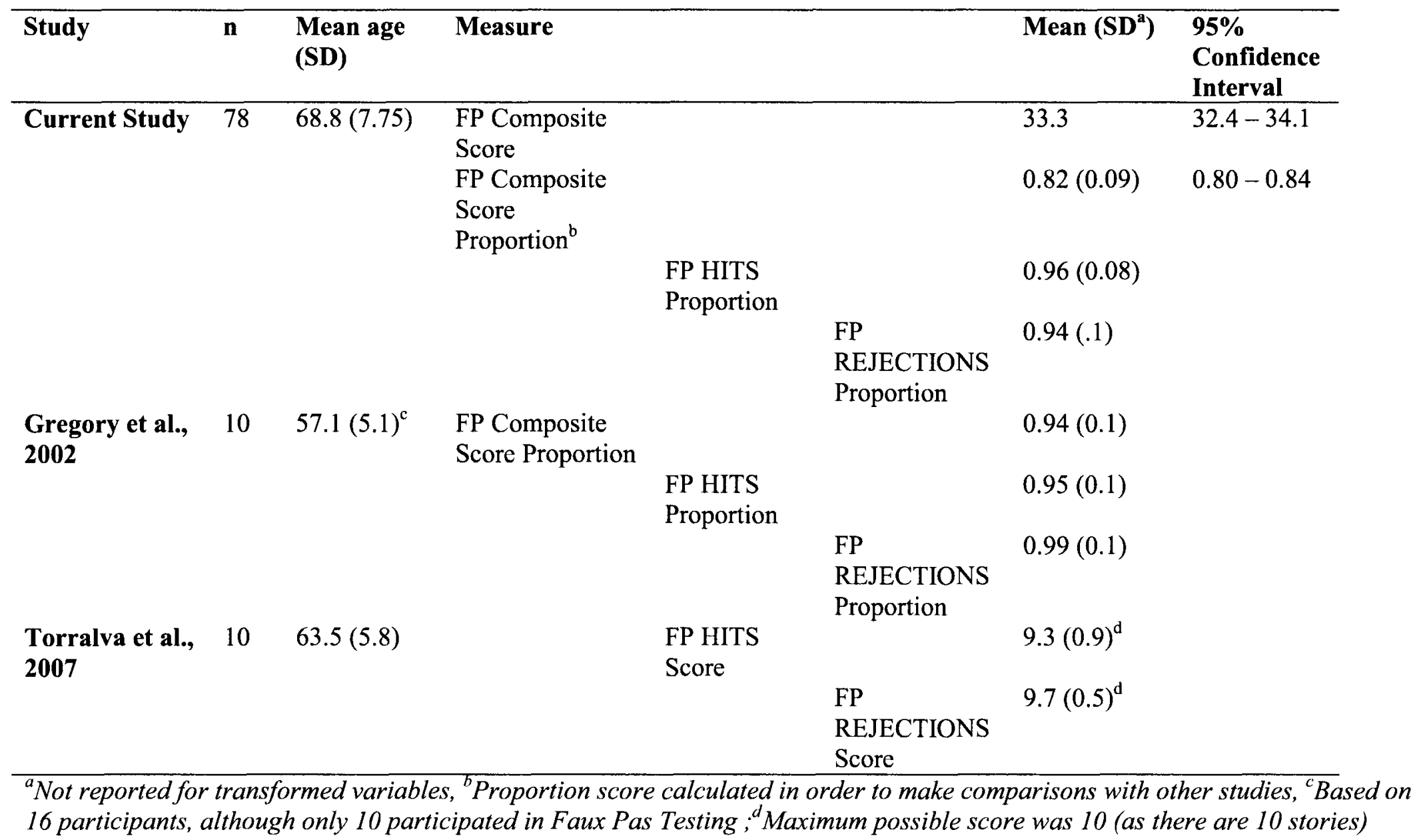


Table 9.

Social Relations variables - Means and 95\% confidence intervals

\begin{tabular}{lllll}
\hline Measure & $\begin{array}{l}\text { Possible } \\
\text { Score } \\
\text { Range }\end{array}$ & $\mathbf{n}$ & Mean $^{\mathrm{a}}$ & $\mathbf{9 5 \%}$ Confidence Interval \\
\hline Convoy & $\begin{array}{l}\text { Theoretically } \\
\text { Infinite }\end{array}$ & 77 & 24.60 & $21.44-27.98$ \\
PANSE-NSE & $0-96$ & 78 & 10.11 & $8.53-11.76$ \\
ISEL & $6-24$ & 78 & 22.28 & $21.84-22.66$ \\
prSFS & $1-4$ & 76 & 3.41 & $3.33-3.49$ \\
& & & & \\
\hline
\end{tabular}

${ }^{a}$ Based on transformed score

Note: Convoy $=$ measure of social network size

PANSE-NSE = Positive and Negative Social Exchanges Measure - Negative Social Exchange subscale $I S E L=$ Interpersonal Support Evaluation List - Short Form

prSFS = Peer-Report Social Functioning Scale 
Table 10.

Correlations between Social Relations, Health, Demographics, and Depression

\begin{tabular}{|c|c|c|c|c|c|c|c|c|c|c|}
\hline Measure & 1. & 2. & 3. & 4. & 5. & 6. & 7. & 8. & 9. & 10. \\
\hline 1. Convoy & -- & -.02 & $-.43 * *$ & 0 & $-.42 * *$ & .18 & .11 & -.09 & -.02 & $-.30 * *$ \\
\hline 2. PANSE-NSE & & -- & $.33 * *$ & .03 & .02 & -.16 & -.20 & -.08 & 0 & $.27^{*}$ \\
\hline 3. ISEL & & & -- & .17 & $.25^{*}$ & -.11 & $-.27^{*}$ & .06 & .09 & $.38 * *$ \\
\hline 4. PrSFS & & & & -- & $.24^{*}$ & -.16 & -.20 & .07 & -.19 & $.24^{*}$ \\
\hline 5. Vascular Risk & & & & & -- & $-.44 * *$ & $-.43 * *$ & -.11 & -.17 & .21 \\
\hline 6. CMI & & & & & & -- & .22 & .11 & -.08 & -.06 \\
\hline $\begin{array}{l}\text { 7. PP Health Self- } \\
\text { Rating }\end{array}$ & & & & & & & -- & .12 & .21 & $-.48^{* *}$ \\
\hline 8. PP Age & & & & & & & & - & -.06 & -.04 \\
\hline 9. PP Education & & & & & & & & & - & .012 \\
\hline 10. PP GDS & & & & & & & & & & $\ldots$ \\
\hline
\end{tabular}

${ }^{*} p<.05,{ }^{* *} p<.01$

Note: Convoy = measure of social network size; PANSE-NSE = Positive and Negative Social Exchanges Measure - Negative Social Exchange subscale; ISEL = Interpersonal Support Evaluation List - Short Form; prSFS = Peer-Report Social Functioning Scale Vascular Risk = cumulative vascular risk score; CMI = Charlson Comorbidity Index; PP GDS = Primary Participant Geriatric Depression Scale score 
Measures of awareness - Means and Standard Deviations ${ }^{a}$ (or 95\% confidence intervals)

\begin{tabular}{llllllll}
\hline Measure & N & $\begin{array}{l}\text { Mean } \\
\text { Discrepancy }\end{array}$ & SD $^{\mathbf{a}}$ & $\begin{array}{l}\text { 95\% Confidence } \\
\text { Interval }\end{array}$ & $\begin{array}{l}\text { n (\%) under- } \\
\text { estimating } \\
\text { functioning }\end{array}$ & $\begin{array}{l}\text { n (\%) 0 } \\
\text { discrepancy }\end{array}$ & $\begin{array}{l}\text { n (\%) over- } \\
\text { estimating } \\
\text { functioning }\end{array}$ \\
\hline $\begin{array}{l}\text { PrSFS } \\
\text { Awareness }\end{array}$ & 76 & -0.82 & $\mathrm{a}$ & $(-3.37)-(+1.80)$ & $41(53.9 \%)$ & $3(3.9 \%)$ & $32(42.2 \%)$ \\
$\begin{array}{l}\text { MARS- } \\
\text { MFS }\end{array}$ & 76 & -1.22 & 8.09 & $(-3.07)-(+0.63)$ & $47(61.8 \%)$ & $3(3.9 \%)$ & $26(34.3 \%)$ \\
$\begin{array}{l}\text { Awareness } \\
\text { HVLT-R }\end{array}$ & 78 & -0.23 & 1.12 & $(-0.48)-(+0.02)$ & $34(43.6 \%)$ & $25(32.1 \%)$ & $19(24.4 \%)$ \\
$\begin{array}{l}\text { Prediction } \\
\text { HVLT-R } \\
\text { Postdiction }\end{array}$ & 77 & -0.01 & 0.90 & $(-0.22)-(+0.19)$ & $24(31.2 \%)$ & $31(40.3 \%)$ & $22(28.6 \%)$ \\
$\begin{array}{l}\text { LN-Seq } \\
\text { Prediction }\end{array}$ & 77 & -0.75 & 0.83 & $(-0.94)-(-0.56)$ & $49(63.6 \%)$ & $25(32.5 \%)$ & $3(3.9 \%)$ \\
$\begin{array}{l}\text { LN-Seq } \\
\text { Postdiction }\end{array}$ & 76 & -0.71 & 1.04 & $(-0.95)-(-0.47)$ & $47(61.8 \%)$ & $20(26.3 \%)$ & $9(11.8 \%)$ \\
\hline
\end{tabular}

${ }^{\mathrm{a}}$ Not reported for transformed variables

${ }^{b}$ Based on transformed score

Note: prSFS Awareness=Discrepancy between primary participant (PP) and informant (IN) ratings of PP social functioning on the prSFS

MARS-MFS Awareness = Discrepancy between PP and IN ratings of PP memory on the MARS-MFS

$H V L T-R$ Prediction Awareness = Discrepancy between prediction and actual performance on HVLT-R Trial 1

HVLT-R Postdiction Awareness = Discrepancy between prediction and actual performance on HVLT-R Total Recall

$L N$-Seq Prediction Awareness = Discrepancy between prediction and actual performance on Letter-Number Sequencing subtest

$L N-S e q$ Postdiction Awareness = Discrepancy between postdiction and actual performance on Letter-Number Sequencing subtest 
Table 12

Correlations between Awareness, Health, Demographics, and depression

\begin{tabular}{|c|c|c|c|c|c|c|c|c|c|c|c|c|}
\hline Measure & 1. & $2 .^{a}$ & 3. & 4. & 5. & 6. & 7. & 8. & 9. & 10. & 11. & 12. \\
\hline 1. PrSFS Awareness & -- & $.28^{*}$ & .06 & .02 & .11 & .04 & $.26^{*}$ & -.18 & -.11 & -.04 & -.04 & .21 \\
\hline $\begin{array}{l}\text { 2. MARS-MFS } \\
\text { Awareness }^{\mathrm{a}}\end{array}$ & & -- & .03 & -.02 & .12 & .13 & .07 & -.12 & .04 & -.11 & .20 & .14 \\
\hline $\begin{array}{l}\text { 3. HVLT-R Prediction } \\
\text { Awareness }\end{array}$ & & & -- & $.43^{* *}$ & .09 & .18 & .10 & -.16 & .07 & -.11 & .14 & -.07 \\
\hline $\begin{array}{l}\text { 4. HVLT-R Postdiction } \\
\text { Awareness }\end{array}$ & & & & -- & .18 & .22 & $-.23^{\mathrm{b}}$ & .03 & 0 & .20 & $-.26^{*}$ & .21 \\
\hline $\begin{array}{l}\text { 5. LN-Seq Prediction } \\
\text { Awareness }\end{array}$ & & & & & -- & $.65^{* *}$ & .08 & .07 & 0 & -.03 & 0 & -.09 \\
\hline $\begin{array}{l}\text { 6. LN-Seq Postdiction } \\
\text { Awareness }\end{array}$ & & & & & & -- & .10 & -.13 & 0 & -.19 & .11 & -.15 \\
\hline 7. Vascular Risk & & & & & & & -- & $-.44 * *$ & $-.43 * *$ & -.11 & -.17 & .21 \\
\hline 8. CMI & & & & & & & & -- & .22 & .11 & -.08 & -.06 \\
\hline $\begin{array}{l}\text { 9. PP Health Self- } \\
\text { Rating }\end{array}$ & & & & & & & & & -- & .12 & .21 & $-.48 * *$ \\
\hline 10. PP Age & & & & & & & & & & -- & -.06 & -.04 \\
\hline 11. PP Education & & & & & & & & & & & -- & .012 \\
\hline 12. PP GDS & & & & & & & & & & & & -- \\
\hline
\end{tabular}


Table 13.

Correlations between Performance-Based Measures of Awareness and Associated Cognitive Variables

\begin{tabular}{|c|c|c|c|c|}
\hline & $\begin{array}{l}\text { Associated } \\
\text { Cognitive } \\
\text { Variable: }\end{array}$ & $\begin{array}{l}\text { HVLT-R Trial } 1 T \\
\text { score }\end{array}$ & $\begin{array}{l}\text { HVLT-R Total Recall } T \\
\text { score }\end{array}$ & $\begin{array}{l}\text { LN-Sequencing } \\
\text { Total } T \text { score }\end{array}$ \\
\hline $\begin{array}{l}\text { Awareness } \\
\text { Variable: }\end{array}$ & & & & \\
\hline $\begin{array}{l}\text { HVLT-R } \\
\text { Prediction } \\
\text { Awareness }\end{array}$ & & $-.75^{* *}$ & & \\
\hline $\begin{array}{l}\text { HVLT-R } \\
\text { Postdiction } \\
\text { Awareness }\end{array}$ & & & $-.27^{*}$ & \\
\hline $\begin{array}{l}\text { LN-Seq } \\
\text { Prediction } \\
\text { Awareness }\end{array}$ & & & & $-.35^{* *}$ \\
\hline $\begin{array}{l}\text { LN-Seq } \\
\text { Postdiction } \\
\text { Awareness }\end{array}$ & & & & $-.31 * *$ \\
\hline
\end{tabular}

*Significant at $\mathrm{p}<.05 ;{ }^{* *}$ Significant at $\mathrm{p}<.01$ 
Table 14.

Significant Mean Differences between Men and Women on the HVLT-R performance-based Awareness Measures

\begin{tabular}{llll}
\hline Variable & Statistic & $\begin{array}{l}\text { Mean for Males } \\
\text { (SD) }\end{array}$ & Mean for Females (SD) \\
\hline $\begin{array}{l}\text { HVLT-R Prediction } \\
\text { Awareness }\end{array}$ & $\mathrm{t}(76)=-3.40, \mathrm{p}<.01$ & $0.41(1.01)$ & $-0.49(1.07)$ \\
$\begin{array}{l}\text { HVLT-R Postdiction } \\
\text { Awareness }\end{array}$ & $\mathrm{t}(75)=-2.72, \mathrm{p}<.01$ & $0.41(0.91)$ & $-0.18(0.84)$ \\
\hline
\end{tabular}


Table 15.

Significant Differences between the African-American group and the non-Hispanic White group

\begin{tabular}{llll}
\hline Variable & Statistic & $\begin{array}{l}\text { African-American mean (SD or } \\
\mathbf{9 5 \%} \text { CI) }\end{array}$ & $\begin{array}{l}\text { Non-Hispanic White mean } \\
\text { (SD or 95\% CI) }\end{array}$ \\
\hline FP Composite & $\mathrm{t}(75)=-3.79, \mathrm{p}<.001$ & $26.7195 \% \mathrm{CI}[18.15,33.27]$ & $33.6195 \% \mathrm{CI}[32.83,34.35]$ \\
$\begin{array}{l}\text { HVLT-R } \\
\begin{array}{l}\text { Prediction } \\
\text { Awareness }\end{array}\end{array}$ & $\mathrm{t}(75)=-2.16, \mathrm{p}=.03$ & $0.80(\mathrm{SD}=0.84)$ & $-0.28(\mathrm{SD}=1.09)$ \\
$\begin{array}{l}\text { Health (self- } \\
\text { rating) }\end{array}$ & $\mathrm{t}(75)=2.11, \mathrm{p}<.05$ & $1.80(\mathrm{SD}=1.30)$ & $2.63(\mathrm{SD}=0.81)$ \\
$\begin{array}{l}\text { Education } \\
\begin{array}{l}\text { Verbal IQ } \\
\text { (NAART) }\end{array}\end{array}$ & $\mathrm{t}(75)=1.91, \mathrm{p}=.06$ & $3.00(\mathrm{SD}=0.71)$ & $3.90(\mathrm{SD}=1.04)$ \\
\hline
\end{tabular}


Table 16.

Correlations between ToM and Health Variables, Demographic and Depression

\begin{tabular}{|c|c|c|c|c|c|c|c|c|}
\hline Measure & 1. & 2. & 3. & 4. & 5. & 6. & 7. & 8. \\
\hline 1. FP Composite & -- & .10 & 0 & $.24^{*}$ & -.15 & .05 & -.17 & .05 \\
\hline 2. EYES & & -- & .09 & 0 & -.20 & $.33 * *$ & -.19 & -.09 \\
\hline 3. Vascular Risk & & & -- & $-.44 * *$ & $-.43 * *$ & -.11 & -.17 & .21 \\
\hline 4. CMI & & & & -- & .22 & .11 & -.08 & -.06 \\
\hline 5. PP Health Self-Rating & & & & & -- & .12 & .21 & $-.48 * *$ \\
\hline 6. PP Age & & & & & & -- & -.06 & -.04 \\
\hline 7. PP Education & & & & & & & -- & .012 \\
\hline 8. PP GDS & & & & & & & & - \\
\hline
\end{tabular}

${ }^{*} p<.05, * * p<.01$

Note: Vascular Risk = cumulative vascular risk score; $C M I=$ Charlson Comorbidity Index; PP GDS = Primary Participant Geriatric Depression Scale score 
Table 17

Correlations between ToM and Cognition

\begin{tabular}{|c|c|c|c|c|c|c|c|c|}
\hline Measure & 1. & 2. & 3. & 4. & 5. & 6. & 7. & 8. \\
\hline 1. FP Composite & -- & .10 & -.03 & -.20 & -.16 & .14 & .15 & -.19 \\
\hline 2. EYES & & -- & $-.27^{*}$ & $-.42 *$ & $-.38 * *$ & $.23^{*}$ & .22 & $-.33 * *$ \\
\hline 3. Visual Acuity & & & -- & $.27^{*}$ & .15 & -.14 & -.05 & .15 \\
\hline 4. NAART & & & & -- & $.51 * *$ & $-.28^{*}$ & $-.35 * *$ & $.583^{* *}$ \\
\hline 5. DRS-2 & & & & & -- & $-.40 * *$ & $-.34 * *$ & $.39 * *$ \\
\hline $\begin{array}{l}\text { 6. HVLT-R Delayed } \\
\text { Recall }\end{array}$ & & & & & & -- & $.26^{*}$ & $-.35 * *$ \\
\hline 7. $\mathbf{F A B}$ & & & & & & & -- & $-.33 * *$ \\
\hline 8. LN-Seq & & & & & & & & -- \\
\hline
\end{tabular}

${ }^{*} p<.05,{ }^{* *} p<.01$ 
Table 18

Correlations between Social Relations and Cognition

\begin{tabular}{|c|c|c|c|c|c|c|c|c|c|c|}
\hline Measure & 1. & 2. & 3. & 4. & 5. & 6. & 7. & 8. & 9. & 10. \\
\hline 1. Convoy & -. & -.02 & $-.43 * *$ & 0 & .13 & .17 & $.28^{*}$ & $-.33 * *$ & -.11 & $.28^{*}$ \\
\hline 2. PANSE-NSE & & -- & $.33^{* *}$ & .03 & -.18 & -.05 & .03 & -.08 & .12 & -.04 \\
\hline 3. ISEL & & & -- & .17 & -.16 & -.08 & $-.24^{*}$ & .07 & .19 & -.22 \\
\hline 4. prSFS & & & & -- & -.13 & -.03 & -.07 & $-.27^{*}$ & .12 & 0 \\
\hline 5. Visual Acuity & & & & & -- & $.27^{*}$ & .15 & -.14 & -.05 & .15 \\
\hline 6. NAART & & & & & & -- & $.51^{* *}$ & $-.28 *$ & $-.35^{* *}$ & $.58 * *$ \\
\hline 7. DRS-2 & & & & & & & -- & $-.40 * *$ & $-.34 * *$ & $.39 * *$ \\
\hline $\begin{array}{l}\text { 8. HVLT-R Delayed } \\
\text { Recall }\end{array}$ & & & & & & & & -- & $.26^{*}$ & $-.35^{* *}$ \\
\hline 9. FAB & & & & & & & & & - & $-.33 * *$ \\
\hline 10. LN-Seq & & & & & & & & & & -- \\
\hline
\end{tabular}

Note: Convoy = measure of social network size; PANSE-NSE = Positive and Negative Social Exchanges Measure - Negative Social Exchanges; ISEL = Interpersonal Support Evaluation List - Short Form; prSFS = Peer-Report Social Functioning Scale 
Table 19.

Correlations between Awareness and Cognition

\begin{tabular}{|c|c|c|c|c|c|c|c|c|c|c|c|c|}
\hline Measure & 1. & $2 .^{a}$ & 3. & 4. & 5. & 6. & 7. & 8. & 9. & 10. & 11. & 12. \\
\hline 1. prSFS Awareness & -- & $.28^{*}$ & .06 & .02 & .11 & .04 & .05 & .13 & .09 & -.19 & .07 & 0 \\
\hline $\begin{array}{l}\text { 2. MARS-MFS } \\
\text { Awareness }^{\mathrm{a}}\end{array}$ & & -- & .03 & -.02 & .12 & .13 & .05 & .17 & -.07 & -.14 & .06 & -.02 \\
\hline 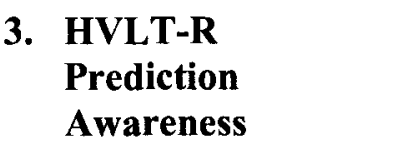 & & & -- & $.429 * *$ & .09 & .18 & .05 & -.05 & $-.23^{*}$ & $.55^{* *}$ & $.31 * *$ & -.07 \\
\hline 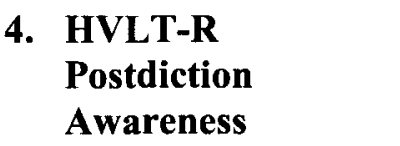 & & & & -- & .18 & .22 & .20 & .18 & -.01 & .18 & .12 & .19 \\
\hline $\begin{array}{l}\text { 5. LN-Seq Prediction } \\
\text { Awareness }\end{array}$ & & & & & -- & $.65^{* *}$ & .09 & -.10 & -.07 & .11 & .10 & $-.35^{* *}$ \\
\hline $\begin{array}{l}\text { 6. LN-Seq Postdiction } \\
\text { Awareness }\end{array}$ & & & & & & -- & .10 & 0 & .03 & .13 & .10 & $-.31^{* *}$ \\
\hline 7. Visual Acuity & & & & & & & -- & $.27^{*}$ & .15 & -.14 & -.05 & .15 \\
\hline 8. NAART & & & & & & & & -- & $.51 * *$ & $-.28^{*}$ & $-.35 * *$ & $.58 * *$ \\
\hline 9. DRS-2 & & & & & & & & & -- & $-.40 * *$ & $-.34 * *$ & $.39 * *$ \\
\hline $\begin{array}{l}\text { 10. HVLT-R Delayed } \\
\text { Recall }\end{array}$ & & & & & & & & & & -- & $.26 *$ & $-.35^{* *}$ \\
\hline 11. FAB & & & & & & & & & & & -- & $-.33^{* *}$ \\
\hline 12. LN-Seq & & & & & & & & & & & & -- \\
\hline
\end{tabular}


Table 20.

Significant Mean Differences on Cognition between Impaired and Non-Impaired Groups, as measured by ToM tests

\begin{tabular}{|c|c|c|c|c|}
\hline $\begin{array}{l}\text { ToM Measure } \\
\text { of Impairment }\end{array}$ & Variable & Statistic & $\begin{array}{l}\text { Mean for Impaired (SD or } \\
95 \% \mathrm{CI} \text { ) }\end{array}$ & $\begin{array}{l}\text { Mean for Non-Impaired } \\
\text { (SD or } 95 \% \mathrm{CI} \text { ) }\end{array}$ \\
\hline FP Composite & $\begin{array}{l}\text { Estimated Verbal } \\
\text { IQ (NAART) }\end{array}$ & $t(76)=-2.49, p<.05$ & $103.58(11.09)$ & $109.76(9.72)$ \\
\hline EYES & $\begin{array}{l}\text { Estimated Verbal } \\
\text { IQ (NAART) }\end{array}$ & $\begin{array}{l}\mathrm{t}(76)=-3.88, \mathrm{p}< \\
.001\end{array}$ & $95.35(10.17)$ & $109.31(9.59)$ \\
\hline EYES & $\begin{array}{l}\text { Global Cognition } \\
\text { (DRS-2 Scaled } \\
\text { Score) }\end{array}$ & $\mathrm{t}(75)=-3.36, \mathrm{p}<.01$ & $8.63(1.85)$ & $11.46(2.31)$ \\
\hline EYES & $\begin{array}{l}\text { Working } \\
\text { Memory (LN- } \\
\text { Seq) }\end{array}$ & $\mathrm{t}(75)=-2.86, \mathrm{p}<.01$ & $47.50(8.83)$ & $56.97(8.86)$ \\
\hline EYES & $\begin{array}{l}\text { Frontal Lobe } \\
\text { Functioning } \\
\text { (FAB } T \text { score) }\end{array}$ & $\mathrm{t}(76)=2.09, \mathrm{p}<.05$ & $51.72(95 \%$ CI $[39.47,60.55])$ & $\begin{array}{l}60.16 \\
(95 \% \text { CI }[57.90,62.13])\end{array}$ \\
\hline $\begin{array}{l}\text { FP } \\
\text { REJECTIONS }\end{array}$ & $\begin{array}{l}\text { Frontal Lobe } \\
\text { Functioning } \\
\text { (FAB } T \text { score) }\end{array}$ & $\mathrm{t}(76)=2.19, \mathrm{p}<.05$ & $\stackrel{*}{52.41}(95 \% \mathrm{CI}[44.73,58.56])$ & $\begin{array}{l}60.29 \\
(95 \% \text { CI }[57.96,62.31])\end{array}$ \\
\hline
\end{tabular}


Table 21

Correlations between ToM and Social Relations Variables

\begin{tabular}{lllllll}
\hline Measure & $\mathbf{1 .}$ & $\mathbf{2 .}$ & $\mathbf{3 .}$ & $\mathbf{4 .}$ & $\mathbf{5 .}$ & $\mathbf{6 .}$ \\
\hline 1. FP Composite & -- & .10 & -.01 & .05 & -.01 & -.08 \\
2. EYES & & -- & -.10 & .07 & .11 & 0 \\
3. Convoy & & -- & -.02 & $-.43^{* *}$ & 0 \\
4. PANSE-NSE & & & - & & $.33^{* *}$ & .03 \\
5. ISEL & & & & -- & .17 \\
6. prSFS & & & & & & -
\end{tabular}

${ }^{*} p<.05,{ }^{* *} p<.01$

Note: PANSE-NSE = Positive and Negative Social Exchange Measure-Negative Social Exchange subscale; $I S E L=$ Interpersonal Support Evaluation List -Short Form; prSFS = Peer-Report Social Functioning Scale 
Table 22.

Correlations between ToM and Awareness Variables

\begin{tabular}{|c|c|c|c|c|c|c|c|c|}
\hline Measure & 1. & 2. & 3. & 4." & 5. & 6. & 7. & 8. \\
\hline 1. FP Composite & -- & .10 & -.10 & $-.25^{*}$ & .08 & .13 & -.03 & -.11 \\
\hline 2. EYES & & -- & -.14 & -.15 & .18 & -.04 & .04 & -.05 \\
\hline 3. prSFS Awareness & & & -- & $.28^{*}$ & .06 & .02 & .11 & .04 \\
\hline 4. MARS-MFS Awareness ${ }^{2}$ & & & & -- & .03 & -.02 & .12 & .13 \\
\hline $\begin{array}{l}\text { 5. HVLT-R Prediction } \\
\text { Awareness }\end{array}$ & & & & & -- & $.429 * *$ & .09 & .18 \\
\hline $\begin{array}{l}\text { 6. HVLT-R Postdiction } \\
\text { Awareness }\end{array}$ & & & & & & - & .18 & .22 \\
\hline $\begin{array}{l}\text { 7. LN Seq Prediction } \\
\text { Awareness }\end{array}$ & & & & & & & -- & $.65^{* *}$ \\
\hline $\begin{array}{l}\text { 8. LN Seq Postdiction } \\
\text { Awareness }\end{array}$ & & & & & & & & -- \\
\hline
\end{tabular}


Table 23.

Significant Mean Differences on Awareness Measures between Impaired and Non-Impaired Groups, as measured by ToM tests

\begin{tabular}{|c|c|c|c|c|}
\hline $\begin{array}{l}\text { ToM Measure } \\
\text { of Impairment }\end{array}$ & $\begin{array}{l}\text { Awareness } \\
\text { Variable }\end{array}$ & Statistic & $\begin{array}{l}\text { Mean for Impaired (SD or } \\
95 \% \mathrm{CI} \text { ) }\end{array}$ & $\begin{array}{l}\text { Mean for Non-Impaired } \\
\text { (SD or } 95 \% \text { CI) }\end{array}$ \\
\hline FP Composite & $\begin{array}{l}\text { MARS-MFS } \\
\text { Awareness }\end{array}$ & $t(74)=-2.18, p<.05$ & $-4.22(7.54)$ & $0.08(8.05)$ \\
\hline $\begin{array}{l}\text { FP } \\
\text { REJECTIONS }\end{array}$ & $\begin{array}{l}\text { MARS-MFS } \\
\text { Awareness }\end{array}$ & $\mathrm{t}(74)=-3.09, \mathrm{p}<.01$ & $-8.20(8.15)$ & $-0.17(7.60)$ \\
\hline $\begin{array}{l}\text { FP } \\
\text { REJECTIONS }\end{array}$ & $\begin{array}{l}\text { HVLT-R } \\
\text { Postdiction } \\
\text { Awareness }\end{array}$ & $\mathrm{t}(75)=1.98, \mathrm{p}=.052^{\mathrm{a}}$ & $0.50(0.71)$ & $-.09 \quad(0.90)$ \\
\hline EYES & prSFS Awareness & $\mathrm{t}(74)=-1.86, p=.068^{\mathrm{a}}$ & $\begin{array}{l}-7.24(95 \% \mathrm{CI}[-15.98 \\
5.09])^{\mathrm{b}}\end{array}$ & $\begin{array}{l}-0.06 \\
(95 \% \mathrm{CI}[-2.57,2.70])^{\mathrm{b}}\end{array}$ \\
\hline EYES & $\begin{array}{l}\text { LN-Seq } \\
\text { Prediction } \\
\text { Awareness }\end{array}$ & $\mathrm{t}(75)=1.84, \mathrm{p}=.07^{\mathrm{a}}$ & $-0.25(0.89)$ & $-0.81(0.81)$ \\
\hline
\end{tabular}

\footnotetext{
transformed scores were converted back to raw scores for reporting of means and $95 \%$ confidence intervals
} 
Table 24

Reference Table for significant relationships between ToM variables and selected study variables across analyses methods

\begin{tabular}{|c|c|c|c|c|c|c|}
\hline $\begin{array}{l}\text { General } \\
\text { Construct }\end{array}$ & Study Variable & EYES & $\begin{array}{l}\text { EYES } \\
\text { Impairment }\end{array}$ & $\begin{array}{l}\text { Faux Pas } \\
\text { Composite }\end{array}$ & $\begin{array}{l}\text { Faux Pas } \\
\text { Composite } \\
\text { Impairment }\end{array}$ & $\begin{array}{l}\text { Faux Pas } \\
\text { REJECTION } \\
\text { S Impairment }\end{array}$ \\
\hline \multirow[t]{3}{*}{ Demographics } & Age & $* *$ & $\mathrm{x}$ & & & \\
\hline & Education & & & & & \\
\hline & Ethnicity & & & $* *$ & * & $\mathrm{x}$ \\
\hline \multirow[t]{2}{*}{ Health } & CMI & & & $*$ & & \\
\hline & PD screener & & & & & \\
\hline Depression & GDS & & $\mathrm{x}$ & & & \\
\hline \multirow[t]{3}{*}{ Cognition } & NAART & ** & $* *$ & & $*$ & \\
\hline & DRS-2 & $* *$ & ** & & & \\
\hline & \begin{tabular}{|l|} 
HVLT-R Delayed Recall \\
\end{tabular} & $*$ & & & & \\
\hline \multirow{2}{*}{ Social Relations } & \begin{tabular}{|l} 
PANSE-NSE \\
\end{tabular} & & & & & \\
\hline & prSFS & & & & & \\
\hline \multirow[t]{6}{*}{ Awareness } & MARS-MFS Awareness & & & $*$ & $*$ & $* *$ \\
\hline & prSFS Awareness & & $x$ & & & \\
\hline & HVLT-R Prediction Awareness & & & & & \\
\hline & LN-Seq Prediction Awareness & & $\mathrm{x}$ & & & \\
\hline & HVLT-R Postdiction Awareness & & & & & $\mathrm{x}$ \\
\hline & LN-Seq Postdiction Awareness & & & $*$ a & & \\
\hline
\end{tabular}

Note: $\mathrm{x}=$ approached significance, ${ }^{*}=$ significant at $\mathrm{p}<.05,{ }^{* *}=$ significant at $\mathrm{P}<.01$,

${ }^{a}$ only significant when minority participants removed from analysis 
Figure 1.

Model of relationship between ToM and social variables

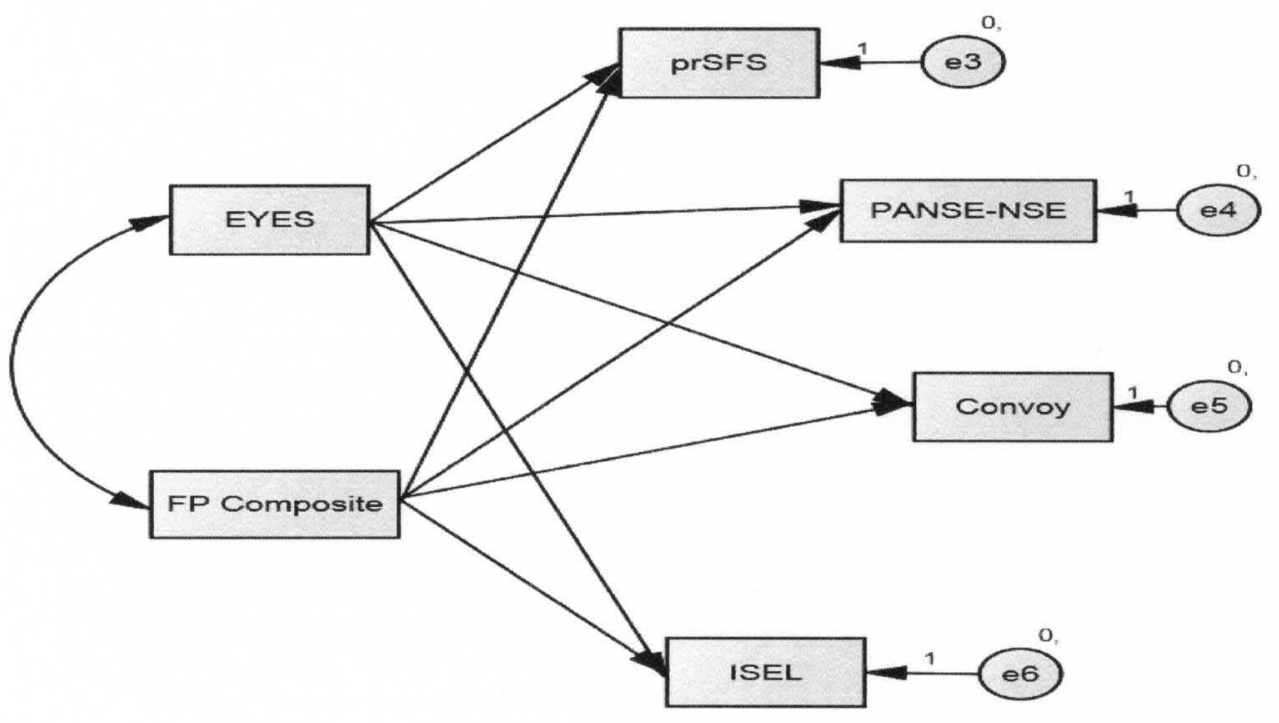

Note: $\mathbf{E Y E S}=$ Reading the EYES in the Mind - Revised score

FP Composite Score $=$ Faux Pas Composite score

prSFS = Peer Report Social Functioning Scale

PANSE-NSE = Positive and Negative Social Exchange measure - Negative Social

Exchange subscale

Convoy $=$ Convoy Measure for social network size

ISEL = Interpersonal Support Evaluation List - Short Form 
Figure 2.

Model of hypotheses related to ToM and awareness

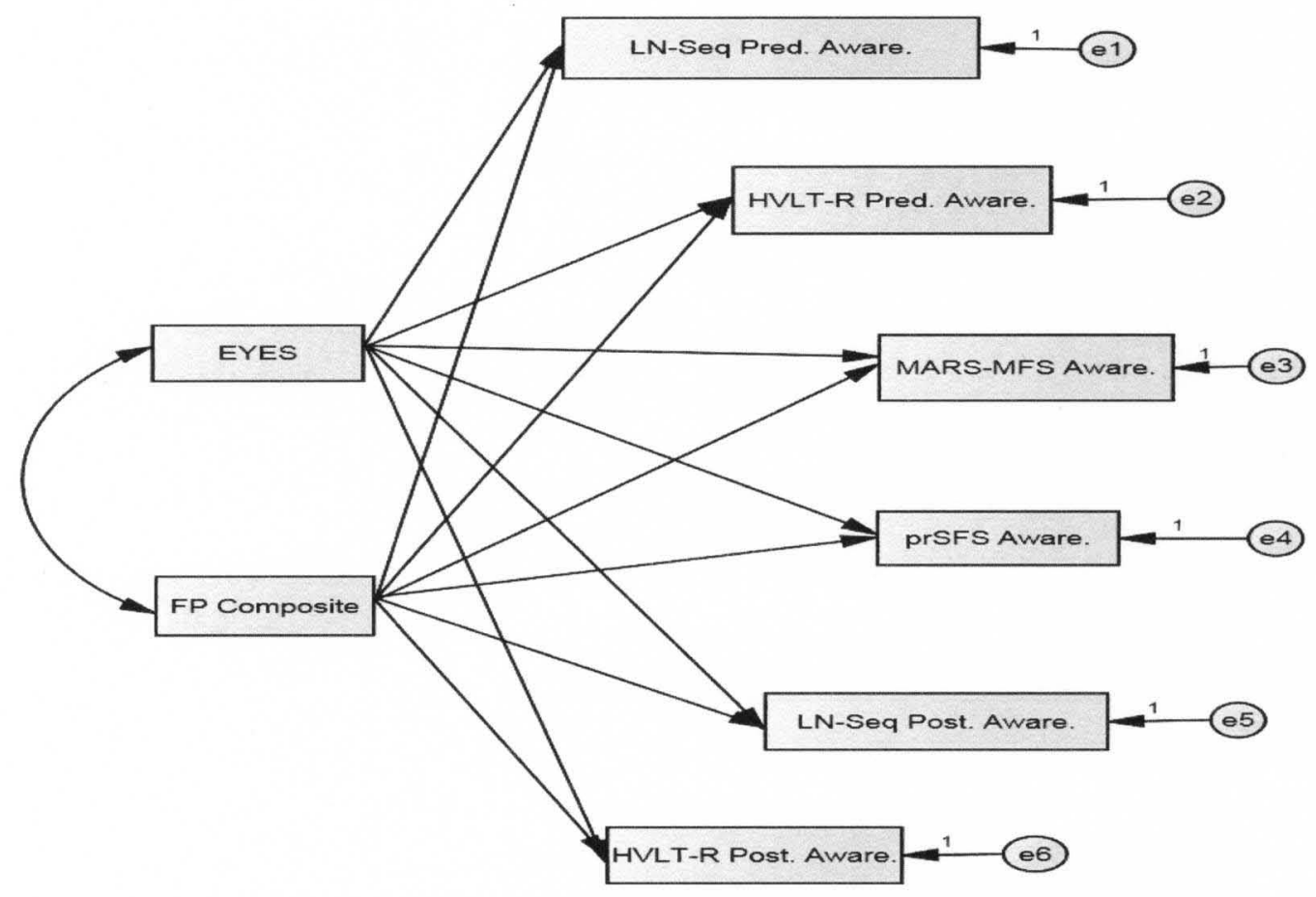

Note: $\mathbf{E Y E S}=$ Reading the EYES in the Mind - Revised score

FP Composite Score $=$ Faux Pas Composite score

$\mathbf{L N}$-Seq Prediction Awareness = Discrepancy between predicted performance and actual performance on the Letter-Number Sequencing subtest

HVLT-R Prediction Awareness = Discrepancy between predicted performance and actual performance on HVLT-R.

MARS-MFS Awareness = Discrepancy score between informant and primary participant ratings of primary participant memory on MARS-MFS

prSFS Awareness = Discrepancy score between informant and primary participant ratings of primary participant social functioning on prSFS.

LN-Seq Postdiction Awareness = Discrepancy between postdicted performance and actual performance on Letter-Number Sequencing

HVLT-R Postdiction Awareness = Discrepancy between postdicted performance and actual performance on HVLT-R. 
Figure 3.

Model of ToM and Social Relations ${ }^{\mathrm{a}}$

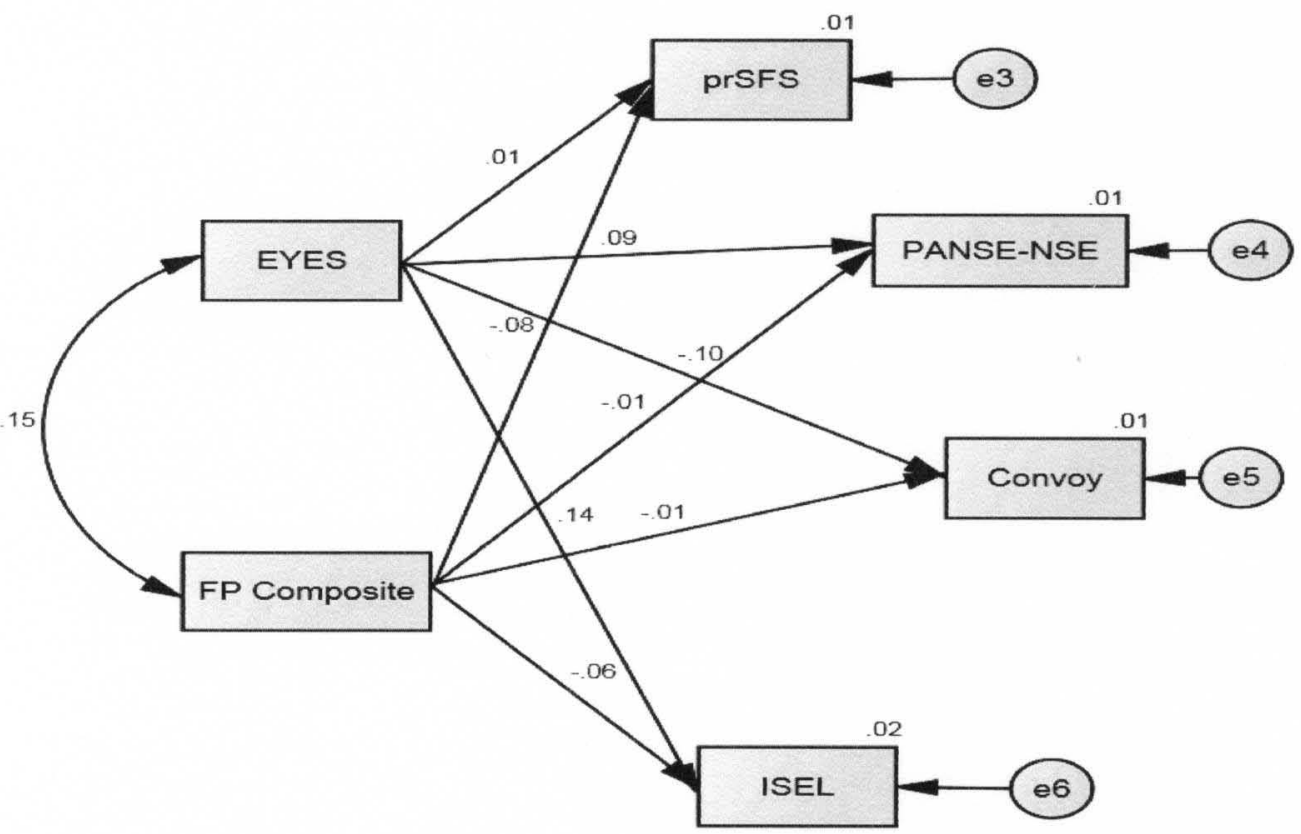

${ }^{a}$ Based on 75 participants and their informants

Note: $\boldsymbol{E Y E S}=$ Reading the Eyes in the Mind Test

Faux Pas $=$ Faux Pas Test

prSFS = Peer-Report Social Functioning Scale (prSFS) Informant report

PANSE-NSE = Negative Social Exchanges as measured by the Positive and Negative Social Exchange (PANSE) measure;

Convoy $=$ measure of social network size

ISEL = Interpersonal Support Evaluation List - Short Form (ISEL) 
Figure 4.

Model of ToM and Awareness ${ }^{a}$

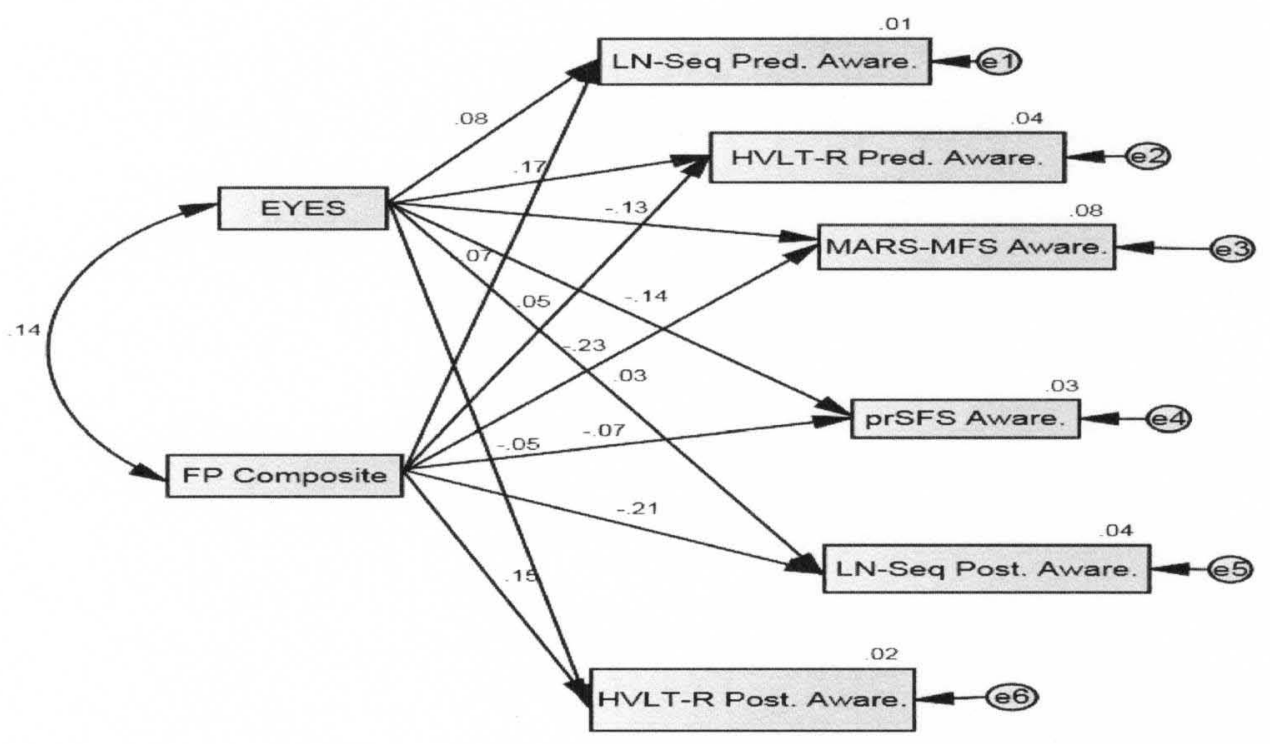

${ }^{a}$ Based on 72 participants and their informants

Note: $\mathbf{E Y E S}=$ Reading the EYES in the Mind - Revised score

FP Composite Score $=$ Faux Pas Composite score

LN-Seq Prediction Awareness = Discrepancy between predicted performance and actual performance on the Letter-Number Sequencing subtest

HVLT-R Prediction Awareness = Discrepancy between predicted performance and actual performance on HVLT-R.

MARS-MFS Awareness= Discrepancy score between informant and primary participant ratings of primary participant memory on MARS-MFS

prSFS Awareness = Discrepancy score between informant and primary participant ratings of primary participant social functioning on prSFS.

LN-Seq Postdiction Awareness = Discrepancy between postdicted performance and actual performance on Letter-Number Sequencing

HVLT-R Postdiction Awareness = Discrepancy between postdicted performance and actual performance on HVLT-R. 


\title{
CURRICULUM VITAE
}

\author{
Sarah V. Rowe, M.A.
}

\section{EDUCATION \& TRAINING}

Ph.D. - Clinical Psychology - July 2005 - Present

M.A. - Clinical Psychology - December 2007

University of Louisville, Louisville, $\mathrm{KY}$

- APA-Accredited Clinical Psychology Ph.D. Program

- Expected Date of Graduation: December 2011, GPA: 4.0

- Date of Dissertation Defense: August 10, 2011

- Faculty Mentor: Benjamin T. Mast, Ph.D.

- Dissertation: Theory of Mind, Social Functioning, and Awareness of Ability in Older Adults

- Internship: VA Pittsburgh Healthcare System, Pittsburgh, PA

- APA-Accredited Internship

- August 16, 2010-August 12, 2011

\section{B.A. Psychology, January 2005}

Queens College, City University of New York, Flushing, NY

- Summa Cum Laude, Department Honors - Psychology, GPA: 4.0

\section{B.A. English and Drama (Double Major), 1996}

University of Georgia, Athens, GA

- Summa Cum Laude, Highest Honor Graduate, GPA 3.9

\section{HONORS}

- Max and Edith Weiner Award for work with patients who have Alzheimer's disease, 2005

- Lakowitz Scholarship - for undergraduate volunteer work in an inpatient setting, 2004.

- Psi Chi Honor Society, 2004

- Phi Beta Kappa Honor Society, 1996

- UGA Alumni Scholar, 1992-1996

- Georgia Governor's Scholar, 1992-1996

- Georgia Hope Scholar, 1994-1996 


\section{CLINICAL AND WORK EXPERIENCE}

\section{VA Pittsburgh Healthcare System Clinical Internship}

\section{8/16/2010-8/12/2011}

Geriatric Research Education Clinical Center (GRECC) rotation

8/16/2010 - 12/30/2010, Supervisor: Bernadette Lauber, Ph.D.

- Provided neuropsychological evaluations in the Geriatric Evaluation and Management Clinic, Geriatric Driving Safety Clinic, and Home Based Primary Care (HBPC) Team.

- Conducted CBT with HBPC patients coping with adjustment to multiple medical disorders, including incontinence and sexual dysfunction, as well as grief, depression, anxiety, and caregiver burden.

- Served as a team member during interdisciplinary team meetings and meetings with family members in each clinic.

- Participated in weekly didactics and case conferences related to aging and geriatric care as well as a monthly geropsychology journal club.

- Conducted personality assessments with OEF/OIF veterans using the MCMIIII and MMPI-2.

Externship/Half-rotation in the HJ Heinz Progressive Care Center (Community Living Center - CLC)

1 day/week, Supervisor: Trent Thatcher, Psy.D., January 2011-August 2011

- Provided initial and brief neuropsychological evaluations \& capacity assessments in extended care facility.

- Gained experience with behavioral interventions and psychotherapy in CLC.

Planned Full Rotations:

Anxiety and Adjustment Disorders Clinic

1/3/2011-4/2011, Supervisor: Dawnelle Paldino, Ph.D.

- Carried out evaluations in the Mental Health Initial Evaluation clinic, a walk-in clinic.

- Conducted individual CBT with veterans diagnosed with a range of Axis I disorders, including anxiety disorders, adjustments disorders, and depression.

- Completed Personality Assessments utilizing the MMPI-2 and MCMI-III.

- Provided Integrative Behavioral Couple Therapy (IBCT) with couples experiencing marital distress.

Behavioral Medicine Clinic (BMC)

4/2011-8/12/2011, Supervisor: Cynthia Kirsch, Ph.D.

- Conducted outpatient group and limited individual interventions focused on improvement of health behaviors and increasing coping abilities in veterans with chronic medical conditions.

- Groups included: smoking cessation, chronic pain management, weight control (MOVE).

- Conducted Phase II psychological interviews for patients being considered for organ transplants and will provide feedback to the transplant team. 
- Gained experience in biofeedback training.

Study of Thinking and Relationships (STAR) 2/1/2010 - Present (follow-up study) University of Louisville, Louisville, KY, Supervisor: Benjamin T. Mast, Ph.D.

- Administered 2-3 hour psychological test battery to individuals age 60 years and older living in the Louisville Metro area. The test battery included the DRS-2, HVLT-R, NAART, Visual Acuity Test, Frontal Assessment Battery (FAB), and Letter-Number Sequencing from the WAIS-III. The battery also included measures of social functioning and theory of mind (Eyes Test, Faux Pas Test). (Baseline study)

- Trained and supervised six undergraduate research assistants.

Psychological Associate, Private Practice of David Winsch, Ph.D.

8/3/2009 - 12/31/2009

Louisville, KY, Supervisor: David Winsch, Ph.D.

- Position entailed completing court-ordered psychological assessments, including clinical interview, administration, scoring and interpretation of tests, and report writing for 3-5 cases per week.

- Cases involved adults and children referred for evaluation due to the intervention of social service organizations, including protective services and detention facilities, in the states of Indiana and Kentucky.

- Referral questions tended to focus on diagnostic and treatment issues as well as parenting abilities.

Clinical Graduate Teaching Assistant, Psychological Services Center (PSC) 7/2008-6/2009

University of Louisville, Louisville, KY, Supervisor: Bernadette Walter, Ph.D.

- 20 hour/week placement in outpatient mental health training clinic. This placement involved administrating intake interviews, providing peer supervision, teaching labs on assessment and interviewing skills, and performing administrative duties. Clients tended to be low-income community residents with a range of Axis I and Axis II disorders.

Graduate Student Therapist, Psychological Services Center (PSC), 8/2005 - 6/2009 University of Louisville, Louisville, $K Y$

Psychological Assessments

Child Assessment Supervisor: Bernadette Walter, Ph.D.

Adult Assessment Supervisors: Paul Bock, Ph.D.; David Winsch, Ph.D.

- Completed psychological assessments involving giftedness, learning disabilities and ADHD in both children and adults.

Interpersonal Therapy Team, Supervisor: Stanley Murrell, Ph.D., 7/2007-6/2009

- Provided time-limited dynamic therapy (TLDP) and interpersonal therapy to clients experiencing difficulties in their relationships as well as clients diagnosed with personality disorders (Axis II). 


\section{Integrative Therapy Team for Patients with Severe Mental Illness}

Supervisor: Richard Lewine, Ph.D., 7/2005-6/2007

- Provided weekly therapy to clients diagnosed with severe mental illness. Services involved cognitive-behavioral therapy (CBT), skills training, \& case management.

- Co-led weekly inpatient groups on an inpatient unit at University of Louisville Hospital.

Graduate Student Therapist, Central State Hospital, Louisville, KY, 7/2007 - 6/2008 Supervisors: Jay P. Irby, Ph.D. (Geriatric Unit), Katherine Hoover, Ph.D. (Adult Acute

Unit)

- 20 hour/week practicum in an inpatient setting with two six-month rotations: 1) geriatric psychiatric unit 2) acute psychiatric unit.

- Position involved providing individual therapy as well as psychological (including personality and neuropsychological) assessment services for psychiatric inpatients with severe mental illness.

Graduate Student Therapist/Assessment Practicum, Wedgewood Healthcare Center, Clarksville, IN, 7/2006-6/2007

Supervisors: Suzanne Meeks, Ph.D. and Benjamin T. Mast, Ph.D.

- Facility provided long-term care as well as inpatient rehabilitation services.

- Provided behavior therapy focused on increasing engagement in pleasant events for depressed residents with dementia.

- Provided neuropsychological assessment services with residents and rehabilitation patients.

\section{RESEARCH EXPERIENCE}

\section{Theory of Mind, Social Functioning, and Awareness of Ability in Older Adults}

Dissertation Study, University of Louisville, April 2009-Present

Supervisor: Benjamin T. Mast, Ph.D.

- Study investigates whether theory of mind tasks may be useful in predicting unawareness of ability levels as well as problematic social functioning in community-dwelling older adults. Participation includes individuals who may be classified as normally aging as well as those diagnosed with dementia.

- Study involves original data collection from 80 community-dwelling older adults (aged at least 60 years) and their informants.

- Project Coordinator - Conducted literature review, generated hypotheses, designed study, conducted power analyses, trained six research assistants, recruited participants, supervising data collection.

\section{Meta-Analysis of the Vascular Depression Hypothesis}

University of Louisville, 2008-Present

Supervisor: Benjamin T. Mast, Ph.D.

- Collected, evaluated, and coded articles for inclusion.

- Statistical Analysis 
-Designed Excel Spreadsheet to calculate three different types of effect sizes. -Carried out preliminary meta-analysis using SPSS

- Second author on manuscript (in the writing process)

Neuropsychiatric Symptom Profiles in Dementia and MCI

University of Louisville, December 2009-March 2010

Supervisor: Benjamin T. Mast, Ph.D.

- Secondary data analysis of the Aging Demographics and Memory Study

(ADAMS) from the Health and Retirement Study.

- Study used exploratory and confirmatory factor analysis to investigate existing models of neuropsychiatric symptom profiles in dementia.

- Analysis included 311 participants with mild cognitive impairment (MCI) and 206 participants with dementia.

\section{Frontal Syndromes and Caregiver Burden}

University of Louisville, 2007-2008

Supervisor: Benjamin T. Mast, Ph.D.

- Utilized data from the Aging Demographics and Memory Study (ADAMS) which is part of the Health and Retirement Study (HRS). The relationships between three frontal syndromes (disinhibition, apathy, and executive dysfunction) and caregiver burden, strain, and depression were investigated.

\section{Early Detection Trial of Sub-Clinical Cognitive Impairment}

University of Louisville, 2006-2007

Principal Investigator: Toni Miles, M.D., Ph.D.

- Provided Neuropsychological Assessments of Older Adult Participants for Large Interdisciplinary Research Study

- Test battery included: Dementia Rating Scale-2, Controlled Oral Word Association Test, Hopkins Verbal Learning Test, Mini-Mental State Examination, Trail Making Tests A \& B, WMS-R Logical Memory Subtest, Boston Naming Test, WAIS-R Digit Symbol Coding, WAIS-R Digit Span, Grooved Pegboard Test, Grip Strength Test, SCID-Depression, Geriatric Depression Scale.

\section{Investigating the Relationship between Frontal Syndromes and Pleasant Events in} Primary Care Geriatric Patients

University of Louisville, 2006

Supervisor: Benjamin T. Mast, Ph.D.

- Administered neuropsychological tests to older adults recruited through geriatric primary care clinics in Louisville, $\mathrm{Ky}$.

- Utilized original dataset to investigate the relationship between engagement in pleasant events and the presence of frontal syndromes in patients recruited from a geriatric primary care clinic. 
Utility of the Frontal Systems Behavior Scale (FrSBe) for detecting dementia in geriatric primary care patients.

University of Louisville, 2006

Supervisor: Benjamin T. Mast, Ph.D.

- Administered neuropsychological tests to older adults recruited through geriatric primary care clinics in Louisville, Ky.

- Investigated the psychometric properties and utility of the FrSBe for detecting dementia in geriatric primary care patients.

Research Coordinator, 2003-5/2005

Neuropsychology Laboratory of Aging and Dementia, Queens College, CUNY, Flushing, NY

Neuropsychology, Division of Geriatrics, Department of Medicine, Winthrop-University Hospital, Mineola, Long Island, NY, Supervisor: Nancy S. Foldi, Ph.D.

- Responsible for contact, scheduling, and follow-up with patients and patient families for neuropsychological evaluations, as well as contact with other service providers.

- Initially reviewed patients for inclusion criteria regarding research studies.

- Maintenance of MS Access database.

- Maintenance of SPSS laboratory databases, which include clinical, experimental, and reaction time data management.

- Experience in IRB and grant preparation.

- Administered neuropsychological tests to subjects participating in research.

1996-2001 Performed in professional theatrical productions for:

CLIMB Theater Company (Atlanta, GA; from St. Paul, MN)

Horizon Theater Company (Atlanta, GA)

Dad's Garage Theater Company (Atlanta, GA)

24 Hour Plays/Improv (Atlanta, GA)

\section{TEACHING EXPERIENCE}

Graduate Teaching Assistant Positions, University of Louisville, Louisville, KY Personality, Spring 2010

- Wrote Multiple Choice Exams, Graded Multiple Choice Exams, managed student grades using Blackboard, and provided out-of-class tutoring to undergraduate students.

Psychological Services Center, University of Louisville, 7/2008-6/2009

- Taught labs on interviewing and intellectual assessment to first-year students.

- Provided graduate student therapists of all levels with peer supervision during weekly scheduled shifts.

Graduate Statistics, Spring 2007 
- Taught one lab per week to first-year graduate students in clinical and experimental psychology programs, graded weekly homework, ran study sessions, and assisted professor in grading exams.

\section{Undergraduate Statistics, Fall 2006}

- Taught two weekly lab sections for undergraduate psychology majors and ran study sessions.

\section{Introduction to Psychology, Fall 2005 \& Spring 2006}

- Taught three weekly lab sections in the Fall semester and two weekly lab sections in the Spring semester.

\section{Guest Lectures}

- Undergraduate Abnormal Psychology, Department of Psychological and Brain Sciences, University of Louisville: Cognitive Disorders and Life Span Issues. November, 2009.

- Graduate Psychological Assessment, Department of Psychological and Brain Sciences, University of Louisville: Assessment for dementia. April, 2009.

- Graduate Gerontologic Audiology, Department of Audiology, University of Louisville Medical School: Neuropsychology and Aging, March 2009

\section{PUBLICATIONS}

Mast, B.T., Yochim, B., Carmasin, J., \& Rowe, S.V. (in press). Vascular depression: a neuropsychological perspective. In (F. López-Muñoz and C. Álamo, Eds) Neurobiology of Depression (Frontiers in Neuroscience Book Series). CRC Press, Taylor \& Francis.

Mast, B.T., Zimmerman, J., \& Rowe, S.V. (2009). What do we know about the aging brain? Implications for learning in late life. In M.C. Smith \& N. DeFrates-Densch (Eds.), Handbook of Research on Adult Learning and Development (pp. 695-731). NY, NY: Routledge.

Mast, B.T., \& Vedrody, S. (2006). Poststroke depression: a biopsychosocial approach. Current Psychiatry Reports, 8(1), 25-33.

\section{ABSTRACTS \& POSTER PRESENTATIONS}

Rowe, S.V., Shouse, J., Carmasin, J., \& Mast, B.T. Awareness of Cognitive Functioning and Theory of Mind in Community-Dwelling Older Adults. Poster presented at

the 2011Conference of the International Neuropsychological Society in Boston, MA.

Rowe, S.V., \& Mast, B.T. Neuropsychiatric Syndromes in Dementia and Mild Cognitive Impairment: Confirmatory and Exploratory Factor Analysis of the NPI. Poster presented at the 2010 Convention of the American Association of Geriatric Psychiatry. 
Zimmerman, J.A., Holley, C.K., Rowe, S.V., Healy, P.J., Mast, B.T. Meta-Analysis of the Vascular Depression Hypothesis. Poster Presented at the 2008 Convention of the Gerontological Society of America.

Rowe, S.V. Disruption of Prefrontal Cortex Circuitry Linkedto Caregiver Burden. Presented in caregiving symposium at the 2007 Convention of the Gerontological Society of America.

Vedrody, S., \& Mast, B.T. Frontal syndromes predict engagement in pleasant events. Poster Presented at the 2006 Convention of the Gerontological Society of America.

Vedrody, S., Holley, C.K., \& Mast, B.T. Frontal systems behavior scale in geriatric primary care patients. Poster presented at the 2006 Convention of the American Psychological Association.

Azar, A.R., Holley, C.K., Welsh, D.L., Vedrody, S., \& Mast, B.T. Effect of vascular risk and late-life depression on executive dysfunction. Poster Presented at the 2006 Convention of the American Psychological Association.

Foldi, N.S., Horn-Levinson, L., Vedrody, S. \& Leavitt, V.M., (2004). Early detection of treatment change of acetylcholinesterase inhibitor in Alzheimer disease using measures of visual attention. Neurobiology of Aging, 25, S2, S192 (abstract).

Foldi, N.S., Vedrody, S., Horn-Levinson, L., Lombardi, K.I., White, R.E.C., Redfield, J. (2005). Visual Attention Measures Detect Early Changes of an Acetylcholinesterase Inhibitor (AChE-I) in Alzheimer Disease (AD). Journal of the International Neuropsychology Society (abstract).

\section{PROFESSIONAL MEMBERSHIPS}

- American Psychological Association (APA) - Student Affiliate

- APA 12-2 Clinical Geropsychology

- APA 40 Neuropsychology

- Gerontological Society of America (GSA)

- Kentucky Psychological Association (KPA)

\section{SERVICE ACTIVITIES}

- VA Pittsburgh Clinical Training Committee (CTC) Intern Representative, 20102011

- Peer mentor for doctoral student, 2007-2009.

- Initiated and organized the Clinical Psychology Doctoral Peer Mentorship Program, 2007 
- Student Representative to the University of Louisville Clinical Psychology Faculty, 2007-2008

- Q-Bucs (Queens Children's Psychiatric Center), 2004 -2005 